\title{
PROPOSTAS DE ENSINO DE MATEMÁTICA PARA DEFICIENTES VISUAIS: REVISÃO SISTEMÁTICA EXPLORATÓRIA DA LITERATURA
}

\author{
F. C. S. BARBOSA ${ }^{1}$, E. J. R. DE MEDEIROS ${ }^{2}$, S. R. R. DE MEDEIROS ${ }^{3}$, R. N. DE MEDEIROS JÚNIOR ${ }^{4}$ \\ Instituto Federal de Educação, Ciência e Tecnologia do Rio Grande do Norte ${ }^{1,2,3,4}$ \\ ORCID ID: https://orcid.org/0000-0001-9885-1011 ${ }^{1}$ \\ cleiton.sb04@gmail.com ${ }^{1}$
}

Submetido 31/01/2020 - Aceito 18/12/2020

DOI: $10.15628 /$ holos.2020.9483

\section{RESUMO}

A Matemática é essencial para o desenvolvimento básico e para formação de indivíduos, portanto, cabe uma preocupação específica quanto ao seu ensino a deficientes visuais. A adaptação ou desenvolvimento de materiais adequados, tem o objetivo de garantir equidade entre os estudantes. Sendo assim, é importante estimular a reflexão e difundir os estudos de novas tecnologias auxiliares no processo de inclusão dos alunos com deficiência visual. Esta pesquisa buscou reunir e sistematizar propostas dessa natureza, voltadas ao ensino de matemática. Foram identificados 138 trabalhos, sendo $46 \%$ considerados eficientes; $30 \%$ satisfatórios; $4 \%$ necessitam de melhorias; e $1 \%$ ineficientes. Quanto aos conteúdos, as maiores quantidades referem-se à Geometria e Aritmética. Com relação às metodologias, as mais adotadas foram: Materiais Manipulativos e Tecnologias Assistivas. O conteúdo sistematizado pode contribuir com a difusão do conhecimento, favorecendo um ensino de matemática mais igualitário aos deficientes visuais.

PALAVRAS-CHAVE: Ensino, Matemática, Deficientes Visuais, Revisão Sistemática.

\section{MATH TEACHING PROPOSALS FOR VISUALLY IMPAIRED: SYSTEMATIC EXPLORATORY LITERATURE REVIEW}

\begin{abstract}
Mathematics is essential for basic development and for the formation of individuals, therefore, there is a specific concern regarding its teaching to visually impaired people. The adaptation or development of suitable materials, aims to ensure equity among students. Therefore, it is important to encourage reflection and disseminate studies of new auxiliary technologies in the process of including students with visual impairments. This research sought to gather and systematize proposals of this nature, aimed at teaching mathematics.
\end{abstract}

138 works related to the theme, were identified, $46 \%$ of which were considered efficient; $30 \%$ satisfactory; $4 \%$ need improvement; and $1 \%$ inefficient. As for the contents, the largest quantities refer to Geometry and Arithmetic. Regarding the methodologies, the most adopted were: Manipulative Materials and Assistive Technologies. The systematized content can contribute to the dissemination of knowledge, favoring a more equal teaching of mathematics to the visually impaired.

KEYWORDS: Teaching, Mathematics, Visually Impaired, Systematic Review. 


\section{INTRODUÇÃO}

A visão é o sentido dominante no ser-humano, e representa um ponto essencial em todos os estágios de nossas vidas, sem ela torna-se um desafio aprender a andar, a ler, o período escolar e o trabalho. De acordo com o Relatório Mundial da Visão, elaborado pela Organização Mundial da Saúde - OMS, cerca de 2,2 bilhões de pessoas possuem algum dano à visão ou cegueira propriamente dita, e, dentre esses, aproximadamente 1 bilhão está relacionado a crianças e adolescentes (WHO, 2019).

A literatura mostra que condições insuficientes para reabilitação e acessibilidade podem aumentar consideravelmente os prejuízos em cada etapa da vida, sobretudo nas crianças em idade escolar, cuja deficiência visual pode determinar baixos níveis de desempenho educacional e autoestima, se comparados aos colegas com visão adequada (Augestad, 2017; Chanfreau \& Cebulla, 2009; Toledo, 2010).

Muitos dos impactos ocasionados pela considerável redução ou perda visual podem ser mitigados pela reabilitação e adaptação dos indivíduos atingidos, fornecendo a eles, e aos demais envolvidos, condições acessíveis em todas as esferas da vida, incluindo as necessidades de aprendizado e crescimento profissional. Considerando que a Matemática é essencial para o desenvolvimento básico e para a evolução de indivíduos críticos e pensantes, com participação social e profissional, cabe uma preocupação específica quanto ao seu acesso no caso do ensino a portadores de deficiências visuais. A disciplina possui especificidades, como descritas na Base Nacional Comum Curricular (BNCC):

A Matemática não se restringe apenas à quantificação de fenômenos determinísticos - contagem, medição de objetos, grandezas - e das técnicas de cálculo com os números e com as grandezas, pois também estuda a incerteza proveniente de fenômenos de caráter aleatório. A Matemática cria sistemas abstratos, que organizam e inter-relacionam fenômenos do espaço, do movimento, das formas e dos números, associados ou não a fenômenos do mundo físico (MEC, 2018, p. 265).

Existe ainda a reflexão acerca das necessidades de ensino relacionadas à observação do espaço físico, formas e volumes, o uso da experimentação e ferramentas próprias de aprendizado, que muitas vezes não são inclusivas, embora a BNCC especifique, em seus textos, competências e habilidades que devem ser estimuladas em todos os estudantes:

Apesar de a Matemática ser, por excelência, uma ciência hipotético-dedutiva, porque suas demonstrações se apoiam sobre um sistema de axiomas e postulados, é de fundamental importância também considerar o papel heurístico das experimentações na aprendizagem da Matemática. [...] Essa área, por meio da articulação de seus diversos campos - Aritmética, Álgebra, Geometria, Estatística e Probabilidade -, precisa garantir que os alunos relacionem observações empíricas do mundo real a representações (tabelas, figuras e esquemas) e associem essas representações a uma atividade matemática (conceitos e propriedades), fazendo induções e conjecturas (MEC, 2018, p. 265).

Essas peculiaridades próprias do ensino-aprendizagem de Matemática devem ser pensadas para o ensino de deficientes visuais, de modo a aumentar a efetividade do ensino e manter o 
nivelamento dos estudantes, aproximando-os do que é ofertado às crianças e adolescentes que não possuem perdas visuais. Dentro dessa expectativa, e no conhecimento de que muitas vezes o professor não possui capacitação adequada ou conhecimento de novas metodologias acessíveis para o ensino - principalmente aquelas direcionadas a essa disciplina específica - este artigo se propõe a reunir e sistematizar propostas de ensino de matemática voltadas aos alunos com baixa visão ou cegueira, oportunizando, ao professor, identificar em uma única fonte de pesquisa, diversas técnicas acessíveis com aplicação em variados conteúdos da matemática, em uma estrutura que permita ao docente selecionar aquela que atenda às suas necessidades e de seu aluno.

\section{REFERENCIAL TEÓRICO}

A Educação Especial é uma garantia presente em diversas instâncias normativas, partindo inclusive do que é determinado pelo inciso III do artigo 208 da Constituição Federal, que determina "atendimento educacional especializado aos portadores de deficiência, preferencialmente na rede regular de ensino". (Constituição Federal, 1988)

Além da Constituição, também é possível citar o Decreto 3.298, que concede ao aluno com deficiência, em seu artigo 24, a inclusão da Educação Especial em todos os níveis e modalidades de ensino, e o acesso desses educandos a todos os benefícios concedidos aos demais, enfatizando que "a educação do aluno com deficiência deverá iniciar-se na educação infantil", e que a "educação especial contará com equipe multiprofissional, com a adequada especialização, e adotará orientações pedagógicas individualizadas". Segundo o mesmo documento, a Educação Especial deve ser ofertada "para educando com necessidades educacionais especiais, entre eles o portador de deficiência", e ser constituída como "processo flexível, dinâmico e individualizado, oferecido principalmente nos níveis de ensino considerados obrigatórios" (Decreto 3.298, 1999).

Em relação a promoção das liberdades e direitos das pessoas portadoras de deficiência, bem como, quanto à eliminação da discriminação direcionada a esses indivíduos, é possível mencionar os decretos 3.956 e 6.940, que promulgam, respectivamente, a "Convenção Interamericana para a Eliminação de Todas as Formas de Discriminação contra as Pessoas Portadoras de Deficiência", e a "Convenção Internacional sobre os Direitos das Pessoas com Deficiência", que reafirmam o compromisso de "promover, proteger e assegurar o exercício pleno e equitativo de todos os direitos humanos e liberdades fundamentais por todas as pessoas com deficiência e promover o respeito pela sua dignidade inerente" (Decreto 3.956, 2001; Decreto 6.940, 2009).

No âmbito do Instituto Federal de Educação, Ciência e Tecnologia do Rio Grande do Norte - IFRN, onde foi conduzida a atual pesquisa, as exigências legais quanto à inclusão dos alunos com deficiência foram corroboradas pela Resolução № 05/2017- CONSUP, que aprova a normatização da instituição para a reserva de vagas destinadas aos deficientes e seu ingresso em modalidades de nível médio, graduação e pós-graduação (IFRN, 2017).

O Plano de Desenvolvimento Institucional - PDI 2019-2026 do IFRN, em seu objetivo estratégico ES-4, conduz o fortalecimento de políticas inclusivas, por meio de ações que "garantam 
a inclusão social das pessoas com deficiências e em vulnerabilidade social, democratizando o acesso por meio de ações afirmativas" (IFRN, 2018, p. 197).

De acordo com dados do Núcleo de Atendimento às Pessoas com Necessidades Educacionais Especiais - NAPNE do IFRN, estudam atualmente no instituto, 79 alunos com baixa visão e 23 educandos cegos, distribuídos entre 21 dos diferentes Campi, e em maior número no Campus Natal-Central. O Núcleo, que está presente nas várias unidades do IFRN, foi instituído pela Portaria № 1533/12, e visa promover a inclusão de pessoas com necessidades educacionais específicas, conduzindo, dentre outras iniciativas, a educação para a diversidade; planejamento, construção e adaptação de materiais didáticos e estratégias pedagógicas; e a capacitação dos servidores (IFRN, 2019).

Conhecendo a garantia de educação especial presente nas diversas normativas citadas, é importante compreender como é possível viabilizar o processo de inclusão dos alunos com baixa visão ou cegueira. Inicialmente, é preciso entender que a inclusão completa de um estudante deve abranger a integração com os demais estudantes, docentes e com o espaço à sua volta, além do acesso ao conteúdo que está sendo ofertado naquele ambiente. Como tratam Fernandes e Healy (2010), é fundamental que sejam aplicados materiais que concedam, ao deficiente visual, acesso ao conteúdo de sua base curricular e nível, e a cooperação com os demais estudantes, de modo a ocorrer uma significativa construção do conhecimento.

Conforme a conceituação do Decreto № 5.296, artigo 5으, é considerada portadora de deficiência, a pessoa com "limitação ou incapacidade para o desempenho de atividade", e, no caso da deficiência visual, tem-se a seguinte definição:

[...] cegueira, na qual a acuidade visual é igual ou menor que 0,05 no melhor olho, com a melhor correção óptica; a baixa visão, que significa acuidade visual entre 0,3 e 0,05 no melhor olho, com a melhor correção óptica; os casos nos quais a somatória da medida do campo visual em ambos os olhos for igual ou menor que 60o; ou a ocorrência simultânea de quaisquer das condições anteriores; (Decreto 5.296, 2004).

Nessa perspectiva, surge a Tecnologia Assistiva (TA) que é definida por Bersch (2013, p. 2) como "um auxílio que promoverá a ampliação de uma habilidade funcional deficitária ou possibilitará a realização da função desejada e que se encontra impedida por circunstância de deficiência ou pelo envelhecimento". A autora ainda reforça que a TA é aplicável a alunos com deficiência e "tem por objetivo romper barreiras sensoriais, motoras ou cognitivas" que venham a limitar ou impedir o aluno de ter acesso ou o registro de informações no processo de ensinoaprendizagem (Bersch, 2013, p.12).

No que diz respeito à Matemática - com seus requisitos conceituais, representações numéricas, algébricas e geométricas - com altos níveis de abstração e difícil representação, mesmo alunos com plena visão, e a capacidade de acompanhar todos os recursos utilizados pelo professor, muitas vezes permanecem com dificuldades de compreensão, e diversas estratégias adicionais podem ser requeridas para facilitar o entendimento. Nessa mesma linha de raciocínio, é fácil perceber que metodologias de ensino cujo estímulo é voltado somente, ou principalmente, para o 
sentido da visão irão tornar o aprendizado da disciplina um desafio complexo aos estudantes cegos (Cerva Filho \& Geller, 2013).

Nos registros de Amaral, Ferreira e Dickman (2009), tem-se que as maiores dificuldades de aprendizagem enfrentadas pelos estudantes cegos estão relacionadas à visualização e interpretação de gráficos, desenhos e esquemas variados, e o estudo de Lins e Alchieri (2016, p. 1228) confirma essa constatação em seu levantamento:

Finalizando a investigação sobre a aprendizagem em sala de aula, a maioria dos alunos (65\%) comentou que, quando os professores fazem desenhos, figuras ou gráficos no quadro e não trazem nenhum material em alto relevo, nem detalham o que está sendo posto, geralmente tentam imaginar o que está sendo passado para os demais, demonstrando vontade de compreender e consequentemente de alcançar aquele conhecimento. A imaginação, ao permitir que eles representem os objetos em suas mentes, funciona como uma ponte que tenta aproximá-los do mundo dos videntes e do conhecimento a eles apresentado. Contudo, tal estratégia revela-se problemática, pois os professores passam a não ter controle sobre o que está sendo imaginado pelo aluno e isso pode ocasionar uma aprendizagem errada. Os professores precisam trazer para a sala de aula conteúdos concretos e assim estimular os sentidos remanescentes dos estudantes para que possam tentar garantir a aprendizagem efetiva daqueles conteúdos.

Existem diversas propostas que enfatizam o potencial e uso de outros sentidos para a construção do conhecimento, e que favorecem o aprendizado e o interesse tanto de alunos com visão saudável, quanto aqueles com deficiência, a exemplo do uso de materiais concretos, que permeiam aulas de matemática em variados conteúdos, como a geometria, construções gráficas e funções, e podem estimular o tato dos educandos, aumentando sua percepção e abstração, além de integrar alunos, independente da sua condição visual (Fernandes \& Healy, 2010; Ferreira, 2006; Ferronato, 2002).

O uso do tato pode ser classificado em passivo e ativo. O primeiro refere-se a toda informação não intencional captada pela pele, como sensação de calor, contato com roupas, entre outros. Em contrapartida, o sentido ativo envolve não só a pele, como outras estruturas relacionadas ao sistema háptico, na busca intencional por informação através do toque (Ochaíta \& Rosa apud Nunes \& Lomônaco, 2010).

Assim como enfatizam Nunes e Lomônaco (2010, p. 57), ao utilizar o tato como fonte de informação, o processo ocorre de maneira mais lenta e sequencial, ao exemplo da identificação de objetos grandes, que necessitam ser completamente tocados e seriam mais rapidamente detectados pelo sentido da visão. De todo modo, os autores esclarecem que muitas outras formas de linguagem exigem esse comportamento sequencial, como a música e a leitura, e não são consideradas melhores ou piores. Ainda acrescentam que o tato, apesar de ser uma importante via de informação e interação para os estudantes cegos, não é o único meio, ele promove a percepção de características como formato, textura e temperatura, mas é melhor aplicado em objetos próximos, podendo ser aliado ao sistema cinestésico, que proporciona "informações sobre a orientação espacial, o movimento e o equilíbrio, possibilitando a percepção de posição, da direção do vento, da velocidade do movimento e orientação do corpo".

Nas palavras de Nunes e Lomônaco (2010, p. 57), existe também um descompasso entre a forma de percepção entre alunos cegos e videntes, pois os últimos priorizam a visão em detrimento 
dos demais sentidos, enquanto os outros percebem o mundo pelas capacidades de todos os sentidos possíveis, e "a consequência deste impasse é que a pessoa cega tem que fazer constantes 'ajustes' entre aquilo que ela conhece por meio de suas percepções e aquilo que chega pela fala dos que a rodeiam". Também segundo Rabêllo (2011, p. 56), os cegos "[...] se tornam extremamente sensíveis aos matizes de inflexão, de volume, de cadência, de ressonância e das várias intensidades dos sons das falas dos outros, que passam despercebidos aos videntes".

Nunes e Lomônaco (2010) esclarecem que, de modo geral, a interação e aprendizagem dos sujeitos cegos ocorre de modo diferente dos videntes - nem melhor, nem pior - e se dá pela união de sentidos, ligados também a memórias e vivências passadas, numa diferente modalidade da organização sensorial dos alunos com plena visão. Em relação ao suporte educacional fornecido aos estudantes com deficiência visual, eles ainda apontam:

O aluno cego, em sua vida escolar, necessita de materiais adaptados que sejam adequados ao conhecimento tátil-cinestésico, auditivo, olfativo e gustativo - em especial materiais gráficos tateáveis e o braile. A adequação de materiais tem o objetivo de garantir o acesso às mesmas informações que as outras crianças têm, para que a criança cega não esteja em desvantagem em relação aos seus pares. [...]A estigmatização do deficiente visual prejudica sua personalidade e autoestima. Por isso, é preciso um ambiente educacional o mais adequado possível para o desenvolvimento integral do cego. [...] a falta de apoio especializado nas escolas comuns - ditas "inclusivas" -, tanto pela falta de materiais e recursos para o trabalho com as crianças cegas, quanto pela falta de preparo dos docentes da sala de aula comum, o que leva a um trabalho pedagógico técnico, espontaneísta e muitas vezes inadequado por não dar conta das necessidades do aluno cego. As professoras da sala comum de alunos com deficiência visual demonstraram incertezas sobre como lidar com esses alunos e desconhecimento dos materiais adaptados para o cego (Nunes \& Lomônaco, 2010, p. 60).

Sabendo que o envolvimento e atuação do professor são essenciais para mobilização e aplicação das técnicas de educação especial, é importante estimular a reflexão e difundir os estudos e novas tecnologias que venham a mediar o processo de inclusão dos alunos com deficiência visual, e a metodologia utilizada nesta pesquisa visa reunir e sistematizar propostas dessa natureza, voltadas ao ensino de matemática em especificidade.

\section{METODOLOGIA}

A pesquisa foi desenvolvida nos moldes de uma revisão sistemática exploratória, buscando identificar e categorizar o atual estado da arte em relação à produção científica de novas estratégias e ferramentas para o ensino de matemática a alunos cegos ou com baixa visão. Foi realizada uma busca inicial à literatura, de modo a identificar os principais padrões para a sistematização e determinar os Unitermos e Operadores Booleanos a serem adotados no estudo.

As bases de pesquisa selecionadas foram LILACS, SciELO, Periódicos CAPES, Science Direct e Google Acadêmico. Objetivando identificar a inovação obtida na área nos últimos cinco anos, a consulta selecionou os trabalhos publicados entre 2015 e 2019, exceto para a base SciELO, para a qual o período foi estendido e variou entre 2013 e 2019, devido ao número limitado de resultados. Em todas as bases, foram utilizados os descritores em inglês e português e aceitos estudos em ambos os idiomas. 
A seleção dos trabalhos adequados ao tema se deu em quatro etapas, e a sequência delas foi a categorização dos estudos. A primeira etapa refere-se à utilização dos unitermos, operadores e limitação dos períodos em cada uma das bases, nos dois idiomas. Na segunda parte da seleção, foi realizado o Teste de Relevância A, que analisa apenas os resumos dos trabalhos obtidos na busca, de acordo com os critérios de inclusão/exclusão presentes na Figura 1 (a). Os trabalhos que permaneceram após a etapa anterior, seguem para a terceira parte, que, por sua vez, é relativa ao Teste de Relevância B, que avalia os textos de maneira integral, enquadrando-os em novos critérios detalhados na Figura 1 (b). Para que sejam aceitos pelos testes de relevância, as pesquisas precisam se enquadrar em pelo menos um dos critérios de inclusão, e não se enquadrar em nenhum critério de exclusão. Como o Teste B necessita que seja considerado o artigo por completo, foram eliminados os títulos aos quais não foi possível obter acesso ao texto integral. A última fase da seleção foi destinada à exclusão dos trabalhos duplicados. A síntese do processo de seleção pode ser visualizada na Figura 2.

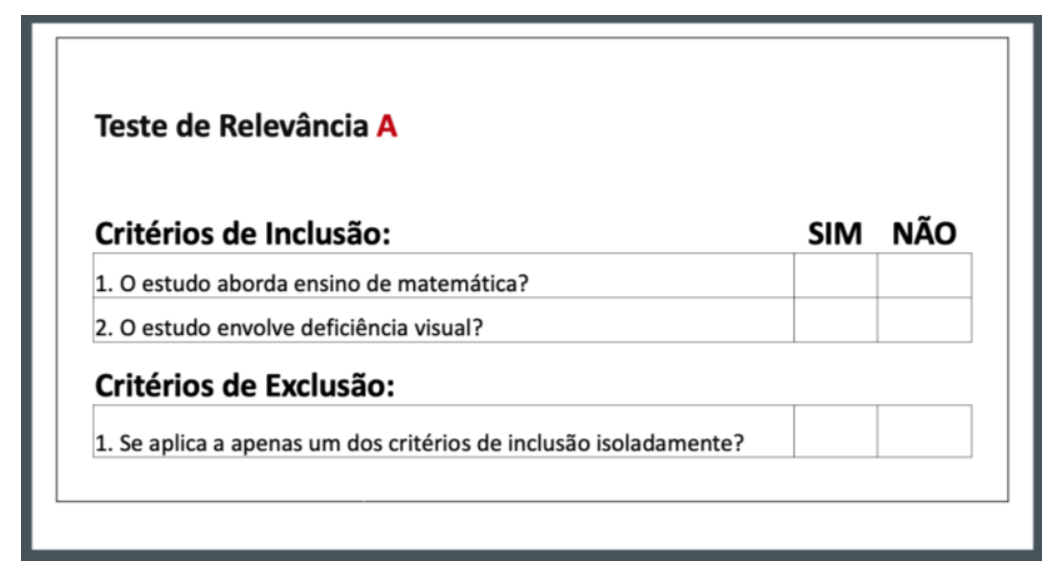

a)

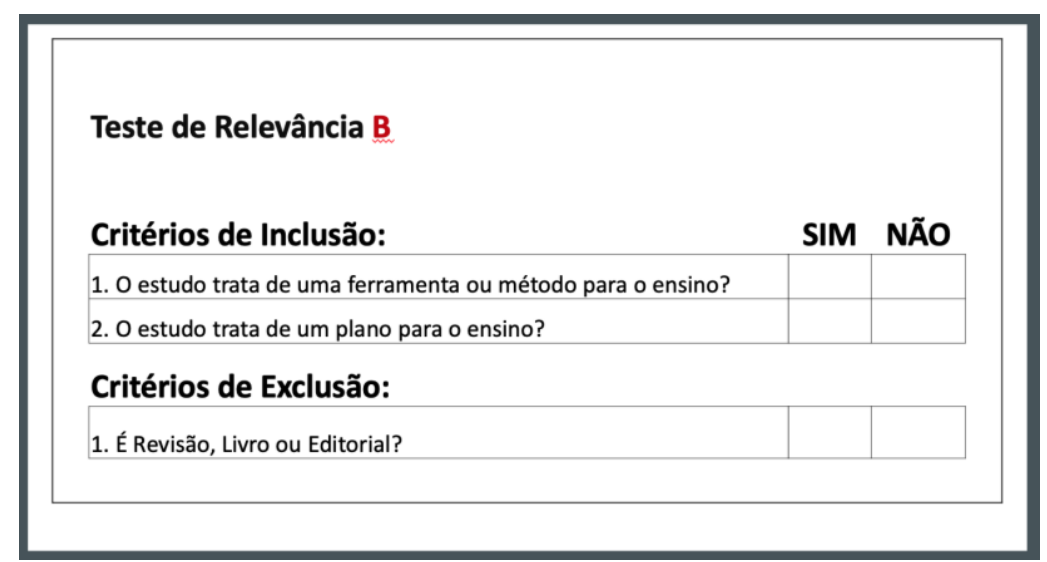

b)

Figura 1: a) Teste de Relevância A; b) Teste de Relevância B. 


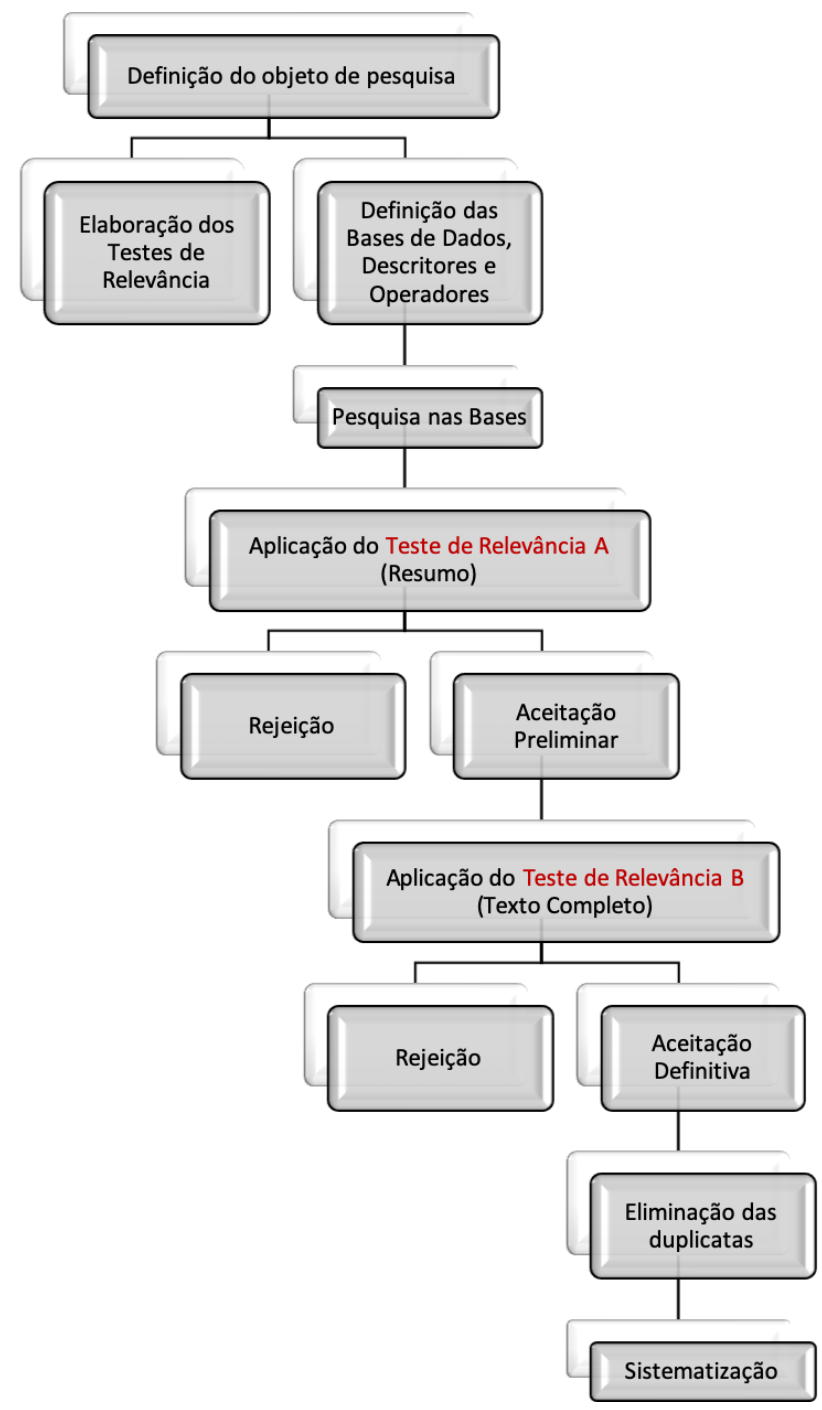

Figura 2: Resumo da Estratégia de Seleção

Os unitermos/operadores utilizados na pesquisa foram "math\$ AND blind\$ AND (visual impairments) AND teach\$” e "matemática AND cegos AND (deficiência visual) AND ensino". Para as bases SciELO e LILACS, esses descritores não obtiveram nenhum resultado e foram alterados para "mathematics AND blind" e "matemática AND cegos". O operador AND indica inclusão dos termos; o cifrão faz um truncamento da palavra e inclui todos os vocábulos que possuem aquele radical; os parênteses são usados para buscar termos compostos.

Para a sistematização dos trabalhos, utilizou-se o software Excel 2016. Os estudos foram plotados em uma planilha, com o registro de suas principais características: Autores; Título; Bases de Pesquisa (vinculação); Descrição Breve da Proposta; Conteúdo ou Aplicação; Tipo de Deficiência; Tipo de Proposta; e Resultado.

\section{RESULTADOS E DISCUSSÕES}

Nesta seção serão apresentados e interpretados os dados obtidos após a seleção e posterior sistematização dos trabalhos. Nas Figuras 3 e 4 é possível observar o resumo dos dados obtidos em cada etapa do processo de seleção das pesquisas, e o maior número de estudos 
encontrados e selecionados foi referente ao Google Acadêmico, com relevante disparidade em comparação às demais bases. A única das bases de pesquisa que não apresentou resultados após a seleção foi a LILACS, também resultante do baixo número inicial de pesquisas encontradas e relacionadas ao tema. Tanto Google Acadêmico, quanto SciELO, apresentaram maior número de resultados na língua portuguesa, demonstrando inclusive, uma importante participação de pesquisadores brasileiros na investigação de metodologias para o ensino de matemática a deficientes visuais.

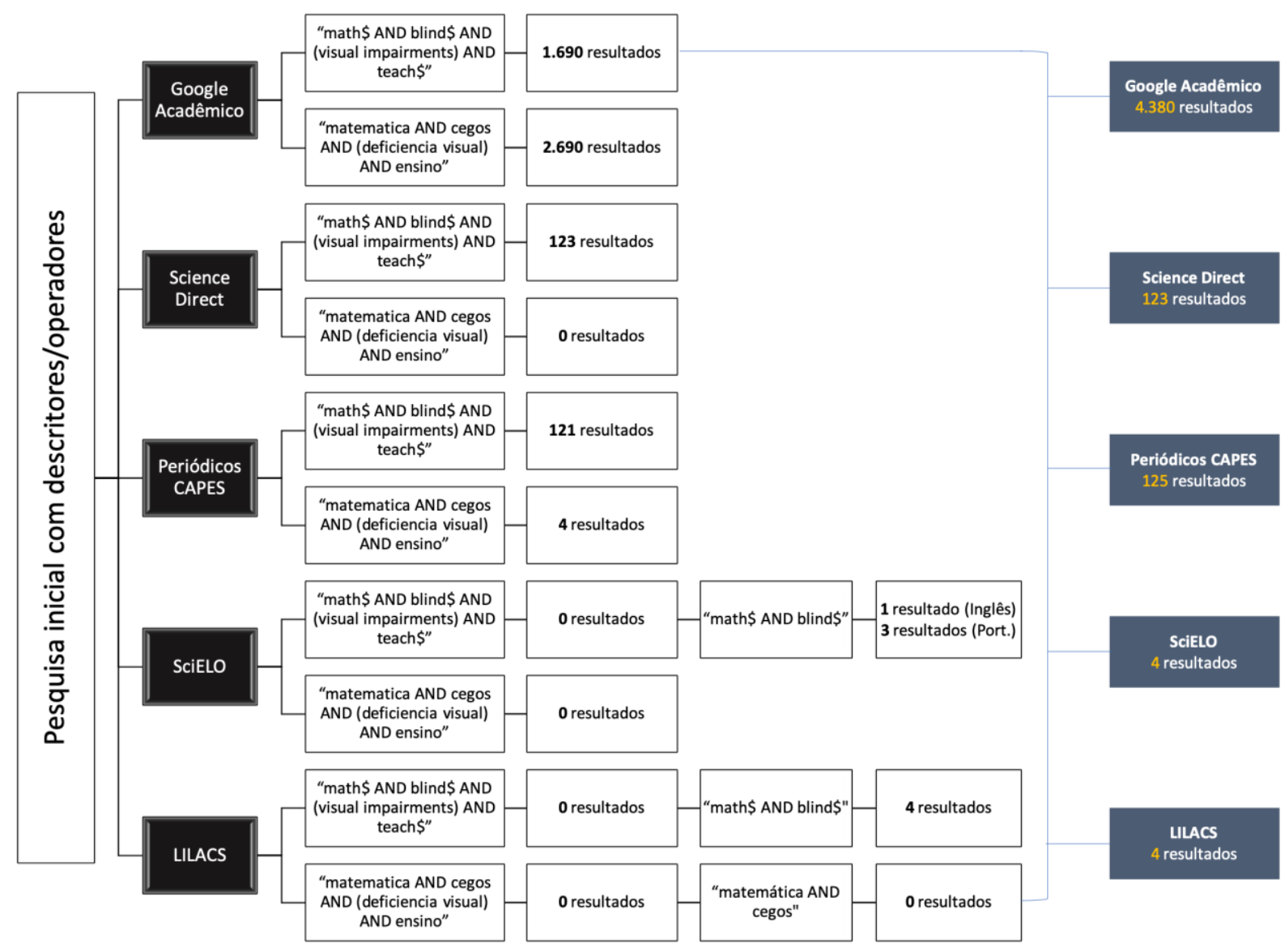

Figura 3: Primeira Etapa da Seleção 


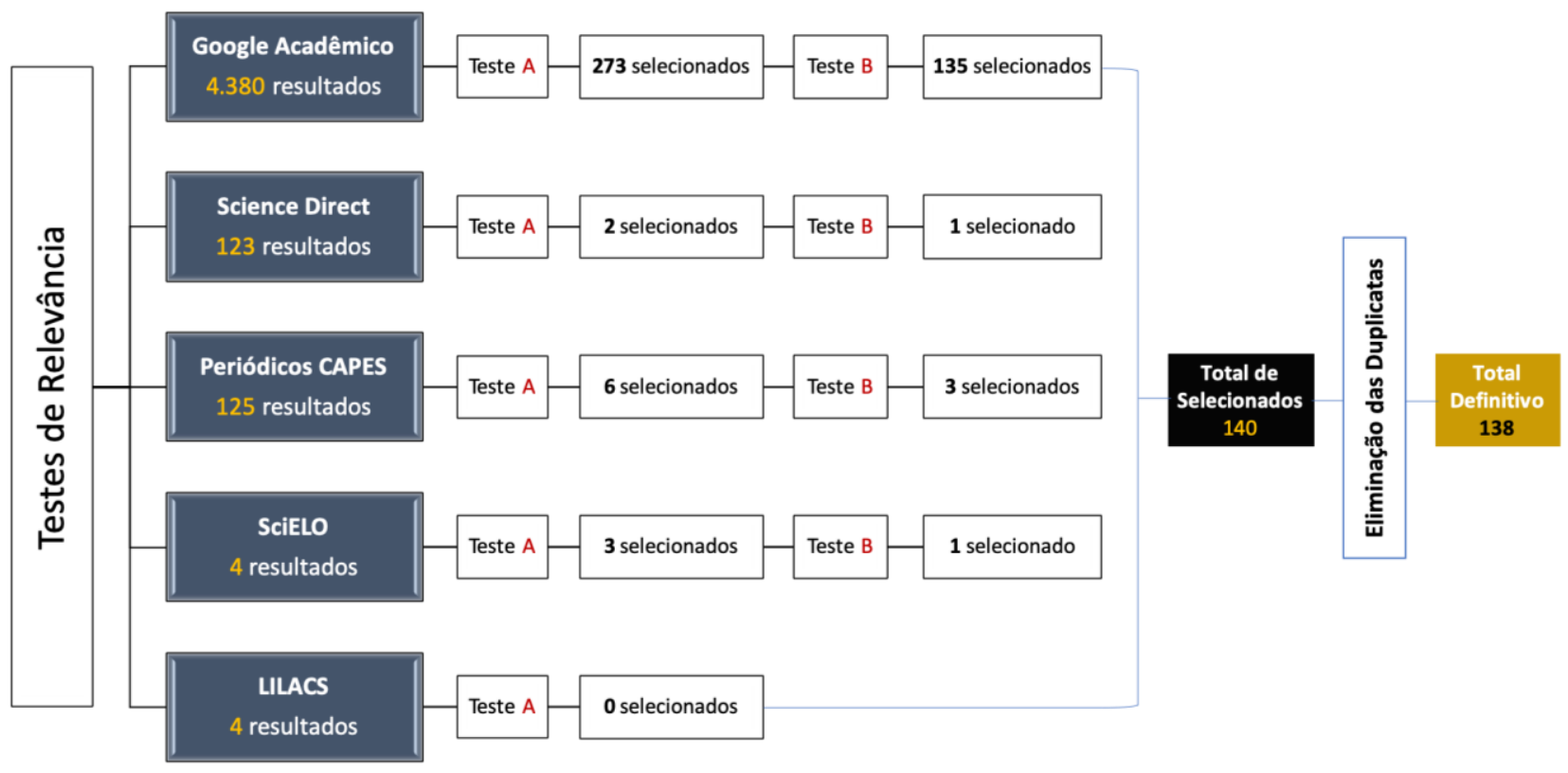

Figura 4: Testes de Relevância

Foram 138 trabalhos selecionados, provenientes de eventos científicos, periódicos ou produzidos como trabalhos de graduação e pós-graduação. A Vinculação desses estudos em relação às bases de pesquisa pode ser vista no Figura 5 , que transmite a superioridade numérica dos artigos em língua portuguesa, bem como, a efetividade do Google Acadêmico em vincular trabalhos científicos, pois interliga diversas bases, periódicos e repositórios, apontando também teses, dissertações e trabalhos de conclusão.

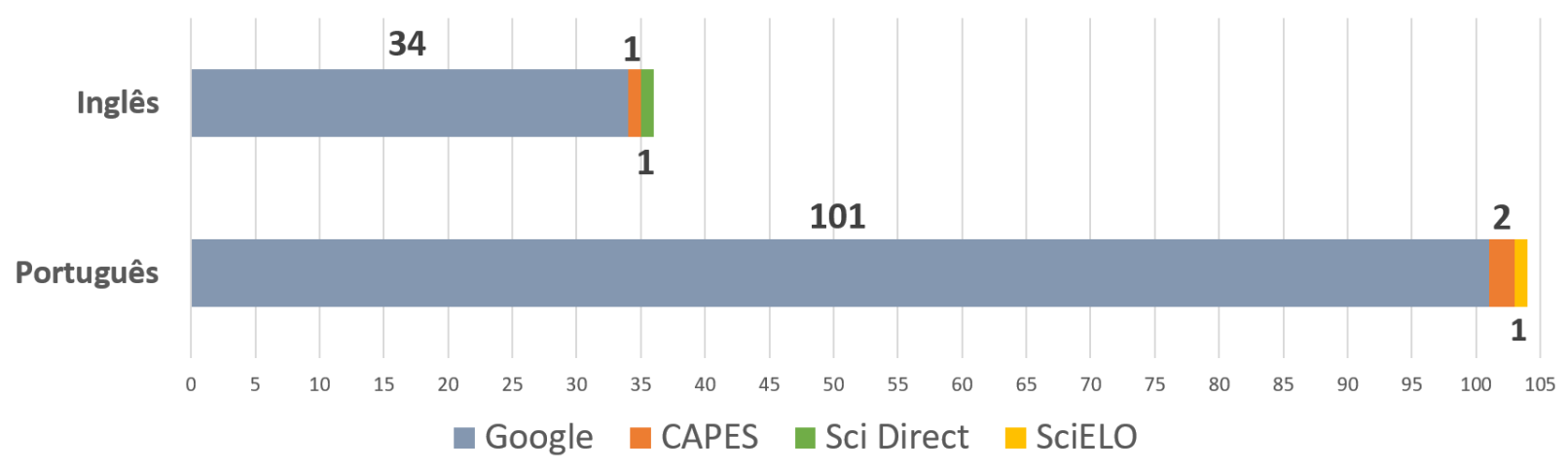

Figura 5: Gráfico da distribuição dos artigos selecionados

A Tabela 1 contém todo o conteúdo da sistematização realizada neste estudo, que, apesar da limitação no período da busca (2015 a 2019), obteve um amplo e variado padrão de resultados, o que traduz a riqueza de possibilidades para o trabalho da Matemática com deficientes visuais. A tabela também permite encontrar estudos adequados, de acordo com a necessidade do professor, categorizando os estudos em relação ao conteúdo e aplicação, ao tipo de metodologia, e também em termos de eficácia da técnica. 
Tabela 1: Sistematização dos Estudos

\begin{tabular}{|c|c|c|c|c|c|c|}
\hline Autor(es) & Título & $\begin{array}{l}\text { Base de } \\
\text { Pesquisa }\end{array}$ & Descrição Breve da Proposta & $\begin{array}{l}\text { Conteúdo ou } \\
\text { Aplicação }\end{array}$ & $\begin{array}{l}\text { Tipo de } \\
\text { Proposta }\end{array}$ & Resultado \\
\hline Alvaristo (2019) & $\begin{array}{l}\text { Uma ferramenta para elaboração de } \\
\text { conceitos matemáticos para } \\
\text { estudantes com deficiência visual: } \\
\text { gráfico em pizza adaptado. }\end{array}$ & $\begin{array}{l}\text { Google } \\
\text { Acadêmico }\end{array}$ & $\begin{array}{l}\text { Desenvolvimento de material } \\
\text { didático manipulável para criação } \\
\text { de gráficos em setores para } \\
\text { estudantes com deficiência visual. }\end{array}$ & Gráficos & $\begin{array}{c}\text { Material } \\
\text { Manipulativo }\end{array}$ & Eficiente \\
\hline Brim (2018) & $\begin{array}{l}\text { Ensino de funções do } 2^{\circ} \text { grau para } \\
\text { alunos com deficiência visual: uma } \\
\text { abordagem para a educação } \\
\text { matemática inclusiva. }\end{array}$ & $\begin{array}{l}\text { Google } \\
\text { Acadêmico }\end{array}$ & $\begin{array}{l}\text { Desenvolvimento de um } \\
\text { procedimento metodológico que } \\
\text { permita ao aluno deficiente visual } \\
\text { apropriar-se do conteúdo de } \\
\text { Função Quadrática. }\end{array}$ & Funções & $\begin{array}{l}\text { Material } \\
\text { Adaptado }\end{array}$ & Eficiente \\
\hline Adusei (2017) & $\begin{array}{l}\text { Geometry Appcessory for Visually } \\
\text { Impaired Children }\end{array}$ & $\begin{array}{l}\text { Google } \\
\text { Acadêmico }\end{array}$ & $\begin{array}{l}\text { Apresentação de um produto } \\
\text { manipulativo digital para crianças, } \\
\text { que descreve objetos geométricos } \\
\text { facilitando a compreensão dos } \\
\text { conceitos de geometria. }\end{array}$ & Geometria & $\begin{array}{l}\text { Material } \\
\text { Manipulativo/ } \\
\text { Software(s) }\end{array}$ & Eficiente \\
\hline $\begin{array}{l}\text { Anjos, Prietch, \& } \\
\text { Freire (2018) }\end{array}$ & $\begin{array}{l}\text { Realização de Testes com Leitores } \\
\text { de Tela para Leitura de Fórmulas } \\
\text { Matemáticas como Auxílio para } \\
\text { Estudantes Cegos }\end{array}$ & $\begin{array}{l}\text { Google } \\
\text { Acadêmico }\end{array}$ & $\begin{array}{l}\text { Pesquisa a respeito do uso de } \\
\text { leitores de tela para fórmulas } \\
\text { matemáticas com o objetivo de } \\
\text { auxiliar o ensino de matemática } \\
\text { para estudantes cegos. }\end{array}$ & Não Especificado & $\begin{array}{l}\text { Tecnologia } \\
\text { Assistiva }\end{array}$ & Insatisfatório \\
\hline $\begin{array}{l}\text { Aragão,Tavares } \\
\text { \& Jesus (2016) }\end{array}$ & $\begin{array}{l}\text { Multiplano pedagógico: do concreto } \\
\text { ao abstrato }\end{array}$ & $\begin{array}{l}\text { Google } \\
\text { Acadêmico }\end{array}$ & $\begin{array}{l}\text { Reflexão e contribuição acerca do } \\
\text { multiplano no ensino de } \\
\text { matemática para estudantes com } \\
\text { deficiência visual. }\end{array}$ & Diversos & $\begin{array}{c}\text { Material } \\
\text { Manipulativo }\end{array}$ & Não Aplicada \\
\hline $\begin{array}{l}\text { Araujo \& Aguiar } \\
\qquad \text { (2018) }\end{array}$ & $\begin{array}{l}\text { Função quadrática para estudantes } \\
\text { cegos: uma proposta de } \\
\text { padronização de gráficos táteis }\end{array}$ & $\begin{array}{l}\text { Google } \\
\text { Acadêmico }\end{array}$ & $\begin{array}{l}\text { Verificação da contribuição de um } \\
\text { caderno de atividades em braile } \\
\text { possibilita o acesso aos diferentes } \\
\text { registros de representação da } \\
\text { função quadrática. }\end{array}$ & Funções & $\begin{array}{l}\text { Livro Didático } \\
\text { Adaptado }\end{array}$ & Não Aplicada \\
\hline $\begin{array}{l}\text { Arruda } \\
\text { \& Bandeira } \\
\text { (2016) }\end{array}$ & $\begin{array}{l}\text { Metodologia para ensinar geometria } \\
\text { para estudantes deficientes visuais } \\
\text { utilizando multiplano e o aplicativo } \\
\text { Geogebra }\end{array}$ & $\begin{array}{l}\text { Google } \\
\text { Acadêmico }\end{array}$ & $\begin{array}{l}\text { Apresentação de uma metodologia } \\
\text { para o ensino com materiais } \\
\text { didáticos diversos e tecnologias } \\
\text { assistivas para auxiliar o ensino de } \\
\text { geometria a deficientes visuais. }\end{array}$ & Geometria & $\begin{array}{l}\text { Método de } \\
\text { Ensino }\end{array}$ & Satisfatório \\
\hline $\begin{array}{l}\text { Asebriy, Raghay } \\
\text { \& Bencharef } \\
\text { (2018) }\end{array}$ & $\begin{array}{l}\text { An Assistive Technology for Braille } \\
\text { Users to Support Mathematical } \\
\text { Learning: A Semantic Retrieval } \\
\text { System }\end{array}$ & $\begin{array}{l}\text { Google } \\
\text { Acadêmico }\end{array}$ & $\begin{array}{l}\text { Apresentação de um sistema que lê } \\
\text { informações matemáticas da web e } \\
\text { as transcreve para a linguagem } \\
\text { braille. }\end{array}$ & Não Especificado & Software(s) & Em Desenvolvimento \\
\hline $\begin{array}{l}\text { Attanayake, } \\
\text { Denholm-Price, } \\
\text { Hunter, Pfluegel, } \\
\text { \& Wigmore, } \\
\text { (2015) }\end{array}$ & $\begin{array}{l}\text { Speech interfaces for mathematics: } \\
\text { opportunities and limitations for } \\
\text { visually impaired learners. }\end{array}$ & $\begin{array}{l}\text { Google } \\
\text { Acadêmico }\end{array}$ & $\begin{array}{l}\text { Análise do potencial do software } \\
\text { TalkMaths, ferramenta de escrita e } \\
\text { leitura de expressões matemáticas } \\
\text { via fala. }\end{array}$ & Não Especificado & Software(s) & Satisfatório \\
\hline Bandeira (2018) & $\begin{array}{l}\text { Olhar sem os olhos e as Matrizes: } \\
\text { conexões entre a educação } \\
\text { matemática e a neurociência }\end{array}$ & $\begin{array}{l}\text { Google } \\
\text { Acadêmico }\end{array}$ & $\begin{array}{l}\text { Elucidação da possibilidade de } \\
\text { ensinar matemática por meio de } \\
\text { material adaptado a estudantes } \\
\text { deficientes visuais. Conexão entre a } \\
\text { matemática e a neurociência. }\end{array}$ & Matrizes & $\begin{array}{c}\text { Material } \\
\text { Manipulativo }\end{array}$ & Eficiente \\
\hline $\begin{array}{l}\text { Barroqueiro, H., } \\
\text { Barroqueiro, M. } \\
\text { \& Dias (2017) }\end{array}$ & $\begin{array}{l}\text { Estratégias de aprendizagem na } \\
\text { inclusão de alunos com deficiência } \\
\text { visual no desenvolvimento cognitivo } \\
\text { da matemática }\end{array}$ & $\begin{array}{l}\text { Google } \\
\text { Acadêmico }\end{array}$ & $\begin{array}{l}\text { Desenvolvimento de estratégias de } \\
\text { aprendizagem com o uso do tato } \\
\text { para formulação e resolução de } \\
\text { problemas por estudantes do } 2^{\circ} \text { e } \\
4^{\circ} \text { anos com deficiência visual. }\end{array}$ & $\begin{array}{l}\text { Resolução de } \\
\text { Problemas }\end{array}$ & $\begin{array}{l}\text { Método de } \\
\text { Ensino }\end{array}$ & Satisfatório \\
\hline $\begin{array}{l}\text { Bateman et al } \\
\text { (2018) }\end{array}$ & $\begin{array}{l}\text { A user-centered design and analysis } \\
\text { of na electrostatic haptic } \\
\text { touchscreen system for students } \\
\text { with visual impairments }\end{array}$ & $\begin{array}{l}\text { Science } \\
\text { Direct }\end{array}$ & $\begin{array}{l}\text { Pesquisa acerca do } \\
\text { desenvolvimento de uma } \\
\text { tecnologia touchscreen para } \\
\text { melhorar as leituras gráficas para } \\
\text { pessoas com Deficiência Visual. }\end{array}$ & Não Especificado & $\begin{array}{l}\text { Tecnologia } \\
\text { Assistiva }\end{array}$ & Satisfatório \\
\hline $\begin{array}{l}\text { Beal \& } \\
\text { Rosenblum } \\
\text { (2015a) }\end{array}$ & $\begin{array}{l}\text { Development of a Math-Learning } \\
\text { App for Students with } \\
\text { Visual Impairments }\end{array}$ & $\begin{array}{l}\text { Google } \\
\text { Acadêmico }\end{array}$ & $\begin{array}{l}\text { Desenvolvimento de aplicativo } \\
\text { para iPad e acessórios para auxiliar } \\
\text { a leitura de textos matemáticos e } \\
\text { resolução de questões. }\end{array}$ & $\begin{array}{l}\text { Resolução de } \\
\text { Problemas }\end{array}$ & Software(s) & Satisfatório \\
\hline $\begin{array}{l}\text { Beal \& } \\
\text { Rosenblum } \\
\text { (2015b) }\end{array}$ & $\begin{array}{l}\text { Use of an Accessible iPad App and } \\
\text { Supplemental Graphics to Build } \\
\text { Mathematics Skills: Feasibility Study } \\
\text { Results }\end{array}$ & $\begin{array}{l}\text { Google } \\
\text { Acadêmico }\end{array}$ & $\begin{array}{l}\text { Avaliação da viabilidade do uso de } \\
\text { um aplicativo iPad para leitura } \\
\text { algébrica incluindo materiais em } \\
\text { braile e acessíveis. }\end{array}$ & Gráficos & Aplicativo & Precisa de Melhorias \\
\hline $\begin{array}{l}\text { Beal \& } \\
\text { Rosenblum } \\
\text { (2018) }\end{array}$ & $\begin{array}{l}\text { Evaluation of the Effectiveness of a } \\
\text { Tablet Computer Application (App) } \\
\text { in Helping Students with Visual } \\
\text { Impairments Solve Mathematics } \\
\text { Problems }\end{array}$ & $\begin{array}{l}\text { Google } \\
\text { Acadêmico }\end{array}$ & $\begin{array}{l}\text { Avaliação de aplicativo para iPad } \\
\text { para ajudar os alunos com } \\
\text { deficiência visual a resolver } \\
\text { problemas matemáticos. }\end{array}$ & $\begin{array}{l}\text { Resolução de } \\
\text { Problemas }\end{array}$ & Aplicativo & Eficiente \\
\hline
\end{tabular}




\begin{tabular}{|c|c|c|c|c|c|c|}
\hline $\begin{array}{c}\text { Bernardo, Garcez } \\
\text { \& Santos (2019) }\end{array}$ & $\begin{array}{l}\text { Recursos e metodologias } \\
\text { indispensáveis ao ensino de } \\
\text { matemática para alunos com } \\
\text { deficiência visual }\end{array}$ & $\begin{array}{l}\text { Google } \\
\text { Acadêmico }\end{array}$ & $\begin{array}{l}\text { Apresentação de recursos didáticos } \\
\text { imprescindíveis para o ensino da } \\
\text { matemática para alunos com } \\
\text { deficiência visual. }\end{array}$ & Diversos & $\begin{array}{l}\text { Múltiplas } \\
\text { Propostas }\end{array}$ & Satisfatório \\
\hline $\begin{array}{l}\text { Bier } \\
\text { \& Sroczyński } \\
\text { (2019) }\end{array}$ & $\begin{array}{l}\text { Rule based intelligent system } \\
\text { verbalizing mathematical notation }\end{array}$ & $\begin{array}{l}\text { Google } \\
\text { Acadêmico }\end{array}$ & $\begin{array}{l}\text { Descrição do desenvolvimento de } \\
\text { uma ferramenta que gera a } \\
\text { verbalização da linguagem } \\
\text { matemática. }\end{array}$ & Não Especificado & Software(s) & Eficiente \\
\hline Blumberg, 2019 & $\begin{array}{l}\text { Deficiente visual e o tato como nova } \\
\text { perspectiva dos conhecimentos } \\
\text { matemáticos: vivenciando } \\
\text { experiências }\end{array}$ & $\begin{array}{c}\text { Google } \\
\text { Acadêmico }\end{array}$ & $\begin{array}{l}\text { Investigação por meio de } \\
\text { atividades com recursos didáticos } \\
\text { variados e adaptados do processo } \\
\text { de construção do conhecimento } \\
\text { matemático de estudantes com DV. }\end{array}$ & Diversos & $\begin{array}{l}\text { Múltiplas } \\
\text { Propostas }\end{array}$ & Precisa de Melhorias \\
\hline $\begin{array}{c}\text { Boonstra } \\
\text { (2017) }\end{array}$ & $\begin{array}{l}\text { Improving the mathematical reading } \\
\text { skills of students who read braille by } \\
\text { scaffolding reading strategies }\end{array}$ & $\begin{array}{c}\text { Google } \\
\text { Acadêmico }\end{array}$ & $\begin{array}{l}\text { Propõe novas técnicas de leitura de } \\
\text { textos em braile para melhorar a } \\
\text { leitura de problemas matemáticos } \\
\text { de alunos deficientes visuais }\end{array}$ & Não Especificado & $\begin{array}{l}\text { Método de } \\
\text { Ensino }\end{array}$ & Eficiente \\
\hline $\begin{array}{l}\text { Bouck, Weng, \& } \\
\text { Satsangi, (2016) }\end{array}$ & $\begin{array}{l}\text { Digital versus Traditional: Secondary } \\
\text { Students with Visual Impairments' } \\
\text { Perceptions of a Digital Algebra } \\
\text { Textbook }\end{array}$ & $\begin{array}{l}\text { Google } \\
\text { Acadêmico }\end{array}$ & $\begin{array}{l}\text { Aplicação e avaliação de um livro } \\
\text { digital de álgebra para alunos } \\
\text { deficientes visuais. }\end{array}$ & Álgebra & $\begin{array}{l}\text { Tecnologia } \\
\text { Assistiva }\end{array}$ & Precisa de Melhorias \\
\hline $\begin{array}{l}\text { Brandão, } \\
\text { Silva } \\
\text { \& Magalhães } \\
\text { (2019) }\end{array}$ & $\begin{array}{l}\text { Discentes com Deficiência Visual: } \\
\text { Estudo de Caso com Cálculo } \\
\text { Diferencial e Integral Adaptado }\end{array}$ & $\begin{array}{c}\text { Google } \\
\text { Acadêmico }\end{array}$ & $\begin{array}{l}\text { Utilização da eclética para ensinar } \\
\text { cálculo diferencial e integral para } \\
\text { duas estudantes com baixa visão } \\
\text { num curso de engenharia }\end{array}$ & $\begin{array}{l}\text { Cálculo } \\
\text { Diferencial e } \\
\text { Integral }\end{array}$ & $\begin{array}{l}\text { Método de } \\
\text { Ensino }\end{array}$ & Eficiente \\
\hline $\begin{array}{c}\text { Brawand \& } \\
\text { Johnson (2016) }\end{array}$ & $\begin{array}{l}\text { Effective Methods for Delivering } \\
\text { Mathematics Instruction to Students } \\
\text { with Visual Impairments }\end{array}$ & $\begin{array}{c}\text { Google } \\
\text { Acadêmico }\end{array}$ & $\begin{array}{l}\text { Descrição do uso de diversos } \\
\text { materiais concretos, tecnologias } \\
\text { assistivas e alternativas para } \\
\text { implementar as aulas de } \\
\text { matemática inclusiva. }\end{array}$ & Diversos & $\begin{array}{l}\text { Múltiplas } \\
\text { Propostas }\end{array}$ & Não Aplicada \\
\hline $\begin{array}{l}\text { Brzostek- } \\
\text { Pawłowska } \\
\text { (2019) }\end{array}$ & $\begin{array}{l}\text { Multimedia Mathematical } \\
\text { Communication in a Diverse Group } \\
\text { of Students }\end{array}$ & $\begin{array}{c}\text { Google } \\
\text { Acadêmico }\end{array}$ & $\begin{array}{l}\text { Desenvolvimento de uma } \\
\text { metodologia de estudo e um } \\
\text { Tecnologias Assistivas para auxiliar } \\
\text { a leitura de textos matemáticos e } \\
\text { sua transcrição para a linguagem } \\
\text { braile. }\end{array}$ & Não Especificado & Software(s) & Eficiente \\
\hline $\begin{array}{l}\text { Caetano; Mello; } \\
\text { \& Antonow. } \\
\text { (2016) }\end{array}$ & $\begin{array}{l}\text { O ensino de frações para educandos } \\
\text { cegos. }\end{array}$ & $\begin{array}{c}\text { Google } \\
\text { Acadêmico }\end{array}$ & $\begin{array}{l}\text { Apresentação de uma atividade } \\
\text { envolvendo operações com frações } \\
\text { usando o multiplano e o software } \\
\text { DOSVOX. }\end{array}$ & Fração & $\begin{array}{l}\text { Material } \\
\text { Manipulativo/ } \\
\text { Software(s) }\end{array}$ & Eficiente \\
\hline $\begin{array}{c}\text { Camelo \& Silva } \\
\text { (2017) }\end{array}$ & $\begin{array}{l}\text { Práticas inclusivas em um curso de } \\
\text { licenciatura em Matemática: um } \\
\text { estudante cego e a visão de suas } \\
\text { duas tutoras }\end{array}$ & $\begin{array}{c}\text { Google } \\
\text { Acadêmico }\end{array}$ & $\begin{array}{l}\text { Relato acerca da experiência de } \\
\text { duas tutoras de um aluno cego do } \\
\text { curso de Licenciatura em } \\
\text { Matemática do IFMG, suas práticas } \\
\text { em ensino inclusivo nos encontros } \\
\text { de tutoria. }\end{array}$ & Diversos & $\begin{array}{l}\text { Material } \\
\text { Manipulativo/ } \\
\text { Braile }\end{array}$ & Eficiente \\
\hline Castro (2017) & $\begin{array}{l}\text { Aplicação do soroban para } \\
\text { resolução de problemas envolvendo } \\
\text { as quatro operações fundamentais }\end{array}$ & $\begin{array}{c}\text { Google } \\
\text { Acadêmico }\end{array}$ & $\begin{array}{l}\text { Verificar a aprendizagem } \\
\text { significativa com a aplicação } \\
\text { do soroban como recurso didático } \\
\text { no ensino das quatro operações } \\
\text { matemáticas. }\end{array}$ & Aritmética Básica & $\begin{array}{c}\text { Material } \\
\text { Manipulativo }\end{array}$ & Eficiente \\
\hline Costa (2016) & $\begin{array}{l}\text { Veicular conceitos matemáticos em } \\
\text { estudantes cegos no ensino superior } \\
\text { politécnico: pertinência } \\
\text { da utilização do multiplano }\end{array}$ & $\begin{array}{c}\text { Google } \\
\text { Acadêmico }\end{array}$ & $\begin{array}{l}\text { Utilização do multiplano para sanar } \\
\text { dificuldades de aprendizado de } \\
\text { gráficos de matemática por alunos } \\
\text { cegos. }\end{array}$ & Gráficos & $\begin{array}{c}\text { Material } \\
\text { Manipulativo }\end{array}$ & Eficiente \\
\hline Costa (2019) & $\begin{array}{l}\text { Avaliação das Relações Pré- } \\
\text { Aritméticas em Crianças e } \\
\text { Adolescentes com Deficiência Visual }\end{array}$ & $\begin{array}{c}\text { Google } \\
\text { Acadêmico }\end{array}$ & $\begin{array}{l}\text { Avaliação das habilidades } \\
\text { matemáticas de contagem e } \\
\text { medida de crianças e adolescentes } \\
\text { com deficiência visual }\end{array}$ & Aritmética Básica & $\begin{array}{c}\text { Material } \\
\text { Manipulativo }\end{array}$ & Eficiente \\
\hline $\begin{array}{c}\text { Cruz \& } \\
\text { Ferreira(2018) }\end{array}$ & $\begin{array}{l}\text { O uso do origami adaptado para o } \\
\text { ensino das formas geométricas } \\
\text { planas a uma aluna com deficiência } \\
\text { visual }\end{array}$ & $\begin{array}{c}\text { Google } \\
\text { Acadêmico }\end{array}$ & $\begin{array}{l}\text { Discussão das potencialidades do } \\
\text { origami no desenvolvimento e } \\
\text { caracterização de figuras } \\
\text { geométricas planas }\end{array}$ & Geometria & $\begin{array}{c}\text { Material } \\
\text { Manipulativo }\end{array}$ & Satisfatório \\
\hline $\begin{array}{l}\text { DePountis, } \\
\text { Pogrund, Griffin- } \\
\text { Shirley \& Lan } \\
\text { (2015) }\end{array}$ & $\begin{array}{l}\text { Technologies Used in the Study of } \\
\text { Advanced Mathematics by Students } \\
\text { who Are Visually Impaired in } \\
\text { Classrooms: Teachers' Perspectives }\end{array}$ & $\begin{array}{c}\text { Google } \\
\text { Acadêmico }\end{array}$ & $\begin{array}{l}\text { Exame das perspectivas de } \\
\text { professores e alunos acerca de } \\
\text { tecnologias e sua utilização em } \\
\text { aulas para auxiliar o ensino de } \\
\text { matemática. }\end{array}$ & Diversos & $\begin{array}{l}\text { Múltiplas } \\
\text { Propostas }\end{array}$ & Eficiente \\
\hline Dias (2017) & $\begin{array}{l}\text { Matemática para cegos: uma } \\
\text { possibilidade no ensino de } \\
\text { polinômios }\end{array}$ & $\begin{array}{c}\text { Google } \\
\text { Acadêmico }\end{array}$ & $\begin{array}{l}\text { Reconhecer as potencialidades e } \\
\text { limitações da ação do professor } \\
\text { visando a apropriação das noções } \\
\text { de polinômios. }\end{array}$ & Polinômios & $\begin{array}{l}\text { Método de } \\
\text { Ensino }\end{array}$ & Satisfatório \\
\hline
\end{tabular}




\begin{tabular}{|c|c|c|c|c|c|c|}
\hline $\begin{array}{l}\text { Dias \& Panossian } \\
\text { (2018) }\end{array}$ & $\begin{array}{l}\text { O ensino de polinômios usando } \\
\text { material acessivel para alunos } \\
\text { cegos: potencialidades e limitações }\end{array}$ & $\begin{array}{l}\text { Google } \\
\text { Acadêmico }\end{array}$ & $\begin{array}{l}\text { Reconhecer as potencialidades e } \\
\text { limitações do uso de material } \\
\text { concreto para o ensino de } \\
\text { operações com polinômios para } \\
\text { uma turma regular com cegos } \\
\text { incluídos. }\end{array}$ & Polinômios & $\begin{array}{c}\text { Material } \\
\text { Manipulativo }\end{array}$ & Satisfatório \\
\hline Dias, et al (2018) & $\begin{array}{l}\text { Matemática, Computação e Braille: } \\
\text { Desafios da Pedagogia, da Semiótica } \\
\text { e da Síntese da Fala }\end{array}$ & $\begin{array}{l}\text { Google } \\
\text { Acadêmico }\end{array}$ & $\begin{array}{l}\text { Descrição de estratégias adotando } \\
\text { a codificação AsciiMath, que torna } \\
\text { expressões matemáticas sonoras e } \\
\text { não ambíguas. }\end{array}$ & $\begin{array}{l}\text { Expressões } \\
\text { Matemáticas }\end{array}$ & $\begin{array}{l}\text { Tecnologia } \\
\text { Assistiva }\end{array}$ & Não Aplicada \\
\hline Duffy et al (2017) & $\begin{array}{l}\text { WeDRAW: Using multisensory } \\
\text { serious games to explore concepts } \\
\text { in primary mathematics }\end{array}$ & $\begin{array}{l}\text { Google } \\
\text { Acadêmico }\end{array}$ & $\begin{array}{l}\text { Avaliação de um projeto que dá } \\
\text { assistência ao ensino da } \\
\text { matemática por meio de jogos } \\
\text { multissensoriais. }\end{array}$ & Aritmética Básica & $\begin{array}{l}\text { Tecnologia } \\
\text { Assistiva }\end{array}$ & Precisa de Melhorias \\
\hline $\begin{array}{c}\text { Emerson \& } \\
\text { Anderson (2018) }\end{array}$ & $\begin{array}{l}\text { Using Description to Convey } \\
\text { Mathematics Content in Visual } \\
\text { Images to Students who Are Visually } \\
\text { Impaired }\end{array}$ & $\begin{array}{c}\text { Google } \\
\text { Acadêmico }\end{array}$ & $\begin{array}{l}\text { Adaptação de livro didático de } \\
\text { matemática focando na qualidade } \\
\text { da descrição de imagens, para o } \\
\text { ensino de alunos com deficiência } \\
\text { visual. }\end{array}$ & Não Especificado & $\begin{array}{l}\text { Livro Didático } \\
\text { Adaptado }\end{array}$ & Precisa de Melhorias \\
\hline Ferreira (2019) & $\begin{array}{l}\text { O Ensino de simetria para alunos } \\
\text { com deficiência visual. }\end{array}$ & $\begin{array}{l}\text { Google } \\
\text { Acadêmico }\end{array}$ & $\begin{array}{l}\text { Reflexão sobre o uso de material } \\
\text { concreto para o ensino de simetria } \\
\text { para alunos com deficiência visual. }\end{array}$ & Geometria & $\begin{array}{c}\text { Material } \\
\text { Manipulativo }\end{array}$ & Eficiente \\
\hline $\begin{array}{l}\text { Figueira, Lima, } \\
\text { Borges \& Soares } \\
\text { (2015) }\end{array}$ & $\begin{array}{l}\text { A Dynamic Environment to the } \\
\text { Learning of Geometric Concepts by } \\
\text { Visually Impaired People: A Brazilian } \\
\text { Case Study }\end{array}$ & $\begin{array}{l}\text { Google } \\
\text { Acadêmico }\end{array}$ & $\begin{array}{l}\text { Apresenta um ambiente } \\
\text { computacional para o aprendizado } \\
\text { de conceitos geométricos por meio } \\
\text { de tecnologias adaptadas }\end{array}$ & Geometria & $\begin{array}{l}\text { Tecnologia } \\
\text { Assistiva }\end{array}$ & Eficiente \\
\hline $\begin{array}{l}\text { Flores, Sombrio, } \\
\text { Takimoto \& } \\
\text { Ulbricht (2015) }\end{array}$ & $\begin{array}{l}\text { A aprendizagem de geometria por } \\
\text { alunos cegos }\end{array}$ & $\begin{array}{l}\text { Google } \\
\text { Acadêmico }\end{array}$ & $\begin{array}{l}\text { Discussão sobre o ensino de } \\
\text { geometria e o uso de impressora } \\
\text { 3D para produção de maquetes. }\end{array}$ & Geometria & $\begin{array}{l}\text { Tecnologia } \\
\text { Assistiva }\end{array}$ & Satisfatório \\
\hline $\begin{array}{l}\text { Franco, L., } \\
\text { Martini, } \\
\text { Franco, M, } \\
\text { \& Silva (2018) }\end{array}$ & $\begin{array}{l}\text { Desenvolvimento de um programa } \\
\text { aplicativo para o ensino de grupo } \\
\text { das permutações a deficientes } \\
\text { visuais }\end{array}$ & $\begin{array}{l}\text { Google } \\
\text { Acadêmico }\end{array}$ & $\begin{array}{l}\text { Apresentação de um aplicativo } \\
\text { para auxiliar o ensino de grupos de } \\
\text { permutações para deficientes } \\
\text { visuais. }\end{array}$ & $\begin{array}{l}\text { Grupos de } \\
\text { Permutações }\end{array}$ & Aplicativo & Não Aplicada \\
\hline $\begin{array}{l}\text { Frankel \& } \\
\text { Brownstein } \\
\text { (2016) }\end{array}$ & $\begin{array}{l}\text { An Evaluation of the Usefulness of } \\
\text { Prosodic and Lexical Cues for } \\
\text { Understanding Synthesized Speech } \\
\text { of Mathematics }\end{array}$ & $\begin{array}{l}\text { Google } \\
\text { Acadêmico }\end{array}$ & $\begin{array}{l}\text { Apresentação de ferramentas para } \\
\text { sintetizar expressões algébricas por } \\
\text { meio da voz por meio do MathML. } \\
\text { Continuidade e refinamento. }\end{array}$ & Não Especificado & Software(s) & Eficiente \\
\hline $\begin{array}{c}\text { Frankel, } \\
\text { Brownstein, \& } \\
\text { Soiffer (2017) }\end{array}$ & $\begin{array}{l}\text { Expanding Audio Access to } \\
\text { Mathematics Expressions by } \\
\text { Students With Visual Impairments } \\
\text { via MathML }\end{array}$ & $\begin{array}{l}\text { Google } \\
\text { Acadêmico }\end{array}$ & $\begin{array}{l}\text { Avaliação de ferramentas para } \\
\text { sintetizar expressões algébricas por } \\
\text { meio da voz com o MathML. }\end{array}$ & $\begin{array}{l}\text { Expressões } \\
\text { Algébricas }\end{array}$ & $\begin{array}{l}\text { Tecnologia } \\
\text { Assistiva }\end{array}$ & Eficiente \\
\hline Freire (2017) & $\begin{array}{l}\text { Uma jornada dos números naturais } \\
\text { aos racionais com uma aluna com } \\
\text { deficiência visual }\end{array}$ & $\begin{array}{l}\text { Google } \\
\text { Acadêmico }\end{array}$ & $\begin{array}{l}\text { Análise da construção da imagem } \\
\text { mental dos números racionais de } \\
\text { uma aluna cega no decorrer da } \\
\text { aplicação de atividades voltadas } \\
\text { para a construção do número } \\
\text { racional }\end{array}$ & $\begin{array}{l}\text { Conjuntos } \\
\text { Numéricos }\end{array}$ & $\begin{array}{c}\text { Material } \\
\text { Manipulativo/ } \\
\text { Software(s) }\end{array}$ & Eficiente \\
\hline Furlan (2016) & $\begin{array}{l}\text { Conceitos geométricos, } \\
\text { deslocamentos e localização } \\
\text { espacial de estudantes com cegueira } \\
\text { congênita }\end{array}$ & $\begin{array}{l}\text { Google } \\
\text { Acadêmico }\end{array}$ & $\begin{array}{l}\text { Contribuição no ensino de } \\
\text { conteúdos de geometria para } \\
\text { estudantes cegos por meio de uma } \\
\text { sequência didática adaptada. }\end{array}$ & Geometria & $\begin{array}{l}\text { Múltiplas } \\
\text { Propostas }\end{array}$ & Satisfatório \\
\hline Galvão (2018) & $\begin{array}{l}\text { Inclusão de alunos deficientes } \\
\text { visuais no ensino de matemática no } \\
\text { contexto da educação tecnológica } \\
\text { em um Instituto Federal de } \\
\text { Educação, Ciências e Tecnologia }\end{array}$ & $\begin{array}{l}\text { Google } \\
\text { Acadêmico }\end{array}$ & $\begin{array}{l}\text { Avaliar as contribuições de uma } \\
\text { proposta pedagógica por meio da } \\
\text { Modelagem Matemática embasada } \\
\text { na educação tecnológica para } \\
\text { deficientes visuais }\end{array}$ & $\begin{array}{l}\text { Modelagem } \\
\text { Matemática }\end{array}$ & $\begin{array}{l}\text { Método de } \\
\text { Ensino }\end{array}$ & Satisfatório \\
\hline $\begin{array}{l}\text { Goddard } \\
\text { (2017) }\end{array}$ & $\begin{array}{l}\text { The use of Mobile Applications to } \\
\text { support the development of } \\
\text { arithmetic skills in visually or } \\
\text { hearing impaired children at Key } \\
\text { Stage } 1 \text { level }\end{array}$ & $\begin{array}{l}\text { Google } \\
\text { Acadêmico }\end{array}$ & $\begin{array}{l}\text { Exploração das potencialidades das } \\
\text { ferramentas de dispositivos móveis } \\
\text { para auxiliar o desenvolvimento } \\
\text { das habilidades aritméticas de } \\
\text { crianças de cinco a sete anos. }\end{array}$ & Aritmética Básica & Aplicativo & Eficiente \\
\hline Gonçalves (2017) & $\begin{array}{l}\text { A trajetória de inclusão de um } \\
\text { estudante cego em um curso de } \\
\text { licenciatura: estratégias pedagógicas } \\
\text { e seus desafios }\end{array}$ & $\begin{array}{l}\text { Google } \\
\text { Acadêmico }\end{array}$ & $\begin{array}{l}\text { Relato da trajetória de inclusão de } \\
\text { um aluno cego de Licenciatura em } \\
\text { Matemática, focado no processo } \\
\text { de ensino de Cálculo Diferencial e } \\
\text { Integral. }\end{array}$ & $\begin{array}{l}\text { Cálculo } \\
\text { Diferencial e } \\
\text { Integral }\end{array}$ & $\begin{array}{c}\text { Material } \\
\text { Manipulativo }\end{array}$ & Satisfatório \\
\hline Guedes (2016) & $\begin{array}{l}\text { A planificação de sólidos } \\
\text { geométricos no ensino de geometria } \\
\text { para alunos deficientes visuais }\end{array}$ & $\begin{array}{l}\text { Google } \\
\text { Acadêmico }\end{array}$ & $\begin{array}{l}\text { Identificação dos conhecimentos } \\
\text { geométricos de estudantes } \\
\text { Deficientes Visuais e videntes } \\
\text { usando a planificação de sólidos } \\
\text { geométricos. }\end{array}$ & Geometria & $\begin{array}{c}\text { Material } \\
\text { Manipulativo }\end{array}$ & Eficiente \\
\hline
\end{tabular}




\begin{tabular}{|c|c|c|c|c|c|c|}
\hline $\begin{array}{l}\text { Guedes \& Freire } \\
\text { (2018) }\end{array}$ & $\begin{array}{l}\text { Estratégias de Navegação em } \\
\text { Fórmulas Matemáticas na } \\
\text { Web para Pessoas com Deficiência } \\
\text { Visual }\end{array}$ & $\begin{array}{l}\text { Google } \\
\text { Acadêmico }\end{array}$ & $\begin{array}{l}\text { Elaboração de estratégias de } \\
\text { leitura e navegação web para } \\
\text { acessar conteúdos matemáticos } \\
\text { por meio de softwares leitores de } \\
\text { telas. }\end{array}$ & Não Especificado & $\begin{array}{l}\text { Tecnologia } \\
\text { Assistiva }\end{array}$ & Não Aplicada \\
\hline $\begin{array}{l}\text { Hassan \& Salleh } \\
\text { (2017) }\end{array}$ & $\begin{array}{l}\text { Development and assessment of the } \\
\text { usability of mathematical teaching } \\
\text { module for visually impaired fourth } \\
\text { year students }\end{array}$ & $\begin{array}{l}\text { Google } \\
\text { Acadêmico }\end{array}$ & $\begin{array}{l}\text { Descrição do desenvolvimento de } \\
\text { um método de ensino de } \\
\text { matemática para alunos do quarto } \\
\text { ano com deficiência visual. }\end{array}$ & $\begin{array}{l}\text { Ensino de } \\
\text { Matemática } \\
\text { Inclusiva }\end{array}$ & $\begin{array}{l}\text { Método de } \\
\text { Ensino }\end{array}$ & Eficiente \\
\hline $\begin{array}{l}\text { Hassan, Salleh, } \\
\text { M., Bari \& Salleh, } \\
\text { N. (2015) }\end{array}$ & $\begin{array}{l}\text { A23-Enhancing students with visual } \\
\text { impairment's understanding in } \\
\text { mathematics using manipulative } \\
\text { materials }\end{array}$ & $\begin{array}{l}\text { Google } \\
\text { Acadêmico }\end{array}$ & $\begin{array}{l}\text { Analisa as percepções de } \\
\text { professores de matemática acerca } \\
\text { do uso de materiais manipulativos } \\
\text { para ensinar e apresenta atividades } \\
\text { realizadas. }\end{array}$ & Não Especificado & $\begin{array}{c}\text { Material } \\
\text { Manipulativo }\end{array}$ & Eficiente \\
\hline $\begin{array}{l}\text { Ipek \& Vural } \\
\text { (2017) }\end{array}$ & $\begin{array}{l}\text { Teaching Mathematics And Material } \\
\text { Development Process For Total } \\
\text { Blind And Visually Impaired } \\
\text { Students }\end{array}$ & $\begin{array}{l}\text { Google } \\
\text { Acadêmico }\end{array}$ & $\begin{array}{l}\text { Apresentação de uma série de } \\
\text { materiais manipulativos adaptados } \\
\text { para o ensino de conceitos de } \\
\text { geometria plana e espacial. }\end{array}$ & Geometria & $\begin{array}{l}\text { Método de } \\
\text { Ensino }\end{array}$ & Eficiente \\
\hline $\begin{array}{l}\text { Junthong, } \\
\text { Netpradit \& } \\
\text { Boonlue (2018) }\end{array}$ & $\begin{array}{l}\text { Design and Development of } \\
\text { Teaching Tools in Dimensional } \\
\text { Geometry for Visually Impaired } \\
\text { Students Using Object models from } \\
\text { 3D Printing }\end{array}$ & $\begin{array}{l}\text { Google } \\
\text { Acadêmico }\end{array}$ & $\begin{array}{l}\text { Apresenta a criação de objetos de } \\
\text { ensino de geometria por meio de } \\
\text { uma impressora 3D. }\end{array}$ & Geometria & $\begin{array}{c}\text { Material } \\
\text { Manipulativo }\end{array}$ & Eficiente \\
\hline $\begin{array}{c}\text { Kaleff } \\
\text { \& Rosa (2015) }\end{array}$ & $\begin{array}{l}\text { Introdução ao conceito de curvas de } \\
\text { nível visando à inclusão do aluno } \\
\text { com deficiência visual nas aulas de } \\
\text { Geometria }\end{array}$ & $\begin{array}{l}\text { Google } \\
\text { Acadêmico }\end{array}$ & $\begin{array}{l}\text { Apresentação de experiência } \\
\text { didática do ensino de curvas de } \\
\text { nível para deficientes visuais. }\end{array}$ & Geometria & $\begin{array}{c}\text { Material } \\
\text { Manipulativo }\end{array}$ & Satisfatório \\
\hline $\begin{array}{l}\text { Kapperman, } \\
\text { Sticken } \\
\text { \& Skutchan } \\
\text { (2016) }\end{array}$ & $\begin{array}{l}\text { Technical Aspects of the } \\
\text { Development of a Web-based, } \\
\text { Interactive Nemeth Code Tutorial }\end{array}$ & $\begin{array}{l}\text { Google } \\
\text { Acadêmico }\end{array}$ & $\begin{array}{l}\text { Descrição dos passos que envolvem } \\
\text { o desenvolvimento do tutorial do } \\
\text { código Nemeth. Propõe ensinar aos } \\
\text { deficientes visuais a linguagem } \\
\text { matemática em braile. }\end{array}$ & Não Especificado & Aplicação Web & Não Aplicada \\
\hline Koepsel (2016) & $\begin{array}{l}\text { Materiais Didáticos no ensino de } \\
\text { Matemática para estudantes com } \\
\text { deficiência visual }\end{array}$ & $\begin{array}{l}\text { Google } \\
\text { Acadêmico }\end{array}$ & $\begin{array}{l}\text { Análise das contribuições dos } \\
\text { materiais didáticos no ensino da } \\
\text { Matemática para alunos com } \\
\text { deficiência visual. }\end{array}$ & Diversos & $\begin{array}{c}\text { Material } \\
\text { Manipulativo }\end{array}$ & Em Desenvolvimento \\
\hline $\begin{array}{l}\text { Koepsel \& Silva } \\
\text { (2018) }\end{array}$ & $\begin{array}{l}\text { Uso de materiais didáticos } \\
\text { instrucionais para inclusão e } \\
\text { aprendizagem matemática de } \\
\text { alunos cegos }\end{array}$ & $\begin{array}{l}\text { Google } \\
\text { Acadêmico }\end{array}$ & $\begin{array}{l}\text { Discussão acerca da importância do } \\
\text { uso de materiais didáticos } \\
\text { manipuláveis nas aulas de } \\
\text { matemática para alunos cegos. }\end{array}$ & $\begin{array}{l}\text { Teorema de } \\
\text { Pitágoras }\end{array}$ & $\begin{array}{c}\text { Material } \\
\text { Manipulativo }\end{array}$ & Eficiente \\
\hline $\begin{array}{l}\text { Lima } \\
(2015)\end{array}$ & $\begin{array}{l}\text { Ludicidade no ensino e } \\
\text { aprendizagem de uma criança com } \\
\text { deficiência visual }\end{array}$ & $\begin{array}{l}\text { Google } \\
\text { Acadêmico }\end{array}$ & $\begin{array}{l}\text { Uso da ludicidade para ampliar o } \\
\text { repertório de habilidades motoras, } \\
\text { táteis, auditivas e de um estudante } \\
\text { com baixa visão na aprendizagem } \\
\text { de conceitos matemáticos. }\end{array}$ & Aritmética Básica & $\begin{array}{l}\text { Método de } \\
\text { Ensino }\end{array}$ & Eficiente \\
\hline Lima (2017) & $\begin{array}{l}\text { Multiplano como recurso didático } \\
\text { para o ensino de função afim a } \\
\text { alunos deficientes visuais }\end{array}$ & $\begin{array}{l}\text { Google } \\
\text { Acadêmico }\end{array}$ & $\begin{array}{l}\text { Análise do processo de inclusão de } \\
\text { pessoas com deficiência visual em } \\
\text { escolas e reflexão acerca do uso do } \\
\text { multiplano no processo de ensino } \\
\text { de função afim. }\end{array}$ & Funções & $\begin{array}{c}\text { Material } \\
\text { Manipulativo }\end{array}$ & Satisfatório \\
\hline $\begin{array}{l}\text { Lima \& Oliveira. } \\
\qquad(2018)\end{array}$ & $\begin{array}{l}\text { A adaptação de material didático } \\
\text { matemático para deficientes visuais }\end{array}$ & $\begin{array}{l}\text { Google } \\
\text { Acadêmico }\end{array}$ & $\begin{array}{l}\text { Sobre a práxis na educação } \\
\text { inclusiva com foco no ensino de } \\
\text { Cálculo para estudantes do ensino } \\
\text { superior com deficiência visual. }\end{array}$ & $\begin{array}{l}\text { Cálculo } \\
\text { Diferencial e } \\
\text { Integral }\end{array}$ & $\begin{array}{l}\text { Material } \\
\text { Adaptado }\end{array}$ & Satisfatório \\
\hline $\begin{array}{l}\text { Lima, Rodrigues, } \\
\text { Almeida, } \\
\text { Cardozo, \& } \\
\text { Freire. (2019) }\end{array}$ & $\begin{array}{l}\text { Análise de verbalizações de } \\
\text { fórmulas matemáticas por } \\
\text { professores com experiência no } \\
\text { ensino de pessoas } \\
\text { com deficiência visual }\end{array}$ & $\begin{array}{l}\text { Google } \\
\text { Acadêmico }\end{array}$ & $\begin{array}{l}\text { Identificação de padrões da fala na } \\
\text { leitura de fórmulas matemáticas a } \\
\text { fim de proporcionar melhorias nas } \\
\text { TA de navegação web do aluno com } \\
\text { DV. }\end{array}$ & $\begin{array}{l}\text { Expressões } \\
\text { Matemáticas }\end{array}$ & $\begin{array}{l}\text { Tecnologia } \\
\text { Assistiva }\end{array}$ & Não Aplicada \\
\hline $\begin{array}{l}\text { Lins, Pereira, } \\
\text { Simões, \& Moura } \\
\text { (2019) }\end{array}$ & $\begin{array}{l}\text { Pesquisas realizadas sobre educação } \\
\text { matemática inclusiva no projeto } \\
\text { OBEDUC em rede UFMS/UEPB/UFAL }\end{array}$ & $\begin{array}{l}\text { Google } \\
\text { Acadêmico }\end{array}$ & $\begin{array}{l}\text { Apresentação de duas pesquisas } \\
\text { sobre práticas inclusivas e } \\
\text { utilização do Jogo da Velha para } \\
\text { trabalhar conceitos geométricos } \\
\text { com deficientes visuais. }\end{array}$ & Geometria & $\begin{array}{l}\text { Material } \\
\text { Manipulativo }\end{array}$ & Eficiente \\
\hline Luiz (2018) & $\begin{array}{l}\text { Teorema de Pitágoras: uma } \\
\text { proposta de ensino e aprendizagem } \\
\text { para alunos deficientes visuais }\end{array}$ & $\begin{array}{l}\text { Google } \\
\text { Acadêmico }\end{array}$ & $\begin{array}{l}\text { Investigação do potencial da } \\
\text { intervenção de ensino estruturada } \\
\text { a partir da confecção de materiais } \\
\text { manipulativos para o ensino do } \\
\text { Teorema de Pitágoras. }\end{array}$ & $\begin{array}{l}\text { Teorema de } \\
\text { Pitágoras }\end{array}$ & $\begin{array}{c}\text { Material } \\
\text { Manipulativo }\end{array}$ & Eficiente \\
\hline Machado (2016) & $\begin{array}{l}\text { Aprendendo a ensinar geometria } \\
\text { plana para estudantes cegos }\end{array}$ & $\begin{array}{l}\text { Google } \\
\text { Acadêmico }\end{array}$ & $\begin{array}{l}\text { Análise das contribuições de um kit } \\
\text { de materiais manipuláveis } \\
\text { utilizados para ensinar conteúdos } \\
\text { de geometria no ensino médio. }\end{array}$ & Geometria & $\begin{array}{c}\text { Material } \\
\text { Manipulativo }\end{array}$ & Eficiente \\
\hline
\end{tabular}




\begin{tabular}{|c|c|c|c|c|c|c|}
\hline $\begin{array}{c}\text { Magalhães } \\
\text { \& Moura (2016) }\end{array}$ & $\begin{array}{l}\text { Moda, média e mediana com o uso } \\
\text { de recursos táteis e tecnológicos: } \\
\text { Multiplano e Geogebra }\end{array}$ & $\begin{array}{c}\text { Google } \\
\text { Acadêmico }\end{array}$ & $\begin{array}{l}\text { Utilização do geogebra e do } \\
\text { multiplano como ferramentas } \\
\text { inclusivas para ensino de conceitos } \\
\text { de estatística básica. }\end{array}$ & Estatística & $\begin{array}{l}\text { Material } \\
\text { Manipulativo/ } \\
\text { Software(s) }\end{array}$ & Eficiente \\
\hline $\begin{array}{c}\text { Mamcasz- } \\
\text { Viginheski, } \\
\text { Shimazaki, Silva, } \\
\text { \& Pacheco (2017) }\end{array}$ & $\begin{array}{l}\text { Formação de conceitos em } \\
\text { Geometria e Álgebra por estudante } \\
\text { com deficiência visual }\end{array}$ & $\begin{array}{l}\text { Google } \\
\text { Acadêmico } \\
\text { Scielo }\end{array}$ & $\begin{array}{l}\text { Apresenta um procedimento } \\
\text { pedagógico para ensinar uma aluna } \\
\text { com cegueira total conceitos que } \\
\text { permeiam a geometria e a álgebra. }\end{array}$ & $\begin{array}{l}\text { Geometria/ } \\
\text { Álgebra }\end{array}$ & $\begin{array}{c}\text { Material } \\
\text { Manipulativo }\end{array}$ & Eficiente \\
\hline $\begin{array}{l}\text { Marques, } \\
\text { Sganzerla, \& } \\
\text { Geller (2018) }\end{array}$ & $\begin{array}{l}\text { Contátil: uma tecnologia assistiva ao } \\
\text { ensino de fundamentos } \\
\text { matemáticos. }\end{array}$ & $\begin{array}{c}\text { Google } \\
\text { Acadêmico }\end{array}$ & $\begin{array}{l}\text { Descrição da construção de uma TA } \\
\text { para auxiliar o ensino da } \\
\text { Matemática para deficientes } \\
\text { visuais, uma adaptação do material } \\
\text { dourado. }\end{array}$ & $\begin{array}{l}\text { Aritmética } \\
\text { Básica/ } \\
\text { Resolução de } \\
\text { Problemas }\end{array}$ & $\begin{array}{l}\text { Tecnologia } \\
\text { Assistiva }\end{array}$ & Eficiente \\
\hline Martins (2017) & $\begin{array}{l}\text { Materiais manipuláveis como } \\
\text { recursos para o ensino de equação } \\
\text { do primeiro grau a deficientes } \\
\text { visuais }\end{array}$ & $\begin{array}{c}\text { Google } \\
\text { Acadêmico }\end{array}$ & $\begin{array}{l}\text { Estudo sobre o ensino da } \\
\text { Matemática, confeç̧ão e aplicação } \\
\text { de material manipulável para } \\
\text { ensino de equação do primeiro } \\
\text { grau para estudantes com DV. }\end{array}$ & $\begin{array}{c}\text { Equação do } 19 \\
\text { Grau }\end{array}$ & $\begin{array}{c}\text { Material } \\
\text { Manipulativo }\end{array}$ & Eficiente \\
\hline $\begin{array}{c}\text { Martins \& } \\
\text { Bianchini (2018) }\end{array}$ & $\begin{array}{l}\text { Resolução gráfica de sistemas de } \\
\text { equações lineares de primeiro grau: } \\
\text { explorando o estilo de pensamento } \\
\text { matemático visual com um sujeito } \\
\text { cego }\end{array}$ & $\begin{array}{c}\text { Google } \\
\text { Acadêmico }\end{array}$ & $\begin{array}{l}\text { Apresentação das estratégias } \\
\text { utilizadas para ensinar a resolução } \\
\text { gráfica Sistemas de Equações } \\
\text { Lineares de Primeiro Grau. }\end{array}$ & $\begin{array}{l}\text { Sistemas de } \\
\text { Equações }\end{array}$ & $\begin{array}{c}\text { Material } \\
\text { Manipulativo }\end{array}$ & Eficiente \\
\hline $\begin{array}{l}\text { McDermott- } \\
\text { Wells } \\
\text { (2015) }\end{array}$ & $\begin{array}{l}\text { Math in the Dark: Tools for } \\
\text { Expressing Mathematical Content by } \\
\text { Visually Impaired Students }\end{array}$ & $\begin{array}{c}\text { Google } \\
\text { Acadêmico }\end{array}$ & $\begin{array}{l}\text { Desenvolvimento de um editor de } \\
\text { texto com o código braille Nemeth } \\
\text { e um chat on-line capacitado com } \\
\text { suporte ao código braille Nemeth }\end{array}$ & Não Especificado & Software(s) & Satisfatório \\
\hline $\begin{array}{l}\text { Mello \& Miranda. } \\
\text { (2016) }\end{array}$ & $\begin{array}{l}\text { O projeto "matemática para além } \\
\text { da visão" e a confecção de uma } \\
\text { ferramenta táctil para educandos } \\
\text { cegos }\end{array}$ & $\begin{array}{c}\text { Google } \\
\text { Acadêmico }\end{array}$ & $\begin{array}{l}\text { Apresentação do projeto } \\
\text { "Matemática para Além da Visão" } \\
\text { do IF Sudeste MG e a confecção de } \\
\text { uma ferramenta táctil para o } \\
\text { ensino de funções para alunos } \\
\text { cegos }\end{array}$ & Funções & $\begin{array}{c}\text { Material } \\
\text { Manipulativo }\end{array}$ & Satisfatório \\
\hline $\begin{array}{c}\text { Mello, Caetano \& } \\
\text { Miranda. (2017) }\end{array}$ & $\begin{array}{l}\text { Ferramentas tácteis no ensino de } \\
\text { Matemática para um estudante } \\
\text { cego: uma experiência no IF Sudeste } \\
\text { MG }\end{array}$ & $\begin{array}{c}\text { Google } \\
\text { Acadêmico }\end{array}$ & $\begin{array}{l}\text { O processo de inclusão e } \\
\text { aprendizagem da disciplina de } \\
\text { Cálculo Diferencial e Integral e seus } \\
\text { fundamentos de um aluno cego. }\end{array}$ & $\begin{array}{l}\text { Cálculo } \\
\text { Diferencial e } \\
\text { Integral }\end{array}$ & $\begin{array}{c}\text { Material } \\
\text { Manipulativo }\end{array}$ & Satisfatório \\
\hline $\begin{array}{l}\text { Mendes Júnior } \\
\text { (2016) }\end{array}$ & $\begin{array}{l}\text { Objeto de aprendizagem hiperligado } \\
\text { com materiais manipuláveis para o } \\
\text { ensino de geometria espacial para } \\
\text { alunos com baixa visão na educação } \\
\text { básica }\end{array}$ & $\begin{array}{c}\text { Google } \\
\text { Acadêmico }\end{array}$ & $\begin{array}{l}\text { Desenvolvimento de uma } \\
\text { tecnologia assistiva que possibilita } \\
\text { o ensino de geometria espacial } \\
\text { para alunos com baixa visão. }\end{array}$ & Geometria & Aplicativo & Eficiente \\
\hline Menezes (2017) & $\begin{array}{l}\text { Investigação do desenvolvimento do } \\
\text { pensamento geométrico por meio } \\
\text { do uso de um videojogo por } \\
\text { estudantes cegos }\end{array}$ & $\begin{array}{c}\text { Google } \\
\text { Acadêmico }\end{array}$ & $\begin{array}{l}\text { Apresentação, impacto e } \\
\text { contribuições do jogo proposto } \\
\text { para o ensino de geometria } \\
\text { (Audiogeometria) para estudantes } \\
\text { deficientes visuais. }\end{array}$ & Geometria & Jogos & Eficiente \\
\hline $\begin{array}{l}\text { Mikułowski \& } \\
\text { Mańkowski } \\
\text { (2018) }\end{array}$ & $\begin{array}{l}\text { An approach of explaining math } \\
\text { function graphs through the } \\
\text { sound representation for blind } \\
\text { students }\end{array}$ & $\begin{array}{c}\text { Google } \\
\text { Acadêmico }\end{array}$ & $\begin{array}{l}\text { Apresentação de proposta de } \\
\text { ferramenta digital que faz a } \\
\text { representação sonora de gráficos } \\
\text { matemáticos. }\end{array}$ & Gráficos & Software(s) & Não Aplicada \\
\hline $\begin{array}{c}\text { Miranda, } \\
\text { Miranda } \\
\text { \& Martini (2019) }\end{array}$ & $\begin{array}{l}\text { ALFAMATECA: Software de } \\
\text { matemática para deficientes visuais } \\
\text { em fase de alfabetização }\end{array}$ & $\begin{array}{c}\text { Google } \\
\text { Acadêmico }\end{array}$ & $\begin{array}{l}\text { Apresentação do software } \\
\text { AlfaMateca, que contribui para o } \\
\text { ensino de matemática na } \\
\text { alfabetização de deficiente visuais. }\end{array}$ & $\begin{array}{l}\text { Alfabetização } \\
\text { Matemática }\end{array}$ & Software(s) & Eficiente \\
\hline $\begin{array}{l}\text { Moeller, } \\
\text { Sganzerla \& } \\
\text { Geller (2018) }\end{array}$ & $\begin{array}{l}\text { Math Touch: tecnologia assistiva } \\
\text { para o desenvolvimento de } \\
\text { conceitos matemáticos básicos }\end{array}$ & $\begin{array}{c}\text { Google } \\
\text { Acadêmico }\end{array}$ & $\begin{array}{l}\text { Descrição da implementação de } \\
\text { uma TA para auxiliar o ensino das } \\
\text { quatro operações a estudantes } \\
\text { deficientes visuais. }\end{array}$ & Aritmética Básica & $\begin{array}{l}\text { Tecnologia } \\
\text { Assistiva }\end{array}$ & Satisfatório \\
\hline $\begin{array}{l}\text { Mollossi, Aguiar, } \\
\text { \& Moretti (2016) }\end{array}$ & $\begin{array}{l}\text { Materiais didáticos para a inclusão } \\
\text { de educandos cegos no } \\
\text { ensino de matemática }\end{array}$ & $\begin{array}{c}\text { Google } \\
\text { Acadêmico }\end{array}$ & $\begin{array}{l}\text { Apresentação e discussão a } \\
\text { respeito de alguns materiais que } \\
\text { podem auxiliar o ensino da } \\
\text { Matemática para estudantes } \\
\text { cegos. }\end{array}$ & Diversos & $\begin{array}{l}\text { Múltiplas } \\
\text { Propostas }\end{array}$ & Não Aplicada \\
\hline Morais (2018) & $\begin{array}{l}\text { Pré-Sorobã: desenvolvimento das } \\
\text { competências matemáticas básicas } \\
\text { do aluno adulto com deficiência } \\
\text { visual }\end{array}$ & $\begin{array}{c}\text { Google } \\
\text { Acadêmico }\end{array}$ & $\begin{array}{l}\text { Possibilidades acerca da aquisição } \\
\text { de conceitos matemáticos para o } \\
\text { manuseio do Sorobã. }\end{array}$ & $\begin{array}{l}\text { Alfabetização } \\
\text { Matemática }\end{array}$ & $\begin{array}{c}\text { Material } \\
\text { Manipulativo }\end{array}$ & Satisfatório \\
\hline $\begin{array}{l}\text { Moreno- } \\
\text { Chaparro, } \\
\text { Martini, León Q., } \\
\text { Sanmiguel \& } \\
\text { Larco (2015) }\end{array}$ & $\begin{array}{l}\text { Designed program for a visually } \\
\text { impaired individual to construct } \\
\text { geometric figures using a braille } \\
\text { printer }\end{array}$ & $\begin{array}{c}\text { Google } \\
\text { Acadêmico }\end{array}$ & $\begin{array}{l}\text { Criação de um programa para } \\
\text { desenhar figuras geométricas em } \\
\text { braile. }\end{array}$ & Geometria & $\begin{array}{l}\text { Tecnologia } \\
\text { Assistiva }\end{array}$ & Em Desenvolvimento \\
\hline
\end{tabular}




\begin{tabular}{|c|c|c|c|c|c|c|}
\hline Nery \& Sá (2019) & $\begin{array}{l}\text { A deficiência visual em foco: } \\
\text { estratégias lúdicas na Educação } \\
\text { Matemática Inclusiva }\end{array}$ & $\begin{array}{l}\text { Google } \\
\text { Acadêmico }\end{array}$ & $\begin{array}{l}\text { Discussão acerca das expressões } \\
\text { lúdicas no ensino da matemática } \\
\text { para alunos com Deficiência Visual. }\end{array}$ & Diversos & $\begin{array}{l}\text { Múltiplas } \\
\text { Propostas }\end{array}$ & Satisfatório \\
\hline $\begin{array}{l}\text { Neves \& Maia } \\
\text { (2018) }\end{array}$ & $\begin{array}{l}\text { O uso de materiais adaptados para o } \\
\text { ensino da matemática } \\
\text { para estudantes com deficiência } \\
\text { visual }\end{array}$ & $\begin{array}{l}\text { Google } \\
\text { Acadêmico }\end{array}$ & $\begin{array}{l}\text { Apresentação de um material } \\
\text { adaptado em braile para ensinar } \\
\text { multiplicação para alunos com } \\
\text { deficiência visual. }\end{array}$ & Aritmética Básica & $\begin{array}{c}\text { Material } \\
\text { Manipulativo }\end{array}$ & Não Aplicada \\
\hline $\begin{array}{c}\text { Oliveira } \\
\text { \& Kaleff (2015) }\end{array}$ & $\begin{array}{l}\text { Sobre uma experiência no ensino de } \\
\text { diferentes sistemas de numéricos } \\
\text { para alunos com deficiência visual: } \\
\text { O caso do sistema binário }\end{array}$ & $\begin{array}{l}\text { Google } \\
\text { Acadêmico }\end{array}$ & $\begin{array}{l}\text { Criação de um produto educacional } \\
\text { voltado para o ensino do sistema } \\
\text { de numeração binário com o uso de } \\
\text { material manipulativo e software } \\
\text { de geometria. }\end{array}$ & $\begin{array}{l}\text { Sistema de } \\
\text { Numeração }\end{array}$ & $\begin{array}{c}\text { Material } \\
\text { Manipulativo }\end{array}$ & Eficiente \\
\hline Oliveira (2016) & $\begin{array}{l}\text { Modelagem no ensino de } \\
\text { matemática: um estudo de caso com } \\
\text { estudantes cegos }\end{array}$ & $\begin{array}{l}\text { Google } \\
\text { Acadêmico }\end{array}$ & $\begin{array}{l}\text { Investigação do potencial uso da } \\
\text { Modelagem Matemática para o } \\
\text { ensino de matemática para alunos } \\
\text { do ensino fundamental com } \\
\text { deficiência visual. }\end{array}$ & Diversos & $\begin{array}{l}\text { Método de } \\
\text { Ensino }\end{array}$ & Satisfatório \\
\hline Oliveira (2019) & $\begin{array}{l}\text { Inclusão de deficientes visuais no } \\
\text { ensino de Geometria Plana }\end{array}$ & $\begin{array}{l}\text { Google } \\
\text { Acadêmico }\end{array}$ & $\begin{array}{l}\text { Elaboração de material didático } \\
\text { sobre geometria com a utilização } \\
\text { de materiais adaptados para } \\
\text { ensinar a um aluno deficiente } \\
\text { visual. }\end{array}$ & Geometria & $\begin{array}{c}\text { Material } \\
\text { Manipulativo }\end{array}$ & Eficiente \\
\hline $\begin{array}{l}\text { Oliveira, Silvânia } \\
\text { \& Cordeiro. } \\
\text { (2015) }\end{array}$ & $\begin{array}{l}\text { O trabalho com o Soroban na } \\
\text { inclusão de alunos deficientes } \\
\text { visuais nas aulas de Matemática }\end{array}$ & $\begin{array}{c}\text { Google } \\
\text { Acadêmico }\end{array}$ & $\begin{array}{l}\text { Elucidar a importância do uso de } \\
\text { recursos didáticos adequados e } \\
\text { materiais manipulativos (em } \\
\text { especial o Soroban) no ensino de } \\
\text { matemática a alunos com DV. }\end{array}$ & Aritmética Básica & $\begin{array}{c}\text { Material } \\
\text { Manipulativo }\end{array}$ & Não Aplicada \\
\hline Paim (2015) & $\begin{array}{l}\text { Matemática para alunos com } \\
\text { deficiência visual: prática para o } \\
\text { ensino de produtos notáveis }\end{array}$ & $\begin{array}{l}\text { Google } \\
\text { Acadêmico }\end{array}$ & $\begin{array}{l}\text { Desenvolvimentos de } \\
\text { metodologias para auxiliar o ensino } \\
\text { de diversos conteúdos } \\
\text { matemáticos para uma aluna cega, } \\
\text { com foco nos produtos notáveis. }\end{array}$ & $\begin{array}{l}\text { Produtos } \\
\text { Notáveis }\end{array}$ & $\begin{array}{c}\text { Material } \\
\text { Manipulativo }\end{array}$ & Satisfatório \\
\hline $\begin{array}{l}\text { Pasquarelli } \\
\text { (2015) }\end{array}$ & $\begin{array}{l}\text { A Inclusão de Alunos com } \\
\text { Deficiência Visual do } 9^{\circ} \text { ano do } \\
\text { Ensino Fundamental no Processo de } \\
\text { Ensino e Aprendizagem de } \\
\text { Estatística }\end{array}$ & $\begin{array}{l}\text { Google } \\
\text { Acadêmico }\end{array}$ & $\begin{array}{l}\text { Promoção do diálogo entre a } \\
\text { inclusão de alunos deficientes } \\
\text { visuais do } 9^{\circ} \text { ano e o ensino da } \\
\text { estatística. }\end{array}$ & Estatística & $\begin{array}{l}\text { Tecnologia } \\
\text { Assistiva }\end{array}$ & Satisfatório \\
\hline $\begin{array}{c}\text { Pasquarelli \& } \\
\text { Manrique (2016) }\end{array}$ & $\begin{array}{l}\text { A inclusão de estudantes com } \\
\text { deficiência visual no ensino e } \\
\text { aprendizagem de estatística: } \\
\text { medidas de tendência central }\end{array}$ & $\begin{array}{l}\text { Plataforma } \\
\text { CAPES }\end{array}$ & $\begin{array}{l}\text { Diálogo sobre a inclusão e ensino } \\
\text { de estatística, no âmbito das } \\
\text { medidas de tendência central, a } \\
\text { estudantes deficientes visuais. }\end{array}$ & Estatística & $\begin{array}{l}\text { Tecnologia } \\
\text { Assistiva }\end{array}$ & Satisfatório \\
\hline $\begin{array}{l}\text { Paulino, Mauso, } \\
\text { Gomes, \& } \\
\text { Rosario (2018) }\end{array}$ & $\begin{array}{l}\text { Geometria plana na educação } \\
\text { inclusiva dos deficientes visuais: um } \\
\text { projeto de ensino desenvolvido no } \\
\text { estágio supervisionado }\end{array}$ & $\begin{array}{l}\text { Google } \\
\text { Acadêmico }\end{array}$ & $\begin{array}{l}\text { Socialização de experiência onde } \\
\text { um projeto de aplicação de } \\
\text { materiais manipulativos foram } \\
\text { utilizados no ensino de geometria } \\
\text { plana para deficientes visuais. }\end{array}$ & Geometria & $\begin{array}{l}\text { Material } \\
\text { Manipulativo/ } \\
\text { Jogos }\end{array}$ & Eficiente \\
\hline $\begin{array}{l}\text { Phillips et al. } \\
\text { (2018) }\end{array}$ & $\begin{array}{l}\text { Solving Problems of Mathematics } \\
\text { Accessibility with Process-driven } \\
\text { Math: Methods and Implications }\end{array}$ & $\begin{array}{l}\text { Google } \\
\text { Acadêmico }\end{array}$ & $\begin{array}{l}\text { Desenvolvimento e avaliação de } \\
\text { um método de ensino para auxiliar } \\
\text { e simplificar o pensamento } \\
\text { matemático na resolução de } \\
\text { problemas. }\end{array}$ & $\begin{array}{l}\text { Resolução de } \\
\text { Problemas }\end{array}$ & $\begin{array}{l}\text { Método de } \\
\text { Ensino }\end{array}$ & Satisfatório \\
\hline $\begin{array}{c}\text { Pinheiro } \\
\text { Rodrigues } \\
\text { \& Faria (2017) }\end{array}$ & $\begin{array}{l}\text { Motivação para aprender: dos } \\
\text { materiais concretos à didática do } \\
\text { professor }\end{array}$ & $\begin{array}{l}\text { Google } \\
\text { Acadêmico }\end{array}$ & $\begin{array}{l}\text { Investiga a motivação de uma } \\
\text { estudante cega em aprender os } \\
\text { conceitos de fração por meio de } \\
\text { material concreto. }\end{array}$ & Fração & $\begin{array}{c}\text { Material } \\
\text { Manipulativo }\end{array}$ & Eficiente \\
\hline $\begin{array}{l}\text { Pinheiro, Araújo, } \\
\& \text { \& } \\
\text { Gonçalves (2016) }\end{array}$ & $\begin{array}{l}\text { Multiplano como auxílio no ensino } \\
\text { de matemática para pessoas cegas }\end{array}$ & $\begin{array}{l}\text { Google } \\
\text { Acadêmico }\end{array}$ & $\begin{array}{l}\text { Verificação de como o multiplano } \\
\text { pode contribuir para promover a } \\
\text { aprendizagem de alunos } \\
\text { deficientes visuais. }\end{array}$ & Aritmética Básica & $\begin{array}{l}\text { Método de } \\
\text { Ensino }\end{array}$ & Não Aplicada \\
\hline $\begin{array}{l}\text { Pinho \& Lima } \\
\text { (2016) }\end{array}$ & $\begin{array}{l}\text { Dobrando sacolas de plástico: um } \\
\text { instrumento no ensino de geometria } \\
\text { para estudantes cegos do ensino } \\
\text { fundamental }\end{array}$ & $\begin{array}{l}\text { Google } \\
\text { Acadêmico }\end{array}$ & $\begin{array}{l}\text { Avaliação da eficácia de uma } \\
\text { oficina de dobraduras de sacolas } \\
\text { plásticas para o ensino de } \\
\text { triângulos retângulos e suas } \\
\text { características. }\end{array}$ & Geometria & $\begin{array}{c}\text { Material } \\
\text { Manipulativo }\end{array}$ & Eficiente \\
\hline $\begin{array}{l}\text { Pinto \& Lima } \\
\text { (2017) }\end{array}$ & $\begin{array}{l}\text { Dobraduras e colagens no ensino de } \\
\text { geometria para estudantes cegos do } \\
\text { Ensino Fundamental no período de } \\
\text { contraturno }\end{array}$ & $\begin{array}{c}\text { Google } \\
\text { Acadêmico }\end{array}$ & $\begin{array}{l}\text { Realização de oficinas lúdicas com } \\
\text { utilização de materiais de baixo } \\
\text { custo para ensino de diversos } \\
\text { conceitos geométricos por meio } \\
\text { das dobraduras. }\end{array}$ & Geometria & $\begin{array}{c}\text { Material } \\
\text { Manipulativo }\end{array}$ & Eficiente \\
\hline $\begin{array}{l}\text { Pitchford, } \\
\text { Kamchedzera, } \\
\text { Hubber } \\
\text { \& Chigeda } \\
\text { (2018) }\end{array}$ & $\begin{array}{l}\text { Interactive Apps Promote Learning } \\
\text { of Basic Mathematics in Children } \\
\text { With Special Educational Needs and } \\
\text { Disabilities }\end{array}$ & $\begin{array}{l}\text { Google } \\
\text { Acadêmico }\end{array}$ & $\begin{array}{l}\text { Investigação acerca do potencial } \\
\text { uso de aplicativos que dão suporte } \\
\text { a alunos com deficiência visual para } \\
\text { desenvolver habilidades } \\
\text { matemáticas básicas }\end{array}$ & $\begin{array}{l}\text { Aritmética } \\
\text { Básica/ } \\
\text { Alfabetização } \\
\text { Matemática }\end{array}$ & Aplicativo & Eficiente \\
\hline
\end{tabular}




\begin{tabular}{|c|c|c|c|c|c|c|}
\hline Quiñonez (2016) & $\begin{array}{l}\text { MatGrafvoice: sistema de } \\
\text { tratamento matemático e } \\
\text { visualização tátil de funções } \\
\text { matemáticas através de uma } \\
\text { impressora Braille }\end{array}$ & $\begin{array}{c}\text { Google } \\
\text { Acadêmico }\end{array}$ & $\begin{array}{l}\text { Desenvolvimento de uma } \\
\text { ferramenta para o tratamento de } \\
\text { funções matemáticas e sua } \\
\text { impressão em uma impressora } \\
\text { braile. }\end{array}$ & Funções & $\begin{array}{l}\text { Tecnologia } \\
\text { Assistiva }\end{array}$ & Não Aplicada \\
\hline Regec (2015) & $\begin{array}{l}\text { Mathematics in inclusive education } \\
\text { of blind students in secondary } \\
\text { school in the Czech Republic }\end{array}$ & $\begin{array}{c}\text { Google } \\
\text { Acadêmico }\end{array}$ & $\begin{array}{l}\text { Avalia o uso de softwares de apoio } \\
\text { a escrita de conteúdo matemático } \\
\text { e investiga o conhecimento de } \\
\text { professores acerca dessas TA. }\end{array}$ & $\begin{array}{l}\text { Expressões } \\
\text { Matemáticas }\end{array}$ & Software(s) & Eficiente \\
\hline $\begin{array}{l}\text { Rodrigues, } \\
\text { Magalhães, } \\
\text { \& Lima (2017) }\end{array}$ & $\begin{array}{l}\text { A utilização do multiplano para a } \\
\text { aprendizagem de alunos deficientes } \\
\text { visuais }\end{array}$ & $\begin{array}{c}\text { Google } \\
\text { Acadêmico }\end{array}$ & $\begin{array}{l}\text { Investigar as contribuições da } \\
\text { utilização do Multiplano para a } \\
\text { aprendizagem de conceitos } \\
\text { matemáticos com alunos } \\
\text { deficientes visuais. }\end{array}$ & Geometria & $\begin{array}{c}\text { Material } \\
\text { Manipulativo }\end{array}$ & Eficiente \\
\hline $\begin{array}{l}\text { Rodriguez- } \\
\text { Ascaso,Letón, } \\
\text { Muñoz-Carenas } \\
\text { \&Finat (2018) }\end{array}$ & $\begin{array}{l}\text { Accessible mathematics videos for } \\
\text { non-disabled students in primary } \\
\text { education }\end{array}$ & $\begin{array}{l}\text { Google } \\
\text { Acadêmico } \\
\text { Plataforma } \\
\text { CAPES }\end{array}$ & $\begin{array}{l}\text { Avaliação do impacto de vídeos } \\
\text { adaptados a estudantes DV } \\
\text { aplicados a estudantes sem DV. } \\
\text { Análise da contribuição de vídeo- } \\
\text { aula de matemática acessível a } \\
\text { deficientes visuais. }\end{array}$ & Números Primos & Multimídia & Eficiente \\
\hline Rosa (2018) & $\begin{array}{l}\text { Uso de Recursos Tecnológicos no } \\
\text { Ensino de Matemática para } \\
\text { Deficientes Visuais }\end{array}$ & $\begin{array}{c}\text { Google } \\
\text { Acadêmico }\end{array}$ & $\begin{array}{l}\text { Compreensão da contribuição do } \\
\text { uso de recursos tecnológicos no } \\
\text { processo de ensino e aprendizagem } \\
\text { de matemática para deficientes } \\
\text { visuais. }\end{array}$ & Não Especificado & $\begin{array}{l}\text { Tecnologia } \\
\text { Assistiva }\end{array}$ & Satisfatório \\
\hline $\begin{array}{l}\text { Salvino \& Onofre } \\
\text { (2016) }\end{array}$ & $\begin{array}{l}\text { Matemática no atendimento } \\
\text { educacional especializado: Um olhar } \\
\text { sobre um aluno cego }\end{array}$ & $\begin{array}{c}\text { Google } \\
\text { Acadêmico }\end{array}$ & $\begin{array}{l}\text { Estudo de caso que investiga o } \\
\text { ensino de matemática para um } \\
\text { aluno com deficiência visual. }\end{array}$ & Aritmética Básica & $\begin{array}{l}\text { Material } \\
\text { Manipulativo/ } \\
\text { Tecnologia } \\
\text { Adaptativa }\end{array}$ & Satisfatório \\
\hline Salvino. (2017) & $\begin{array}{l}\text { Tecnologia assistiva no ensino de } \\
\text { Matemática para um aluno cego do } \\
\text { Ensino Fundamental Desafios e } \\
\text { possibilidades }\end{array}$ & $\begin{array}{l}\text { Google } \\
\text { Acadêmico }\end{array}$ & $\begin{array}{l}\text { Investigação do uso de tecnologias } \\
\text { assistivas, bem como criação de } \\
\text { algumas, no ensino de matemática } \\
\text { para um aluno com cegueira } \\
\text { adquirida. }\end{array}$ & Diversos & $\begin{array}{l}\text { Tecnologia } \\
\text { Assistiva }\end{array}$ & Satisfatório \\
\hline $\begin{array}{c}\text { Santos } \\
\text { \& Borba (2019) }\end{array}$ & $\begin{array}{l}\text { Relações entre ferramentas } \\
\text { materiais e mediação na construção } \\
\text { de conhecimento probabilístico de } \\
\text { um estudante cego }\end{array}$ & $\begin{array}{c}\text { Google } \\
\text { Acadêmico }\end{array}$ & $\begin{array}{l}\text { Estudo de caso voltado a analisar } \\
\text { noções de probabilidade de um } \\
\text { aluno cego, por meio de } \\
\text { intervenção didática. }\end{array}$ & Probabilidade & $\begin{array}{l}\text { Intervenção } \\
\text { Didática }\end{array}$ & Satisfatório \\
\hline $\begin{array}{l}\text { Santos } \\
\text { \& Sganzerla } \\
\text { (2018) }\end{array}$ & $\begin{array}{l}\text { Impressora 3D de baixo custo para } \\
\text { auxiliar cegos e/ou baixa visão na } \\
\text { construção de sólidos geométricos: } \\
\text { Projeto Mark. }\end{array}$ & $\begin{array}{l}\text { Google } \\
\text { Acadêmico }\end{array}$ & $\begin{array}{l}\text { Desenvolvimento de uma } \\
\text { impressora } 3 D \text { de baixo custo para } \\
\text { auxiliar a o ensino de geometria } \\
\text { para estudantes com deficiência } \\
\text { visual. }\end{array}$ & Geometria & $\begin{array}{l}\text { Tecnologia } \\
\text { Assistiva }\end{array}$ & Satisfatório \\
\hline Santos (2016) & $\begin{array}{l}\text { A aprendizagem de conceitos } \\
\text { básicos de probabilidade por uma } \\
\text { dupla de estudantes cegos e } \\
\text { videntes mediados pela maquete } \\
\text { tátil }\end{array}$ & $\begin{array}{l}\text { Google } \\
\text { Acadêmico }\end{array}$ & $\begin{array}{l}\text { Apresentar os resultados de uma } \\
\text { pesquisa envolvendo o ensino de } \\
\text { probabilidade por meio de uma } \\
\text { maquete tátil. }\end{array}$ & Probabilidade & $\begin{array}{c}\text { Material } \\
\text { Manipulativo }\end{array}$ & Satisfatório \\
\hline Santos (2018) & $\begin{array}{l}\text { Introdução ao conceito da função } \\
\text { exponencial: um olhar para a } \\
\text { educação inclusiva }\end{array}$ & $\begin{array}{l}\text { Google } \\
\text { Acadêmico }\end{array}$ & $\begin{array}{l}\text { Propõe o ensino da função } \\
\text { exponencial para alunos inclusos } \\
\text { por meio da utilização do } \\
\text { multiplano e outros materiais } \\
\text { manipulativos. }\end{array}$ & Funções & $\begin{array}{c}\text { Material } \\
\text { Manipulativo }\end{array}$ & Eficiente \\
\hline $\begin{array}{c}\text { Santos \& Mendes } \\
\text { (2016) }\end{array}$ & $\begin{array}{l}\text { Alunos com baixa visão: atividades } \\
\text { pedagógicas e estratégias de } \\
\text { aprendizagem na matemática }\end{array}$ & $\begin{array}{c}\text { Google } \\
\text { Acadêmico }\end{array}$ & $\begin{array}{l}\text { Apresentação de atividades } \\
\text { pedagógicas e estratégias de } \\
\text { aprendizagem de matemática para } \\
\text { alunos com deficiência visual. }\end{array}$ & Não Especificado & $\begin{array}{l}\text { Método de } \\
\text { Ensino }\end{array}$ & Em Desenvolvimento \\
\hline $\begin{array}{l}\text { Santos, Cordeiro, } \\
\text { Gonçalves \& } \\
\text { Thiengo. (2017) }\end{array}$ & $\begin{array}{l}\text { Contribuições da tecnologia na } \\
\text { construção de uma educação } \\
\text { inclusiva: o trabalho com um aluno } \\
\text { deficiente visual nas aulas de } \\
\text { Matemática }\end{array}$ & $\begin{array}{c}\text { Google } \\
\text { Acadêmico }\end{array}$ & $\begin{array}{l}\text { Discussão acerca do ensino de } \\
\text { matrizes com uso da tecnologia, } \\
\text { como recurso pedagógico, para um } \\
\text { aluno com baixa visão. }\end{array}$ & Matrizes & $\begin{array}{l}\text { Recurso } \\
\text { Tecnológico }\end{array}$ & Satisfatório \\
\hline $\begin{array}{l}\text { Santos, Gonzaga } \\
\text { \& Scarpelli (2019) }\end{array}$ & $\begin{array}{l}\text { Translação de polígonos no plano } \\
\text { cartesiano para alunos com } \\
\text { deficiência visual }\end{array}$ & $\begin{array}{c}\text { Google } \\
\text { Acadêmico }\end{array}$ & $\begin{array}{l}\text { Relato de experiência sobre o } \\
\text { ensino de translação de polígonos } \\
\text { no plano cartesiano. }\end{array}$ & $\begin{array}{l}\text { Translação/ } \\
\text { Plano Cartesiano }\end{array}$ & $\begin{array}{c}\text { Material } \\
\text { Manipulativo }\end{array}$ & Satisfatório \\
\hline $\begin{array}{c}\text { Santos, Moraes \& } \\
\text { Sales (2017) }\end{array}$ & $\begin{array}{l}\text { O braile fácil em matemática no } \\
\text { ensino superior: uma experiência } \\
\text { com um aluno cego na perspectiva } \\
\text { de promoção de autonomia }\end{array}$ & $\begin{array}{l}\text { Plataforma } \\
\text { CAPES }\end{array}$ & $\begin{array}{l}\text { Acesso a conteúdos de matemática } \\
\text { de nível superior usando } \\
\text { ferramentas adaptativas para } \\
\text { deficientes visuais, buscando a } \\
\text { autonomia do aluno DV e } \\
\text { capacitação do professor. }\end{array}$ & Diversos & $\begin{array}{l}\text { Tecnologia } \\
\text { Assistiva }\end{array}$ & Satisfatório \\
\hline $\begin{array}{c}\text { Scot \& Souto } \\
\text { (2017) }\end{array}$ & $\begin{array}{l}\text { Uso de Geoplano adaptado como } \\
\text { material didático concreto no } \\
\text { ensino de gráfico de funções } \\
\text { matemáticas: Uma experiência com } \\
\text { deficientes visuais }\end{array}$ & $\begin{array}{c}\text { Google } \\
\text { Acadêmico }\end{array}$ & $\begin{array}{l}\text { Verificação sobre a utilização do } \\
\text { Geoplano adaptado para o ensino } \\
\text { de gráficos de funções } \\
\text { matemáticas a discentes } \\
\text { deficientes visuais. }\end{array}$ & Funções & $\begin{array}{c}\text { Material } \\
\text { Manipulativo }\end{array}$ & Eficiente \\
\hline
\end{tabular}




\begin{tabular}{|c|c|c|c|c|c|c|}
\hline $\begin{array}{l}\text { Segadas-Vianna } \\
\text { (2016) }\end{array}$ & $\begin{array}{l}\text { Resolução de problemas de } \\
\text { combinatória com uso de recursos } \\
\text { didáticos para alunos com } \\
\text { deficiência visual ou surdos }\end{array}$ & $\begin{array}{c}\text { Google } \\
\text { Acadêmico }\end{array}$ & $\begin{array}{l}\text { Utilização dos canais auditivos e } \\
\text { sensores tácteis para auxiliar a } \\
\text { apresentação e resolução de } \\
\text { questões de Análise Combinatória } \\
\text { por meio de recursos didáticos } \\
\text { adaptados. }\end{array}$ & $\begin{array}{c}\text { Análise } \\
\text { Combinatória }\end{array}$ & $\begin{array}{l}\text { Material } \\
\text { Manipulativo/ } \\
\text { Braile }\end{array}$ & Satisfatório \\
\hline $\begin{array}{l}\text { Segadas-Vianna } \\
\text { et al (2016) }\end{array}$ & $\begin{array}{l}\text { A influência dos enunciados e dos } \\
\text { materiais no ensino da análise } \\
\text { combinatória para alunos surdos e } \\
\text { para alunos com deficiência visual }\end{array}$ & $\begin{array}{c}\text { Google } \\
\text { Acadêmico }\end{array}$ & $\begin{array}{l}\text { Aplicação de exercícios de análise } \\
\text { combinatória retirados de livros, } \\
\text { artigos e pelos próprios autores, } \\
\text { adaptados para a LIBRAS e } \\
\text { materiais táteis. }\end{array}$ & $\begin{array}{c}\text { Análise } \\
\text { Combinatória }\end{array}$ & $\begin{array}{c}\text { Material } \\
\text { Adaptado }\end{array}$ & Eficiente \\
\hline $\begin{array}{l}\text { Sganzerla \& } \\
\text { Geller. (2015) }\end{array}$ & $\begin{array}{l}\text { Contátil: Potencialidades de uma } \\
\text { Tecnologia Assistiva, } \\
\text { (re)adaptando o Material Dourado } \\
\text { para Cegos }\end{array}$ & $\begin{array}{c}\text { Google } \\
\text { Acadêmico }\end{array}$ & $\begin{array}{l}\text { Investigação das potencialidades e } \\
\text { limitações da tecnologia assistiva } \\
\text { Contátil, para o ensino de conceitos } \\
\text { básicos de matemática. }\end{array}$ & Aritmética Básica & $\begin{array}{l}\text { Material } \\
\text { Manipulativo/ } \\
\text { Software(s) }\end{array}$ & Eficiente \\
\hline $\begin{array}{l}\text { Sganzerla, } \\
\text { Rodrigues, } \\
\text { Moeller, \& } \\
\text { Geller (2016) }\end{array}$ & $\begin{array}{l}\text { Math Touch: Implementação de } \\
\text { uma TA }\end{array}$ & $\begin{array}{c}\text { Google } \\
\text { Acadêmico }\end{array}$ & $\begin{array}{l}\text { Análise das potencialidades do } \\
\text { Math Touch, uma TA } \\
\text { implementada para o ensino de } \\
\text { Matemática, com recursos que } \\
\text { atendam peculiaridades de alunos } \\
\text { deficientes visuais. }\end{array}$ & $\begin{array}{l}\text { Sistema de } \\
\text { Numeração }\end{array}$ & $\begin{array}{l}\text { Tecnologia } \\
\text { Assistiva }\end{array}$ & Não Aplicada \\
\hline $\begin{array}{l}\text { Shimazaki, } \\
\text { Silva \& Viginheski } \\
\text { (2015) }\end{array}$ & $\begin{array}{l}\text { O ensino de matemática e a } \\
\text { diversidade: o caso de uma } \\
\text { estudante com deficiência visual }\end{array}$ & $\begin{array}{c}\text { Google } \\
\text { Acadêmico }\end{array}$ & $\begin{array}{l}\text { Utilização do tabuleiro de xadrez } \\
\text { para introdução do conceito de } \\
\text { área e com inferência aos Produtos } \\
\text { Notáveis. }\end{array}$ & $\begin{array}{l}\text { Geometria/ } \\
\text { Produtos } \\
\text { Notáveis }\end{array}$ & Jogos & Eficiente \\
\hline $\begin{array}{l}\text { Silva } \\
\text { (2015) }\end{array}$ & $\begin{array}{l}\text { Matemática Inclusiva: ensinando } \\
\text { matrizes a deficientes visuais }\end{array}$ & $\begin{array}{c}\text { Google } \\
\text { Acadêmico }\end{array}$ & $\begin{array}{l}\text { Relato de um processo de ensino- } \\
\text { aprendizagem ao introduzir o } \\
\text { conteúdo de matrizes usando } \\
\text { materiais concretos. }\end{array}$ & Matrizes & $\begin{array}{c}\text { Material } \\
\text { Manipulativo }\end{array}$ & Satisfatório \\
\hline Silva (2015) & $\begin{array}{l}\text { Do improviso às possibilidades de } \\
\text { ensino: estudo de caso de uma } \\
\text { professora de matemática no } \\
\text { contexto da inclusão de estudantes } \\
\text { cegos }\end{array}$ & $\begin{array}{c}\text { Google } \\
\text { Acadêmico }\end{array}$ & $\begin{array}{l}\text { Relato de experiência acerca da } \\
\text { importância da utilização de } \\
\text { variados materiais manipulativos } \\
\text { para se ensinar matemática } \\
\text { sobretudo para deficientes visuais. }\end{array}$ & Diversos & $\begin{array}{c}\text { Material } \\
\text { Manipulativo }\end{array}$ & Eficiente \\
\hline Silva (2015) & $\begin{array}{l}\text { Percepção tátil de objetos do } \\
\text { cotidiano: estudo de caso no } \\
\text { reconhecimento de formas } \\
\text { geométricas e a representação } \\
\text { gráfica de cegos congênitos }\end{array}$ & $\begin{array}{l}\text { Google } \\
\text { Acadêmico }\end{array}$ & $\begin{array}{l}\text { Proposição de mudanças de design } \\
\text { nas representações gráficas } \\
\text { bidimensionais, adaptação para } \\
\text { pessoas cegas. }\end{array}$ & Gráficos & $\begin{array}{c}\text { Material } \\
\text { Manipulativo }\end{array}$ & Satisfatório \\
\hline Silva (2016) & $\begin{array}{l}\text { A utilização do multiplano no ensino } \\
\text { da matemática na educação básica: } \\
\text { uma proposta para a educação } \\
\text { inclusiva. }\end{array}$ & $\begin{array}{c}\text { Google } \\
\text { Acadêmico }\end{array}$ & $\begin{array}{l}\text { Proposta de metodologia para o } \\
\text { ensino de ângulos, trigonometria e } \\
\text { operações matemáticas com o uso } \\
\text { do multiplano. }\end{array}$ & $\begin{array}{l}\text { Trigonometria/ } \\
\text { Geometria/ } \\
\text { Aritmética Básica }\end{array}$ & $\begin{array}{c}\text { Material } \\
\text { Manipulativo }\end{array}$ & Eficiente \\
\hline Silva (2016) & $\begin{array}{l}\text { Conhecimentos de Professores } \\
\text { Sobre o Ensino de Geometria com } \\
\text { Material Manipulável para } \\
\text { Estudantes Cegos }\end{array}$ & $\begin{array}{c}\text { Google } \\
\text { Acadêmico }\end{array}$ & $\begin{array}{l}\text { Abordagem acerca do uso de } \\
\text { material manipulativo para } \\
\text { melhorar a formação de imagens } \\
\text { mentais por pessoas cegas. }\end{array}$ & Geometria & $\begin{array}{c}\text { Material } \\
\text { Manipulativo }\end{array}$ & Em Desenvolvimento \\
\hline $\begin{array}{l}\text { Silva \& Meucci } \\
\text { (2017) }\end{array}$ & $\begin{array}{l}\text { Brincando com Matemática: uma } \\
\text { alternativa educacional tangível e } \\
\text { acessível ao ensino básico }\end{array}$ & $\begin{array}{c}\text { Google } \\
\text { Acadêmico }\end{array}$ & $\begin{array}{l}\text { Utilização do Arduíno e da } \\
\text { linguagem de programação Python } \\
\text { para criar um jogo educativo para } \\
\text { crianças em alfabetização com ou } \\
\text { sem deficiência visual. }\end{array}$ & $\begin{array}{l}\text { Aritmética } \\
\text { Básica/ } \\
\text { Alfabetização } \\
\text { Matemática }\end{array}$ & $\begin{array}{l}\text { Tecnologia } \\
\text { Assistiva }\end{array}$ & Em Desenvolvimento \\
\hline $\begin{array}{l}\text { Silva \& Onofre } \\
\text { (2016) }\end{array}$ & $\begin{array}{l}\text { Jogos matemáticos e alunos com } \\
\text { deficiência visual: Desenhando } \\
\text { ações pedagógicas inclusivas }\end{array}$ & $\begin{array}{c}\text { Google } \\
\text { Acadêmico }\end{array}$ & $\begin{array}{l}\text { Investigar a mediação dos jogos } \\
\text { matemáticos no processo de } \\
\text { ensino e aprendizagem de dois } \\
\text { alunos cegos no Ensino } \\
\text { Fundamental I. }\end{array}$ & Diversos & $\begin{array}{l}\text { Múltiplas } \\
\text { Propostas }\end{array}$ & Eficiente \\
\hline $\begin{array}{c}\text { Silva, } \\
\text { Carvalho } \\
\text { \& Pessoa (2016) }\end{array}$ & $\begin{array}{l}\text { Material manipulável de geometria } \\
\text { para estudantes cegos: reflexões de } \\
\text { professores brailistas }\end{array}$ & $\begin{array}{c}\text { Google } \\
\text { Acadêmico }\end{array}$ & $\begin{array}{l}\text { Análise e reflexões de duas } \\
\text { professoras sobre um material } \\
\text { manipulável de geometria para } \\
\text { estudantes cegos. }\end{array}$ & Geometria & $\begin{array}{c}\text { Material } \\
\text { Manipulativo }\end{array}$ & Satisfatório \\
\hline $\begin{array}{l}\text { Silveira, Aguiar, } \\
\text { \& Frizzarini. } \\
\text { (2019) }\end{array}$ & $\begin{array}{l}\text { Caneta 3D: Uma nova perspectiva } \\
\text { para o ensino de matemática para } \\
\text { cegos }\end{array}$ & $\begin{array}{c}\text { Google } \\
\text { Acadêmico }\end{array}$ & $\begin{array}{l}\text { Verificação da possibilidade de } \\
\text { inclusão da caneta 3D como } \\
\text { recurso auxiliar no ensino da } \\
\text { Matemática para cegos. }\end{array}$ & Não Especificado & $\begin{array}{l}\text { Tecnologia } \\
\text { Assistiva }\end{array}$ & Em Desenvolvimento \\
\hline $\begin{array}{l}\text { Simões \& Lins } \\
\text { (2018) }\end{array}$ & $\begin{array}{l}\text { Trajetória e processo: educação } \\
\text { matemática inclusiva, o uso do jogo } \\
\text { da velha na geometria para alunos } \\
\text { deficientes visuais }\end{array}$ & $\begin{array}{c}\text { Google } \\
\text { Acadêmico }\end{array}$ & $\begin{array}{l}\text { Processo de utilização do Jogo da } \\
\text { Velha no ensino de Geometria para } \\
\text { alunos com deficiência visual. }\end{array}$ & Geometria & $\begin{array}{c}\text { Material } \\
\text { Manipulativo }\end{array}$ & Eficiente \\
\hline $\begin{array}{c}\text { Spinczyka, } \\
\text { Maćkowskib, } \\
\text { Kempac \& } \\
\text { Rojewska (2019) }\end{array}$ & $\begin{array}{l}\text { Factors influencing the process of } \\
\text { learning mathematics among } \\
\text { visually impaired and blind people }\end{array}$ & $\begin{array}{l}\text { Google } \\
\text { Acadêmico }\end{array}$ & $\begin{array}{l}\text { Desenvolvimento e avaliação de } \\
\text { um método de ensino de } \\
\text { matemática por meio de } \\
\text { tecnologias assistivas a alunos } \\
\text { deficientes visuais. }\end{array}$ & $\begin{array}{l}\text { Ensino de } \\
\text { Matemática } \\
\text { Inclusiva/ } \\
\text { Resolução de } \\
\text { Problemas }\end{array}$ & $\begin{array}{l}\text { Método de } \\
\text { Ensino }\end{array}$ & Eficiente \\
\hline
\end{tabular}




\begin{tabular}{|c|c|c|c|c|c|c|}
\hline Splett (2015) & $\begin{array}{l}\text { Inclusão de alunos cegos nas classes } \\
\text { regulares e o processo de ensino e } \\
\text { aprendizagem de matemática }\end{array}$ & $\begin{array}{c}\text { Google } \\
\text { Acadêmico }\end{array}$ & $\begin{array}{l}\text { Análise dos desafios do processo de } \\
\text { ensino e aprendizagem no contexto } \\
\text { da inclusão de alunos cegos e } \\
\text { estudo de caso desse processo. }\end{array}$ & Plano Cartesiano & $\begin{array}{l}\text { Sequência } \\
\text { Didática }\end{array}$ & Satisfatório \\
\hline $\begin{array}{l}\text { Stone, Kay \& } \\
\text { Reynolds (2019) }\end{array}$ & $\begin{array}{l}\text { Teaching Visually Impaired College } \\
\text { Students in Introductory Statistics }\end{array}$ & $\begin{array}{c}\text { Google } \\
\text { Acadêmico }\end{array}$ & $\begin{array}{l}\text { Discussão de variadas alternativas } \\
\text { de ensino de estatística dentro e } \\
\text { fora da sala de aula, tanto no } \\
\text { aspecto de adaptação pedagógica } \\
\text { quanto de materiais manipulativos. }\end{array}$ & Estatística & $\begin{array}{l}\text { Múltiplas } \\
\text { Propostas }\end{array}$ & Satisfatório \\
\hline $\begin{array}{l}\text { Sulistyowati et al } \\
\text { (2019) }\end{array}$ & $\begin{array}{l}\text { The problems of teaching fractional } \\
\text { arithmetic operations for disabled } \\
\text { student using Realistic Mathematics } \\
\text { Education }\end{array}$ & $\begin{array}{l}\text { Google } \\
\text { Acadêmico }\end{array}$ & $\begin{array}{l}\text { Adaptação da Educação } \\
\text { Matemática Realista na resolução } \\
\text { de problemas aritméticos de várias } \\
\text { frações por alunos cegos. }\end{array}$ & Fração & $\begin{array}{c}\text { Material } \\
\text { Manipulativo }\end{array}$ & Precisa de Melhorias \\
\hline Tavares (2018) & $\begin{array}{l}\text { A pessoa com deficiência visual e o } \\
\text { processo de aprendizagem em } \\
\text { matemática: caminhos e } \\
\text { descaminhos }\end{array}$ & $\begin{array}{c}\text { Google } \\
\text { Acadêmico }\end{array}$ & $\begin{array}{l}\text { Compreensão do processo de } \\
\text { aprendizagem de conteúdos } \\
\text { matemáticos de pessoas } \\
\text { deficientes visuais. }\end{array}$ & Diversos & $\begin{array}{l}\text { Múltiplas } \\
\text { Propostas }\end{array}$ & Não Aplicada \\
\hline $\begin{array}{l}\text { Toste, Reis, \& } \\
\text { Victer. (2016) }\end{array}$ & $\begin{array}{l}\text { TABULEIRO DAS EXPRESSÕES: um } \\
\text { auxiliador no ensino da matemática } \\
\text { para alunos com deficiência visual }\end{array}$ & $\begin{array}{l}\text { Google } \\
\text { Acadêmico }\end{array}$ & $\begin{array}{l}\text { Produção de material de apoio ao } \\
\text { estudo das expressões numéricas } \\
\text { em braile. }\end{array}$ & $\begin{array}{l}\text { Expressões } \\
\text { Numéricas }\end{array}$ & $\begin{array}{l}\text { Método de } \\
\text { Ensino }\end{array}$ & Eficiente \\
\hline Uliana (2013) & $\begin{array}{l}\text { Inclusão de Estudantes Cegos nas } \\
\text { Aulas de Matemática: a construção } \\
\text { de um kit pedagógico }\end{array}$ & Scielo & $\begin{array}{l}\text { Apresentação, confecção e } \\
\text { experimentação de um kit } \\
\text { pedagógico adaptado para o ensino } \\
\text { de geometria plana para uma } \\
\text { estudante cega. }\end{array}$ & $\begin{array}{c}\text { Geometria/ } \\
\text { Plano Cartesiano }\end{array}$ & $\begin{array}{c}\text { Material } \\
\text { Manipulativo }\end{array}$ & Eficiente \\
\hline $\begin{array}{l}\text { Uliana \& Leite } \\
\text { (2018) }\end{array}$ & $\begin{array}{l}\text { Educação inclusiva no curso de } \\
\text { extensão universitária: estratégias, } \\
\text { recursos e materiais didáticos no } \\
\text { ensino de matemática para } \\
\text { estudantes da educação básica } \\
\text { com deficiência visual }\end{array}$ & $\begin{array}{c}\text { Google } \\
\text { Acadêmico }\end{array}$ & $\begin{array}{l}\text { Relato referente a um curso de } \\
\text { extensão presencial sobre a } \\
\text { confecção de materiais didáticos de } \\
\text { apoio ao ensino de matemática } \\
\text { alunos deficientes visuais. }\end{array}$ & Diversos & $\begin{array}{c}\text { Material } \\
\text { Adaptado }\end{array}$ & Não Aplicada \\
\hline Vergara (2016) & $\begin{array}{l}\text { Deficiência Visual: Doze ideias para } \\
\text { a aula de matemática em classes } \\
\text { inclusivas }\end{array}$ & $\begin{array}{c}\text { Google } \\
\text { Acadêmico }\end{array}$ & $\begin{array}{l}\text { Estudo sobre a inclusão escolar e } \\
\text { sugestões de materiais que podem } \\
\text { ser utilizados para ensinar } \\
\text { matemática para estudantes } \\
\text { deficientes visuais. }\end{array}$ & Diversos & $\begin{array}{l}\text { Múltiplas } \\
\text { Propostas }\end{array}$ & Não Aplicada \\
\hline $\begin{array}{l}\text { Viginheski et al } \\
\text { (2017) }\end{array}$ & $\begin{array}{l}\text { Análise de produtos desenvolvidos } \\
\text { no mestrado } \\
\text { profissional na área de matemática: } \\
\text { possibilidades de adaptações para o } \\
\text { uso com estudantes cegos }\end{array}$ & $\begin{array}{c}\text { Google } \\
\text { Acadêmico }\end{array}$ & $\begin{array}{l}\text { Análise de produções técnicas para } \\
\text { o ensino da matemática por meio } \\
\text { de revisão bibliográfica. Adaptação } \\
\text { de produtos educacionais para } \\
\text { estudantes deficientes visuais. }\end{array}$ & Diversos & $\begin{array}{c}\text { Material } \\
\text { Adaptado }\end{array}$ & Não Aplicada \\
\hline Wiazowski (2018) & $\begin{array}{l}\text { Sight, touch, hearing: The current } \\
\text { digital options and challenges in } \\
\text { access to math content for learners } \\
\text { with visual impairments }\end{array}$ & $\begin{array}{c}\text { Google } \\
\text { Acadêmico }\end{array}$ & $\begin{array}{l}\text { Investiga a utilização de tecnologias } \\
\text { para o ensino da matemática para } \\
\text { alunos deficientes visuais e } \\
\text { compara o ensino assistido } \\
\text { tradicional com o ensino por meio } \\
\text { digital. }\end{array}$ & $\begin{array}{l}\text { Expressões } \\
\text { Matemáticas }\end{array}$ & Software(s) & Eficiente \\
\hline $\begin{array}{c}\text { Xavier \& Santiago } \\
\text { (2019) }\end{array}$ & $\begin{array}{l}\text { O soroban como instrumento de } \\
\text { aprendizado na } \\
\text { formação de professores do ensino } \\
\text { básico }\end{array}$ & $\begin{array}{c}\text { Google } \\
\text { Acadêmico }\end{array}$ & $\begin{array}{l}\text { Experiência vivenciada em um } \\
\text { curso de formação continuada } \\
\text { contendo em um de seus módulos } \\
\text { o uso do Soroban para ensinar as } \\
\text { operações matemáticas básicas. }\end{array}$ & Aritmética Básica & $\begin{array}{c}\text { Material } \\
\text { Manipulativo }\end{array}$ & Não Aplicada \\
\hline Alvaristo (2019) & $\begin{array}{l}\text { Uma ferramenta para elaboração de } \\
\text { conceitos matemáticos para } \\
\text { estudantes com deficiência visual: } \\
\text { gráfico em pizza adaptado. }\end{array}$ & $\begin{array}{c}\text { Google } \\
\text { Acadêmico }\end{array}$ & $\begin{array}{l}\text { Desenvolvimento de material } \\
\text { didático manipulável para criação } \\
\text { de gráficos em setores para } \\
\text { estudantes com deficiência visual. }\end{array}$ & Gráficos & $\begin{array}{l}\text { Material } \\
\text { Manipulativo }\end{array}$ & Eficiente \\
\hline
\end{tabular}

Uma análise da distribuição quantitativa geral dos artigos selecionados pode ser vista nas Figura 6 e 7, nas quais é possível identificar as categorias predominantes. Em outros termos, as áreas do ensino de matemática com maior número de estudos aplicáveis foram a Geometria e a Aritmética Básica, ou conteúdos diversificados em um mesmo trabalho. As metodologias mais abordadas pelos autores foram Materiais Manipulativos e Tecnologias Assistivas. 


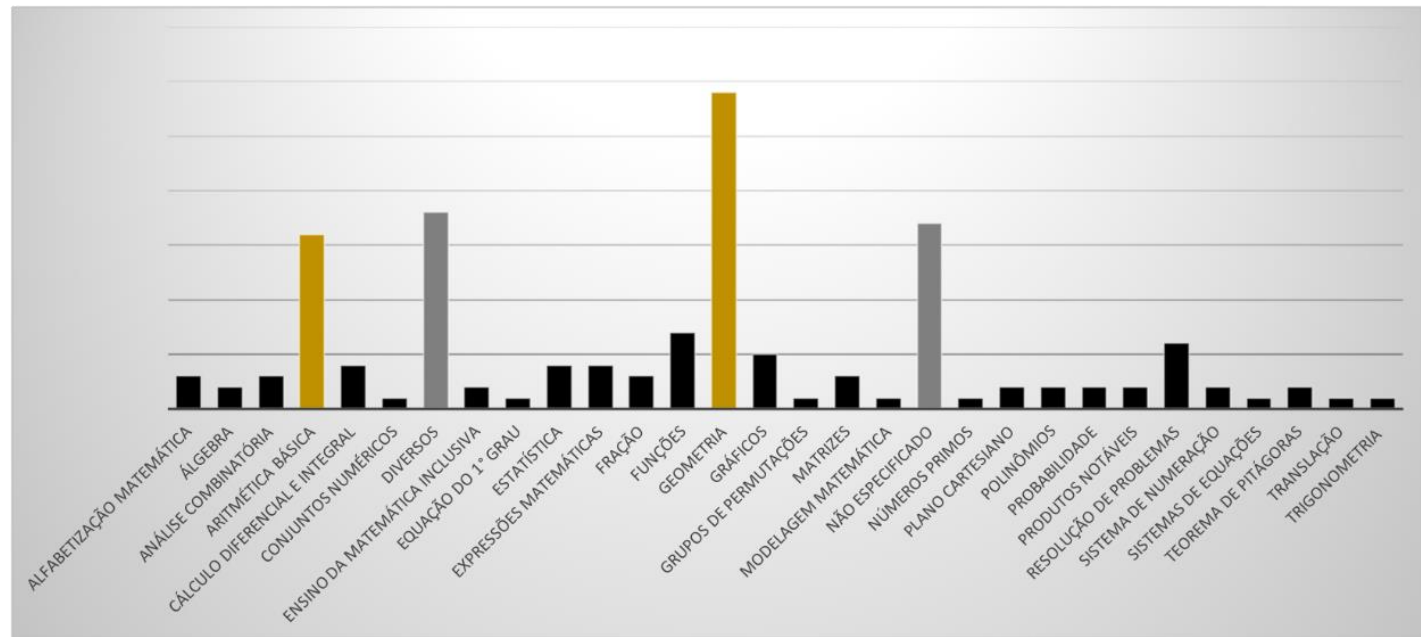

Figura 6: Gráfico contendo a relação entre a quantidade de trabalhos por conteúdo

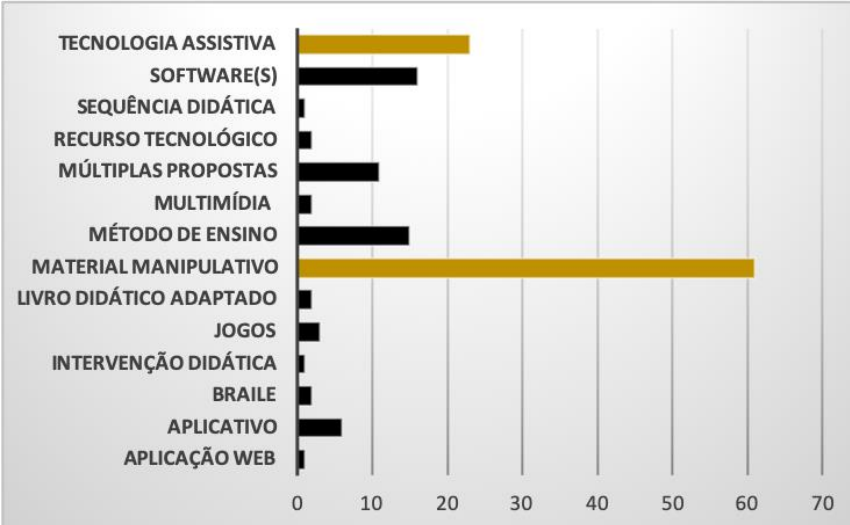

a)

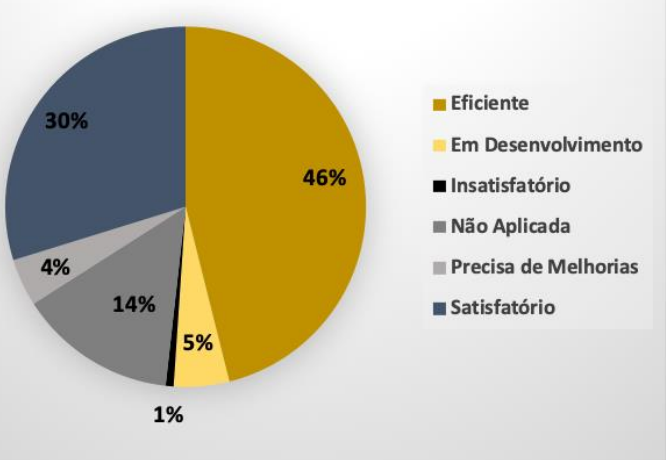

b)

Figura 7: a) Tipo de Proposta ou Metodologia de Ensino; b) Resultado da Proposta

\section{CONCLUSÕES}

A sistematização foi realizada a contento, abordando e categorizando os 138 estudos que passaram pelo processo de seleção, provenientes de eventos científicos, periódicos ou produzidos como trabalhos de graduação e pós-graduação. Em relação à eficácia das técnicas, $46 \%$ foram considerados eficientes; $30 \%$ classificados como satisfatórios; $4 \%$ necessitam de melhorias; e apenas $1 \%$ foi visto como ineficiente.

Quanto aos conteúdos ou aplicações, foram apontados trabalhos em diversificadas áreas do ensino de matemática, com as maiores quantidades referentes à Geometria e à Aritmética Básica. As metodologias mais adotadas pelos autores para abordar os conteúdos foram Materiais Manipulativos e Tecnologias Assistivas.

O conteúdo sistematizado pode contribuir com a difusão do conhecimento e das técnicas que favorecem um ensino mais equalizado de matemática aos deficientes visuais, diminuindo a distância entre a qualidade do que é ofertado a eles e aos alunos com plena visão. Além disso, entende-se que o conteúdo apresentado facilita a busca do docente que deseja ser mais presente no ensino das crianças cegas ou com baixa visão. 


\section{REFERÊNCIAS BIBLIOGRÁFICAS}

Adusei, M. (2017). Geometry Appcessory for Visually Impaired Children (Relatório de Graduação, Graduate School of Creative Design Engineering, Republic of Korea, Graduação em Engenharia de Design). Recuperado de: https://scholarworks.unist.ac.kr/handle/201301/21729

Alvaristo, E. de F. (2019). Uma ferramenta para elaboração de conceitos matemáticos para estudantes com deficiência visual: gráfico em pizza adaptado. (Dissertação, Universidade Federal Tecnológica do Paraná, Ponta Grossa, Programa de Pós-Graduação em Ensino e Tecnologia). Recuperado de: http://repositorio.utfpr.edu.br:8080/jspui/handle/1/3992

Amaral, G. K, Ferreira, A. C. \& Dickman, A. G. (2009). Educação de Estudantes Cegos na Escola Inclusiva: O Ensino de Física. In: 18 Simpósio Nacional de Ensino de Física. Vitória: SNEF. Recuperado de: http://www.cienciamao.usp.br/dados/snef/_educacaodeestudantescego.trabalho.pdf

Anjos, G. P., Prietch, S. S., \& Freire, A. P. (2017). Realização de Testes com Leitores de Tela para Leitura de Fórmulas Matemáticas como Auxílio para Estudantes Cegos. In 8 Escola Regional de Informática de Mato Grosso. Cáceres, SBC. Recuperado de: https://www.researchgate.net/profile/Gleber Marques/publication/332878993 Anais da E scola Regional de Informatica de Mato Grosso 2017 -

Sociedade Brasileira de Computacao/links/5cd08144458515712e973636/Anais-da-EscolaRegional-de-Informatica-de-Mato-Grosso-2017-Sociedade-Brasileira-deComputacao.pdf\#page $=72$

Aragão, G. I, Tavares, J. A. V., \& Jesus, M. A. M. (2016). Multiplano pedagógico: do concreto ao abstrato. In 9 Encontro Internacional de Formação de Professores. Aracaju: UNIT. Recuperado de: https://eventos.set.edu.br/index.php/enfope/article/view/2098

Araujo, L. F. F., \& Aguiar, R. (2018). Função quadrática para estudantes cegos: uma proposta de padronização de gráficos táteis. In 4 Colóquio Luso-Brasileiro de Educação. Braga: UDESC. Recuperado de: http://www.revistas.udesc.br/index.php/colbeduca/article/view/11300

Arruda, K. N., \& Bandeira, S. M. C. (2016). Metodologia para ensinar geometria para estudantes deficientes visuais utilizando multiplano e o aplicativo Geogebra. In 10 Simpósio Linguagens e Identidades da/na Amazônia Sul Ocidental. Rio Branco: UFAC. Recuperado de: https://periodicos.ufac.br/index.php/simposioufac/article/download/899/496

Asebriy, Z., Raghay, S. \& Bencharef, O. (2018). An Assistive Technology for Braille Users to Support Mathematical Learning: A Semantic Retrieval System. Symmetry. 10 (547); 1-16. doi: doi:10.3390/sym10110547.

Attanayake, D., Denholm-Price, J., Hunter, G., Pfluegel, E. \& Wigmore, A. (2015). Speech interfaces for mathematics: opportunities and limitations for visually impaired learners. In IMA International Conference on Barriers and Enablers to Learning Maths: Enhancing Learning and Teaching for All Learners. Recuperado de: https://ima.org.uk/wp/wpcontent/uploads/2015/06/Speech-Interfaces-for-Mathematics-Opportunities-andLimitations-for-Visually-Impaired-Learners.pdf 
Augestad, L. B. (2017). Self-concept and self-esteem among children and young adults with visual impairment: A systematic review. Cogent Psychology. 4(1), 1-19. doi: $10.1080 / 23311908.2017 .1319652$

Barroqueiro, C. H., Barroqueiro, M. E. S., \& Dias, R. A. (2017). Estratégias de aprendizagem na inclusão de alunos com deficiência visual no desenvolvimento cognitivo da matemática. Saber \& Educar 23: 12-21. DOI: http://dx.doi.org/10.17346/se.vol23.295

Bateman, A., Zhao, O. K., Bajcsy, A. V., ... \& Oliveira, M. (2017). A user-centered design and analysis of na electrostatic haptic touch screen system for students with visual impairments. International Journal of Human-Computer Studies. 109: 102-111. Doi: https://doi.org/10.1016/i.ijhcs.2017.09.004

Beal, C. R. \& Rosenblum, L. P. (2015a). Development of a Math-Learning App for Students with Visual Impairments. Journal on Technology and Persons with Disabilities. In 30 Annual International Technology and Persons with Disabilities Conference Scientific/Research Proceedings, San Diego. Recuperado de: http://scholarworks.csun.edu/handle/10211.3/151181

Beal, C. R. \& Rosenblum, L. P. (2018). Evaluation of the Effectiveness of a Tablet Computer Application (App) in Helping Students with Visual Impairments Solve Mathematics Problems. Journal of Visual Impairment \& Blindness. (January-February), 5-19. doi: https://doi.org/10.1177/0145482X1811200102.

Beal, C. R., \& Rosenblum, L. P. (2015b). Use of an Accessible iPad App and Supplemental Graphics to Build Mathematics Skills: Feasibility Study Results. Journal of Visual Impairment \& Blindness, 109(5), 383-394. Doi: https://doi.org/10.1177/0145482X1510900507

Bernardo, F. G., Garcez, W. R., \& Santos, R. C. (2019). Recursos e metodologias indispensáveis ao ensino de matemática para alunos com deficiência visual. Revista de Educação, Ciências e Matemática. $\quad 9(1): \quad 23-42 . \quad$ Recuperado de: http://publicacoes.unigranrio.edu.br/index.php/recm/article/view/4970

Bersch, R. (2013). Introdução à Tecnologia Assistiva. Porto Alegre. Recuperado de: http://www.assistiva.com.br/Introducao Tecnologia Assistiva.pdf

Bier, A. \& Sroczyński, Z. (2019). Rule based intelligent system verbalizing mathematical notation. Multimedia Tools and Applications. 78(19), 28089-28110. Doi: https://doi.org/10.1007/s11042-019-07889-3

Blumberg, V. S. P. (2019). Deficiente visual e o tato como nova perspectiva dos conhecimentos matemáticos: vivenciando experiências (Monografia, Universidade Federal do Rio Grande do Sul, Porto Alegre, Licenciatura em Matemática). Recuperado de: https://www.lume.ufrgs.br/handle/10183/199295

Boonstra, L. (2017). Improving the mathematical reading skills of students who read braille by scaffolding reading strategies. Revista da Associação Médica Brasileira. (July), 1-23. Recuperado de: 
https://dspace.library.uu.nl/bitstream/handle/1874/352628/Intervention\%20Math\%20Braill e\%20-\%20Lisan\%20Boonstra\%20-\%20Research\%20Project\%202017.pdf?sequence=2

Bouck, E. C., Weng, P.-L., \& Satsangi, R. (2016). Digital versus Traditional: Secondary Students with Visual Impairments' Perceptions of a Digital Algebra Textbook. Journal of Visual Impairment \& Blindness, 110(1), 41-52. Doi: https://doi.org/10.1177/0145482X1611000105

Brandão, J. C., Silva, M. A. \& Magalhães, E. B. (2019). Discentes com deficiência visual: estudo de caso com cálculo diferencial e integral adaptado. Id on Line. 13(45): 680-690. doi: https://doi.org/10.14295/idonline.v13i45.1886

Brawand, A. \& Johnson, N. (2016). Effective Methods for Delivering Mathematics Instruction to Students with Visual Impairments. Journal of Blindness Innovation and Research. 6(1). Recuperado de: https://www.nfb.org/images/nfb/publications/jbir/jbir16/ibir060101.html

Brim, J. de F. H. (2018). Ensino de funções do $2^{\circ}$ grau para alunos com deficiência visual: uma abordagem para a educação matemática inclusiva. (Dissertação, Universidade Federal Tecnológica do Paraná, Ponta Grossa, Programa de Pós-Graduação em Ensino e Tecnologia). Recuperado de: http://www.educadores.diaadia.pr.gov.br/arquivos/File/dissertacoes teses/2019/mar2019d issertacao juliana brim.pdf

Brzostek-Pawłowska, J. (2019). Multimedia Mathematical Communication in a Diverse Group of Students. Journal of Telecommunications and Information Technology. 2, 92-103. doi: http://doi.org/10.26636/itit.2019.132819.

Caetano, J. L. P., Mello, F. A., \& Antonow, L. M. (2016). O ensino de frações para educandos cegos. In 12 Encontro Nacional de Educação Matemática. São Paulo, SBEM. Recuperado de: http://www.sbem.com.br/enem2016/anais/pdf/6581 4269 ID.pdf

Camelo, F. G., \& Silva, M. F. D. (2017). Práticas inclusivas em um curso de licenciatura em Matemática: um estudante cego e a visão de suas duas tutoras. Com a Palavra o Professor. Vitória da Conquista. 2(2): 54-76. doi: 10.23864/cpp-v2-n1-151

Castro, N. H. C. (2017). Aplicação do soroban para resolução de problemas envolvendo as quatro operações fundamentais (Monografia, Instituto Federal de Educação, Ciência e Tecnologia do Piauí, Teresina, Licenciatura em Matemática). Recuperado de: http://bia.ifpi.edu.br/jspui/handle/prefix/111

Cerva Filho, O. \& A. C.; Geller, M. (2010). O processo de apropriação de conhecimentos matemáticos por alunos cegos: um estudo de caso (Projeto de Pesquisa, Universidade Luterana do Brasil). Recuperado de: https://docplayer.com.br/67501178-O-processo-deapropriacao-de-conhecimentos-matematicos-por-alunos-cegos-um-estudo-de-caso.html

Chanfreau, J. \& Cebulla, A. (2009). Educational attainment of blind and partially sighted pupils. National Centre for Social Research (NatCen) for RNIB. Recuperado de: https://www.rnib.org.uk/sites/default/files/Nat Cen Nov 2009.doc 
Constituição Federal de 1988. (1988, 5 de outubro). Brasília. Recuperado de: http://www.planalto.gov.br/ccivil 03/constituicao/constituicao.htm

Costa, A. B. (2019). Avaliação das relações pré-aritméticas em crianças e adolescentes com deficiência visual (Tese de Doutorado, Universidade Federal de São Carlos, São Carlos, Programa de Pós-Graduação em Educação Especial). Recuperado de: https://repositorio.ufscar.br/handle/ufscar/11523

Costa, C. J. S. (2016). Veicular conceitos matemáticos em estudantes cegos no ensino superior politécnico: pertinência da utilização do multiplano (Dissertação, Instituto Politécnico Leiria, Leiria, Mestrado em Comunicação Acessível). Recuperado de: https://iconline.ipleiria.pt/handle/10400.8/1900

Cruz, T. N. B., \& Ferreira, R. S. (2018). O uso do origami adaptado para o ensino das formas geométricas planas a uma aluna com deficiência visual. 1(3): 108-119. TANGRAM - Revista de educação matemática. Recuperado de: http://ojs.ufgd.edu.br/index.php/tangram/article/view/8333

Decreto № 3.298. de 20 de dezembro de 1999. (1999, 20 de dezembro). Brasília. Recuperado de: http://www.planalto.gov.br/ccivil 03/decreto/D3298.htm

Decreto № 3.956. de 08 de outubro de 2001. (2001, 08 de outubro). Brasília. Recuperado de: http://www.planalto.gov.br/ccivil_03/decreto/2001/D3956.htm

Decreto № 5.296. de 02 de dezembro de 2004. (2004, 02 de dezembro). Brasília. Recuperado de: https://www.planalto.gov.br/ccivil 03/ Ato2004-2006/2004/Decreto/D5296.htm

Decreto № 6.949. de 25 de agosto de 2009. (2009, 25 de agosto). Brasília. Recuperado de: https://www.planalto.gov.br/ccivil 03/ ato2007-2010/2009/decreto/d6949.htm

DePountis, V. M., Pogrund, R. L., Griffin-Shirley, N., \& Lan, W. Y. (2015). Technologies Used in the Study of Advanced Mathematics by Students who Are Visually Impaired in Classrooms: Teacher's Perspectives. Journal of Visual Impairment \& Blindness, 109(4), 265-278. Doi: https://doi.org/10.1177/0145482X1510900403

Dias, A. F. S., França, J. B. S., Borges, J. A. S., Silveira, J. T. C., Carvalho, M. F., \& Borges, M. R. S. (2018). Matemática, Computação e Braille: Desafios da Pedagogia, da Semiótica e da Síntese da Fala. In 7 Congresso Brasileiro de Informática na Educação. Recuperado de: http://www.brie.org/pub/index.php/sbie/article/view/8175

Dias, C. E. (2017). Matemática para cegos: uma possibilidade no ensino de polinômios (Monografia, Universidade Tecnológica Federal do Paraná, Curitiba, Licenciatura em Matemática). Recuperado de: http://repositorio.roca.utfpr.edu.br/ispui/handle/1/9589

Dias, C. E., \& Panossian, M. L. (2018). O ensino de polinômios usando material acessível para alunos cegos: potencialidades e limitações. Revista de Educação Matemática. São Paulo. 15(20): 409431. doi: doi.org/10.25090/remat25269062v15n202018p409a431 
Duffy, S., Price, S., Volpe, G., Marshall, P., Berthouze, N., Cappagli, G. ..., Gori, M. (2017). WeDRAW: Using multisensory serious games to explore concepts in primary mathematics. In 13 International Conference on Technology in Mathematics Teaching. Lyon: ENS/IFE. Recuperado de: https://discovery.ucl.ac.uk/id/eprint/1561524/

Emerson, R. W., \& Anderson, D. L. (2018). Using Description to Convey Mathematics Content in Visual Images to Students who Are Visually Impaired. Journal of Visual Impairment \& Blindness, 112(2), 157-168. Doi: https://doi.org/10.1177/0145482X1811200204

Fernandes, S. H. A. \& Healy, L. (2010). A inclusão de alunos cegos nas aulas de matemática: explorando área, perímetro e volume através do tato. Bolema: Boletim de Educação Matemática. 23(37), 1111-1135. Recuperado de: http://www.periodicos.rc.biblioteca.unesp.br/index.php/bolema/article/view/4306

Ferreira, B. dos S. (2019). O ensino de simetria para alunos com deficiência visual. (Monografia, Universidade Estadual da Paraíba, Campina Grande, Licenciatura em Matemática). Recuperado de: http://dspace.bc.uepb.edu.br/jspui/handle/123456789/20949

Ferreira, G. L. (2006). O design colaborativo de uma ferramenta para representação de gráfico por aprendizes sem acuidade visual (Dissertação de Mestrado, Pontifícia Universidade Católica de São Paulo, São Paulo, Programa de Pós-Graduação em Educação Matemática). Recuperado de: http://www4.pucsp.br/pos/edmat/mp/trabalhos 2006.html

Ferronato, R. (2002). A construção de um instrumento de inclusão no ensino da matemática (Dissertação de Mestrado, Universidade Federal de Santa Catarina, Programa de PósGraduação em Engenharia de Produção). Recuperado de: https://repositorio.ufsc.br/xmlui/handle/123456789/82939

Figueira, L., Lima, C., Borges, A. \& Soares, A. (2015). A Dynamic Environment to the Learning of Geometric Concepts by Visually Impaired People: A Brazilian Case Study. Computer Science and Engineering. 5(2): 37-46. doi: 10.5923/j.computer.20150502.03.

Flores, A., Sombrio. G. S., Takimoto. T., \& Ulbricht, V. R. (2015). A aprendizagem de geometria por alunos cegos. In 7 Congresso Nacional de Ambientes Hipermídia para Aprendizagem. São Luís: CONAHPA. Recuperado de: http://conahpa.sites.ufsc.br/exposicaolayout/

Franco, L. A. L., Martini, L. C., Franco, M. C. L. G. \& Silva, A. (2018). Desenvolvimento de um programa aplicativo para o ensino de grupo das permutações a deficientes visuais. Proceeding Series of the Brazilian Society of Computational and Applied Mathematics. 6(2): 1-7. doi: https://doi.org/10.5540/03.2018.006.02.0267

Frankel, L., \& Brownstein, B. (2016). An Evaluation of the Usefulness of Prosodic and Lexical Cues for Understanding Synthesized Speech of Mathematics. (Relatório de Pesquisa, Institute of Education Sciences, EUA). Recuperado de: https://onlinelibrary.wiley.com/doi/pdf/10.1002/ets2.12119

Frankel, L., Brownstein, B. \& Soiffer, N. (2017). Expanding Audio Access to Mathematics Expressions by Students With Visual Impairments via MathML. (Relatório de Pesquisa, Institute of 
Education Sciences, EUA). Recuperado de: https://onlinelibrary.wiley.com/doi/abs/10.1002/ets2.12132

Freire, P. C. (2017). Uma jornada dos números naturais aos racionais com uma aluna com deficiência visual (Tese de Doutorado, Universidade Anhanguera de São Paulo, São Paulo, Programa de Pós-Graduação em Educação Matemática). Recuperado de: https://repositorio.pgsskroton.com.br/bitstream/123456789/12171/1/PAULO\%20C\%C3\%89 SAR\%2OFREIRE.pdf

Furlan, F. H. (2016). Conceitos geométricos, deslocamentos e localização espacial de estudantes com cegueira congênita (Dissertação de mestrado, Universidade Federal do Paraná, Curitiba, Mestrado Profissional em Educação). Recuperado de: http://www.acervodigital.ufpr.br/handle/1884/46233

Galvão, L. M. (2018). Inclusão de alunos deficientes visuais no ensino de matemática no contexto da educação tecnológica em um Instituto Federal de Educação, Ciências e Tecnologia (Dissertação de mestrado, Universidade do Vale do Taquari, Lajeado, Mestrado Profissional em Ensino de Ciências Exatas). Recuperado de: https://univates.com.br/bdu/handle/10737/2520

Goddard, M. (2017). The use of Mobile Applications to support the development of arithmetic skills in visually or hearing impaired children at Key Stage 1 level (Monografia, Cardiff Metropolitan University, Wales, Bacharelado em Ciência da Computação). Recuperado de: https://repository.cardiffmet.ac.uk/handle/10369/8634

Gonçalves, S. S. (2017). A trajetória de inclusão de um estudante cego em um curso de licenciatura: estratégias pedagógicas e seus desafios. Com a Palavra o Professor. Vitória da Conquista. 2(2): 54-76. doi: 10.23864/cpp-v2-n1-153

Guedes, H. M. C, \& Freire, A. P. (2018). Estratégias de Navegação em Fórmulas Matemáticas na Web para Pessoas com Deficiência Visual. In 17 Simpósio Brasileiro sobre Fatores Humanos em Sistemas Computacionais. Belém: WTD-IHC. Recuperado de: https://sol.sbc.org.br/index.php/ihc estendido/article/view/4219

Guedes, V. B. (2016). A planificação de sólidos geométricos no ensino de geometria para alunos deficientes visuais (Monografia, Universidade Estadual da Paraíba, Campina Grande, Licenciatura em Matemática). Recuperado de: http://dspace.bc.uepb.edu.br/ispui/handle/123456789/10768

Hassan, N. J. \& Salleh, N. M. (2017). Development and assessment of the usability of mathematical teaching module for visually impaired fourth year students. International Journal of Education, Psychology and Counselling. 2(5), 54-69. Recuperado de: http://www.ijepc.com/PDF/IJEPC2017-05-09-05.pdf

Hassan, N. J., Salleh, M. I., Bari, S. \& Salleh, N. M. (2015). A23-Enhancing students with visual impairment's understanding in mathematics using manipulative materials. In 1 International Conference on Special Education. Bangkok: ICSE. Recuperado de: http://www.academia.edu/download/56680053/7 ICSE BANGKOK THAILAND 2015.pdf 
Instituto Federal de Educação, Ciência e Tecnologia do Rio Grande do Norte (2017). Conselho Superior. Resolução № 05 de 22 de fevereiro de 2017. Natal: IFRN.

Instituto Federal De Educação, Ciência E Tecnologia Do Rio Grande Do Norte (2018). Conselho Superior. Plano de Desenvolvimento Institucional 2019-2026. Natal: IFRN. Recuperado de: https://portal.ifrn.edu.br/ifrn/institucional/pdi-2019-2026/lateral/teste/plano-dedesenvolvimento-institucional-2019-2026

Īpek, J. \& Vural, D. V. (2017).Teaching Mathematics and Material Development Process for Total Blind and Visually Impaired Students. In H. Arslan, C. S. Duse \& M. A. Icbay (Orgs.), Research on Education. (pp. 202-209). Bialystok: IASSR. Recuperado de: https://www.academia.edu/download/55549281/IASSR kitap bolumu.pdf\#page=202

Junthong, N., Netpradit, S. \& Boonlue, S. (2018). Design and Development of Teaching Tools in Dimensional Geometry for Visually Impaired Students Using Object Models from 3D Printing. In 10 International Conference on Languages, Humanities, Education and Social Sciences. Kyoto: LHESS-18. Recuperado de: http://heaig.org/images/proceedings pdf/H0418464.pdf

Kaleff, A. M. M. R., \& Rosa, F. M. C. (2015). Introdução ao conceito de curvas de nível visando à inclusão do aluno com deficiência visual nas aulas de Geometria. In 14 Conferência Interamericana de Educação Matemática. Chiapas: CIAEM. Recuperado de: http://xiv.ciaemredumate.org/index.php/xiv ciaem/xiv ciaem/paper/view/937

Kapperman, G., Sticken, J. \& Skutchan, L. (2016). Technical Aspects of the Development of a Webbased, Interactive Nemeth Code Tutorial. Journal of Blindness Innovation and Research. 6(1). Recuperado de: https://www.nfb.org/images/nfb/publications/ibir/jbir16/ibir060103.html

Koepsel, A. P. P. (2016). Materiais Didáticos no ensino de Matemática para estudantes com deficiência visual. In 20 Encontro Brasileiro de Estudantes de Pós-graduação em Educação Matemática. Curitiba, EBRAPEM. Recuperado de: http://www.ebrapem2016.ufpr.br/wpcontent/uploads/2016/04/gd13 ana koepsel.pdf

Koepsel, A. P. P., \& Silva, V. C. S. (2018). Uso de materiais didáticos instrucionais para inclusão e aprendizagem matemática de alunos cegos. BoEM. Joinville. 6(11): 413-431. doi: http://dx.doi.org/10.5965/2357724X06112018413

Líbera, B. D., \& Silva, V. F. (2017). Relato de experiência: o Dosvox no Ensino Fundamental do Instituto Benjamin Constant. Revista de Iniciação Científica da ULBRA. 17(21). Recuperado de: https://educacaopublica.cecieri.edu.br/edicoes/17/21

Lima, G. M. \& Oliveira, V. G. L. (2018). A adaptação de material didático matemático para deficientes visuais. In 6 Seminário de Pós-Graduação em Educação para Ciências e Matemática. Jataí: IFRN. Recuperado de: http://revistas.ifg.edu.br/semlic/article/view/637

Lima, L. P. S. (2015). Ludicidade no ensino e aprendizagem de uma criança com deficiência visual (Monografia de Especialização, Universidade de Brasília, Brasília, Especialização em Psicopedagogia Clínica e Institucional). Recuperado de: http://bdm.unb.br/handle/10483/11051 
Lima, M. A., Rodrigues, D., Almeida, P. V., Cardoso, P. C. F., \& Freire, A. P. (2019). Análise de verbalizações de fórmulas matemáticas por professores com experiência no ensino de pessoas com deficiência visual. Rev. Est. Ling. Belo Horizonte. 27(3): 1371-1397. doi: 10.17851/22372083.27.3.1371-1397

Lima, N. R. W., \& Pinto, T. M. M. (2017). Dobraduras e colagens no ensino de geometria para estudantes cegos do ensino fundamental no período de contra turno. Ensino \& Pesquisa. 15(4): 237-256. Recuperado de: http://periodicos.unespar.edu.br/index.php/ensinoepesquisa/article/view/13

Lima, T. S. (2017). Multiplano como recurso didático para o ensino de função afim a alunos deficientes visuais (Monografia, Universidade Federal da Paraíba, João Pessoa, Licenciatura em Matemática). Recuperado de: https://repositorio.ufpb.br/jspui/handle/123456789/4396

Lins, A. F., Pereira, P. S., Simões, P. A., \& Moura, A. A. (2019). Pesquisas realizadas sobre educação matemática inclusiva no projeto OBEDUC em rede UFMS/UEPB/UFAL. Braz. J. of Develop. Curitiba. 5(9): 16395-16404. Doi: 10.34117/bjdv5n9-189

Lins, M. \& Alchieri J. C. (2016). Estratégias de Aprendizagem Utilizadas por Estudantes Cegos e Videntes. RIAEE - Revista Ibero-Americana de Estudos em Educação. 11(3), 1221-1241. doi: https://doi.org/10.21723/riaee.v11.n3.7311

Luiz, N. M. (2018). Teorema de Pitágoras: uma proposta de ensino e aprendizagem para alunos deficientes visuais (Dissertação de mestrado, Universidade Federal de São Carlos, Sorocaba, Programa de Pós-Graduação em Ensino de Ciências Exatas). Recuperado de: https://repositorio.ufscar.br/handle/ufscar/10421

Machado, K. S. (2016). Aprendendo a ensinar geometria plana para estudantes cegos (Monografia, Universidade Federal de Rondônia, Ji-Paraná, Licenciatura em Matemática). Recuperado de: http://ri.unir.br/jspui/handle/123456789/1096

Magalhães, R. O., \& Moura, G. L. S. (2016). Moda, média e mediana com o uso de recursos táteis e tecnológicos: Multiplano e Geogebra. In 10 Simpósio Linguagens e Identidades da/na Amazônia Sul Ocidental. Rio Branco: UFAC. Recuperado de: https://periodicos.ufac.br/index.php/simposioufac/article/viewFile/912/509

Mamcasz-Viginheski, L. V., Shimazaki, E. M., Silva, S. C. R., \& Pacheco, E. R. (2017). Formação de conceitos em geometria e álgebra por estudante com deficiência visual. Ciênc. Educ. Bauru. 23(4): 867-879. doi: http://dx.doi.org/10.1590/1516-731320170040008

Marques, C. M., Sganzerla M. A. R., \& Geller, M. (2018). Contátil: uma tecnologia assistiva ao ensino de fundamentos matemáticos. RENOTE - Revista Novas Tecnologias na Educação. 16(1): 1-9. Doi: https://doi.org/10.22456/1679-1916.86035

Martins, E. G., \& Bianchini, B. L. (2018). Resolução gráfica de sistemas de equações lineares de primeiro grau: explorando o estilo de pensamento matemático visual com um sujeito cego. Revista de Produção Discente em Educação Matemática. (1): 82-94. Recuperado de: https://revistas.pucsp.br/pdemat/article/view/37062 
Martins, S. de A. R. (2017). Materiais manipuláveis como recursos para o ensino de equação do primeiro grau a deficientes visuais. (Monografia de Especialização, Universidade Federal Tecnológica do Paraná, Londrina, Especialização Em Educação em Matemática e Ciências). Recuperado de: http://repositorio.roca.utfpr.edu.br/jspui/handle/1/9080

McDermott-Wells, P. M. (2015). Math in the Dark: Tools for Expressing Mathematical Content by Visually Impaired Students (Tese de Doutorado, Nova Southeastern University, Florida, College of Engineering and Computing). Recuperado de: http://nsuworks.nova.edu/cgi/viewcontent.cgi?article=1060\&context=gscis etd/

Mello, F. A., Caetano, J. L. P., \& Miranda, P. R. (2017). Ferramentas tácteis no ensino de Matemática para um estudante cego: uma experiência no IF Sudeste MG. REMAT. 3(1): 11-25. Recuperado de: https://www.periodicos.ifrs.edu.br/index.php/REMAT/article/view/2209/1596

Mello, F. M. \& Miranda, P. R. (2016). O projeto “matemática para além da visão" e a confecção de uma ferramenta táctil para educandos cegos. In 12 Encontro Nacional de Educação Matemática. São Paulo, SBEM. Recuperado de: http://www.sbembrasil.org.br/enem2016/anais/pdf/4748 3939 ID.pdf

Mendes Júnior, J. L. M. (2016). Objeto de aprendizagem hiperligado com materiais manipuláveis para o ensino de geometria espacial para alunos com baixa visão na educação básica (Dissertação de mestrado, Universidade Federal de Goiás, Goiânia, Programa de PósGraduação em Ensino na Educação Básica). Recuperado de: https://repositorio.bc.ufg.br/tede/handle/tede/5999

Menezes, A. L. S. (2017). Investigação do desenvolvimento do pensamento geométrico por meio do uso de um videojogo por estudantes cegos (Tese de Doutorado, Pontifícia Universidade Católica do Rio Grande do Sul, Porto Alegre, Programa de Pós-Graduação em Educação em Ciências e Matemática). Recuperado de: http://tede2.pucrs.br/tede2/handle/tede/8138

Mikułowski, D. \& Mańkowski, J. (2018). An approach of explaining math function graphs through the sound representation for blind students. Studia Informatica. 1-2(22), 21-29. Recuperado de: $\quad$ http://yadda.icm.edu.pl/yadda/element/bwmeta1.element.baztech-52edf771-ba9944ce-b7b9-4e782909a358

Ministério da Educação (2018). Base Nacional Comum Curricular - BNCC. MEC. Recuperado de: http://basenacionalcomum.mec.gov.br/images/BNCC El EF 110518 versaofinal site.pdf

Miranda, F. A. M., Miranda, J. S., \& Martini, L. C. (2019). ALFAMATECA: Software de matemática para deficientes visuais em fase de alfabetização. In 6 Congresso Nacional de Educação. Recuperado de: http://www.editorarealize.com.br/revistas/conedu/trabalhos/TRABALHO EV127 MD1 SA1 $\underline{9 \text { ID10573 16092019001236.pdf }}$

Moeller, J. D., Sganzerla, M. A. R., \& Geller, M. (2018). Math Touch: tecnologia assistiva para o desenvolvimento de conceitos matemáticos básicos. Revista Pesquisa Qualitativa. 6(12): 448469. Doi: http://dx.doi.org/10.33361/RPQ.2018.v.6.n.12.235 
Mollossi, L. F. S. B., Aguiar, R., \& Moretti, M. T. (2016). Materiais didáticos para a inclusão de educandos cegos no ensino de matemática. In 2 Colóquio Luso-Brasileiro de Educação. Joinville:

UDESC.

Recuperado

de: http://periodicos.udesc.br/index.php/colbeduca/article/view/8329

Morais, I. M. (2018). Pré-Sorobã: desenvolvimento das competências matemáticas básicas do aluno com deficiência visual. Revista Com Censo: Estudos Educacionais do Distrito Federal. 5(1): 171-178. Recuperado de: http://www.periodicos.se.df.gov.br/index.php/comcenso/article/view/360

Moreno-Chaparro, C, Martini, L. C. León Q., L., Sanmiguel, J. P. \& Larco, J. C. (2015). Designed program for a visually impaired individual to construct geometric figures using a braille printer. In 13 International Conference e-Society. Madeira: iadis. Recuperado de: https://www.researchgate.net/profile/Piet_Kommers/publication/323277167 ESociety 2015/links/5a8b9298a6fdcc6b1a43dcd1/E-Society-2015.pdf\#page=263

Nery, E. S. S., \& Sá, A. V. M. (2019). A deficiência visual em foco: estratégias lúdicas na Educação Matemática Inclusiva. Revista Educação Especial. Santa Maria. 32: 1-26. doi: http://dx.doi.org/10.5902/1984686X35402

Neves, C. N., \& Maia R. M. C. S. (2018). O uso de materiais adaptados para o ensino da matemática para estudantes com deficiência visual. BoEM. Joinville. 6(11): doi: http://dx.doi.org/10.5965/2357724X06112018119

Nunes, S. \& Lomônaco, J. F. B. (2010). O aluno cego: preconceitos e potencialidades. Revista Semestral da Associação Brasileira de Psicologia Escolar e Educacional. 14(1), 55-64. Recuperado de: http://www.scielo.br/pdf/pee/v14n1/v14n1a06.pdf/Similarpages

Oliveira, D. (2016). Modelagem no ensino de matemática para estudantes cegos. (Dissertação, Universidade Estadual do Centro Oeste, Guarapuava, Programa de Pós-Graduação em Ciências Naturais e Matemática). Recuperado de: http://www2.unicentro.br/ppgen/files/2016/07/DISSERTAÇ̃̃O Daiana.pdf

Oliveira, L. K. (2019). Inclusão de deficientes visuais no ensino de geometria plana (Dissertação de mestrado, Universidade Estadual Paulista, São José do Rio Preto, Mestrado Profissional em Matemática em Rede Nacional - PROFMAT). Recuperado de: https://repositorio.unesp.br/handle/11449/181923

Oliveira, M. F. \& Kaleff, A. (2015). Sobre uma experiência no ensino de diferentes sistemas de numéricos para alunos com deficiência visual: $\mathrm{O}$ caso do sistema binário. In 5 Seminário Nacional de História e Investigações de(em) Aulas de Matemática. Campinas: UNICAMP. Recuperado de: https://www.cempem.fe.unicamp.br/sites/www.cempem.fe.unicamp.br/files/anais shiamv3.invau.pdf\#page $=288$

Paim, E. T. (2015). Matemática para alunos com deficiência visual: prática para o ensino de produtos notáveis (Monografia, Universidade Federal de São João Del-Rei, São João Del-Rei, Licenciatura em Matemática a Distância). Recuperado de: http://dspace.nead.ufsj.edu.br/trabalhospublicos/handle/123456789/45 
Pasquarelli, R. C. C. (2015). A Inclusão de Alunos com Deficiência Visual do $9^{\circ}$ ano do Ensino Fundamental no Processo de Ensino e Aprendizagem de Estatística (Dissertação de mestrado, Pontifícia Universidade Católica do Rio Grande do Sul, Porto Alegre, Programa de PósGraduação em Educação Matemática). Recuperado de: https://leto.pucsp.br/bitstream/handle/11030/1/Rita\%20de\%20Cassia\%20Celio\%20Pasquar elli.pdf

Pasquarelli, R. de C. C., \& Manrique, A. L. (2016). A inclusão de estudantes com deficiência visual no ensino e aprendizagem de estatística: medidas de tendência central. Revista EMP. 18(1): 309-329. Recuperado de: http://revistas.pucsp.br/emp/article/view/26675/pdf

Paulino, A. A., Mauso, A. P. T., Gomes, E. C. R. S., \& Rosario, E. S. (2018). Geometria plana na educação inclusiva dos deficientes visuais: um projeto de ensino desenvolvido no estágio supervisionado. COINSPIRAÇÃO - Revista de Professores que ensinam Matemática. Mato Grosso. 1(2): 223-230. Recuperado de: http://sbemmatogrosso.com.br/publicacoes/

Phillips, C. M. L., Gulley, A. P., Prickett, L. C., Noble, S., Ragland, M. F., Price, J. L., ... Dunn, C. (2018). Solving Problems of Mathematics Accessibility with Process-driven Math: Methods and Implications. In ASEE Annual Conference \& Exposition. Recuperado de: https://par.nsf.gov/servlets/purl/10065780

Pinheiro, A. A., Araújo, A. G. P., \& Gonçalves, L. S. (2016). Multiplano como auxílio no ensino de matemática para pessoas cegas. Campina Grande: CINTEDI. In 2 Congresso Internacional de Educação Inclusiva. Campina Grande: CINTEDI. Recuperado de: http://editorarealize.com.br/revistas/cintedi/trabalhos/TRABALHO EV060 MD1 SA16 ID34 $\underline{96 \text { 12102016174714.pdf }}$

Pinheiro, A. R., Rodrigues, D. F, \& Faria, E. C. (2017). Motivação para aprender: dos materiais concretos à didática do professor. In 6 Encontro Goiano de Educação Matemática. Recuperado de: http://www.sbem-go.com.br/anais/index.php/EnGEM/article/view/24

Pinho, T. M. M. \& Lima, N. R. W. (2016). Dobrando sacolas de plástico: um instrumento no ensino de geometria para estudantes cegos do ensino fundamental. In 3 Congresso Nacional de Educação. Natal: CONEDU. Recuperado de: https://editorarealize.com.br/revistas/conedu/trabalhos/TRABALHO EV056 MD1 SA7 ID38 27 14082016003230.pdf

Pitchford, N.J., Kamchedzera, E., Hubber, P. J., \& Chigeda A. L. (2018). Interactive Apps Promote Learning of Basic Mathematics in Children With Special Educational Needs and Disabilities. Journal Frontiers in Psycholog. 9, 1-14. Doi: https://doi.org/10.3389/fpsyg.2018.00262

Quiñonez, L. D. C. L. (2016). MatGrafvoice: sistema de tratamento matemático e visualização tátil de funções matemáticas através de uma impressora Braille (Dissertação de mestrado, Universidade Estadual de Campinas, Programa de Pós-Graduação em Engenharia Elétrica). Recuperado de: http://repositorio.unicamp.br/handle/REPOSIP/321416

Rabêllo, R. S. (2011). Teatro-educação: uma experiência com jovens cegos. Salvador: EDUFBA. Recuperado de: https://repositorio.ufba.br/ri/bitstream/ri/2803/1/ Teatro.pdf 
Regec, V. (2015). Mathematics in inclusive education of blind students in secondary school in the Czech Republic. Procedi: Social and Behavioral Sciences. 174, 3933-3939. doi: 10.1016/j.sbspro.2015.01.1136.

Rodrigues, P. A., Magalhães, E. B., \& Lima, I. P. (2017). A utilização do multiplano para a aprendizagem de alunos deficientes visuais. In 4 Congresso Nacional de Educação. Recuperado de:

https://editorarealize.com.br/revistas/conedu/trabalhos/TRABALHO EV073 MD1 SA10 ID6 $\underline{665 \text { 11092017133207.pdf }}$

Rodriguez-Ascaso, A., Letón, E., Muñoz-Carenas, J., \& Finat, C. (2018) Accessible mathematics videos for non-disabled students in primary education. PLOS ONE, 13(11). Doi: https://doi.org/10.1371/journal.pone.0208117

Rosa, M. T. (2018). Uso de recursos tecnológicos no ensino de matemática para deficientes visuais (Monografia de Especialização, Universidade Federal do Rio Grande do Sul, Porto Alegre, Especialização em Mídias na Educação). Recuperado de: https://www.lume.ufrgs.br/handle/10183/201756

Salvino, L. G. M. \& Onofre, E. G. (2016). Matemática no atendimento educacional especializado: Um olhar sobre um aluno cego. In 2 Congresso Internacional de Educação Inclusiva. Campina Grande: CINTEDI. Recuperado de: https://editorarealize.com.br/revistas/cintedi/trabalhos/TRABALHO EV060 MD1 SA6 ID83 $\underline{9}$ 18102016191358.pdf

Salvino, L. G. M. (2017). Tecnologia assistiva no ensino de matemática para um aluno cego do ensino fundamental: desafios e possibilidades. (Dissertação, Universidade Estadual da Paraíba, Campina Grande, Programa de Pós-Graduação em Ensino de Ciências e Educação Matemática). Recuperado de: http://tede.bc.uepb.edu.br/jspui/handle/tede/2906

Santos, D. V., Gonzaga, D. S. \& Scarpelli, R. T. (2019). Translação de polígonos no plano cartesiano para alunos com deficiência visual. In 13 Encontro Nacional de Educação Matemática. São Paulo, SBEM. Recuperado de: https://www.sbemmatogrosso.com.br/eventos/index.php/enem/2019/paper/viewPaper/11 $\underline{88}$

Santos, F. B. (2016). A aprendizagem de conceitos básicos de probabilidade por uma dupla de estudantes cegos e videntes mediados pela maquete tátil. In 12 Encontro Nacional de Educação Matemática. São Paulo, SBEM. Recuperado de: http://www.sbem.com.br/enem2016/anais/pdf/7735 3997 ID.pdf

Santos, F. L., Cordeiro, J. P., Gonçalves, N. T. L. P., \& Thiengo, E. R. (2017). Contribuições da tecnologia na construção de uma educação inclusiva: o trabalho com um aluno deficiente visual nas aulas de Matemática. Educação Matemática Debate. Montes Claros. 1(2): doi: http://dx.doi.org/10.24116/emd25266136v1n22017a02

Santos, F. M., Moraes, M. E. L., \& Sales, E. R. (2017). O braile fácil em matemática no ensino superior: uma experiência com um aluno cego na perspectiva de promoção de autonomia. 
Revista REAMEC. 5(1): 165-176. Recuperado de: https://doaj.org/article/9b7abcb5f5bc445b91178391daf6af8a

Santos, J. (2018). Introdução ao conceito da função exponencial: um olhar para a educação inclusiva (Dissertação de mestrado, Universidade Tecnológica Federal do Paraná, Curitiba, Mestrado Profissional em Matemática em Rede Nacional - PROFMAT). Recuperado de: http://repositorio.utfpr.edu.br/jspui/handle/1/2992

Santos, J. L. \& Sganzerla, M. A. R. (2018). Impressora 3D de baixo custo para auxiliar cegos e/ou baixa visão na construção de sólidos geométricos: Projeto mark. Revista de Iniciação Científica da ULBRA. Canoas. 16: 88-107. Recuperado de: http://www.periodicos.ulbra.br/index.php/ic/article/view/4691

Santos, J. L., \& Borba, R. E. S. R. (2019). Relações entre ferramentas materiais e mediação na construção de conhecimento probabilístico de um estudante cego. In 3 Congreso Internacional Virtual de Educación Estadística. Recuperado de: www.ugr.es/local/fam126/civeest.html

Santos, N. F. \& Mendes, A. A. (2017). Alunos com baixa visão: atividades pedagógicas e estratégias de aprendizagem na matemática. 2 Seminário Científico do UNIFACIG. Recuperado de: http://pensaracademico.facig.edu.br/index.php/semiariocientifico/article/view/118

Scot, C. Q. V., \& Souto, K. C. (2017). Uso de Geoplano adaptado como material didático concreto no ensino de gráfico de funções matemáticas: Uma experiência com deficientes visuais. In 10 Encontro Internacional de Formação de Professores. Recuperado de: https://eventos.set.edu.br/index.php/enfope/issue/view/11

Segadas-Vianna, C. S., Bernardo, F. G., Pereira, F. C., Moreira, J. C. S., Santos, R. C., \& Garcez, W. R. (2016). Resolução de problemas de combinatória com uso de recursos didáticos para alunos com deficiência visual ou surdos. In 12 Encontro Nacional de Educação Matemática. São Paulo, SBEM. Recuperado de: http://www.sbem.com.br/enem2016/anais/pdf/5646 2399 ID.pdf

Segadas-Vianna, C. S., Bernardo, F. G., Pereira, F. C., Moreira, J. C. S., Santos, R. C., \& Garcez, W. R. (2016). A influência dos enunciados e dos materiais no ensino da análise combinatória para alunos surdos e para alunos com deficiência visual. REPEM. Campo Mourão. 5(9): 12-32. Recuperado de: https://pdfs.semanticscholar.org/4bed/8c145a29bc6ea6890b6b91859906a4c2e017.pdf

Sganzerla, M. A. R., \& Geller, M. (2015). Contátil: Potencialidades de uma Tecnologia Assistiva, (re)adaptando o Material Dourado para Cegos. (Projeto de Pesquisa, Universidade Luterana do Brasil, Programa de Pós-Graduação em Ensino de Ciências e Matemática). Recuperado de: http://www.tise.cl/volumen11/TISE2015/71-80.pdf

Sganzerla, M. A. R.; Rodrigues, R. da S.; Moeller, J. D.; Geller, M. (2016). Math Touch: Implementação de uma TA (Projeto de Pesquisa, Universidade Luterana do Brasil, Programa de Pós-Graduação em Ensino de Ciências e Matemática). Recuperado de: http://gravatai.ulbra.tche.br/ mariars/MathCava.pdf

Shimazaki, E. M., Silva, S. C. R., \& Viginheski, L. V. M. (2015). O ensino de matemática e a diversidade: o caso de uma estudante com deficiência visual. Interfaces da Educ. Paranaíba 
6(18): 148-164. Recuperado de: https://periodicosonline.uems.br/index.php/interfaces/article/view/1082

Silva, A. C. \& Onofre, E. G. (2016). Jogos matemáticos e alunos com deficiência visual: desenhando ações pedagógicas inclusivas. In 2 Congresso Internacional de Educação Inclusiva. Campina Grande: CINTEDI. Recuperado de: http://www.editorarealize.com.br/revistas/cintedi/trabalhos/TRABALHO EV060 MD1 SA3 ID1146 28072016204632.pdf

Silva, A. C., \& Onofre, E. G. (2016). Jogos matemáticos e alunos com deficiência visual: Desenhando ações pedagógicas inclusivas. In 2 Congresso Internacional de Educação Inclusiva. Campina Grande: CINTEDI. Recuperado de: http://www.editorarealize.com.br/revistas/cintedi/trabalhos/TRABALHO EV060 MD1 SA3 ID1146 28072016204632.pdf

Silva, F. C. P. (2015). Percepção tátil de objetos do cotidiano: estudo de caso no reconhecimento de formas geométricas e a representação gráfica de cegos congênitos (Dissertação de mestrado, Universidade Federal do Paraná, Curitiba, Programa de Pós-Graduação em Design). Recuperado de: http://www.acervodigital.ufpr.br/handle/1884/39896

Silva, L. M. S. (2015). Do improviso às possibilidades de ensino: estudo de caso de uma professora de matemática no contexto da inclusão de estudantes cegos (Tese de Doutorado, Universidade Estadual Paulista, Rio Claro, Programa de Pós-Graduação em Educação Matemática). Recuperado de: https://repositorio.unesp.br/handle/11449/136763

Silva, M. D. (2016). Conhecimentos de Professores Sobre o Ensino de Geometria com Material Manipulável para Estudantes Cegos. In 20 Encontro Brasileiro de Estudantes de Pós-Graduação em Educação Matremática. Curitiba: EBRAPEM. Recuperado de: http://www.ebrapem2016.ufpr.br/wp-content/uploads/2016/04/gd13 mayra_silva.pdf

Silva, M. D., Carvalho, L. M. T. L., \& Pessoa, C. A. S. (2016). Material manipulável de geometria para estudantes cegos: reflexões de professores brailistas. REPEM. Campo Mourão. 5(9): 176-202. Recuperado de: https://www.researchgate.net/profile/Liliane Carvalho/publication/

Silva, R. dos S. (2016). A Utilização Do Multiplano No Ensino Da Matemática Na Educação Básica: Uma Proposta Para A Educação Inclusiva. (Dissertação, Universidade Federal de Tocantins, Palmas, Programa De Mestrado Profissional Em Matemática Em Rede Nacional - PROFMAT). Recuperado de: http://ead.ufac.br/ava/pluginfile.php/36793/mod resource/content/1/2014 02842 RAWLI NSON DOS SANTOS SILVA.pdf

Silva, S. B., \& Meucci, R. D. (2017). Brincando com Matemática: uma alternativa educacional tangível e acessível ao ensino básico. Iniciação - Revista de Iniciação Científica, Tecnológica e Artística. 6(4): 14-21. Recuperado de: http://www1.sp.senac.br/hotsites/blogs/revistainiciacao/

Silva, T. S. (2015). Matemática Inclusiva: ensinando matrizes a deficientes visuais (Dissertação de mestrado, Universidade Federal de Santa Maria, Santa Maria, Mestrado Profissional em 
Matemática em Rede Nacional - PROFMAT). Recuperado de: https://repositorio.ufsm.br/handle/1/10949

Silveira, C., Aguiar, R., \& Frizzarini, S. T. (2019). Caneta 3D: Uma nova perspectiva para o ensino de matemática para cegos. In 3 Simpósio Ibero-Americano de Tecnologias Educacionais. Araranguá, UFSC. Recuperado de: https://150.162.233.193/index.php/sited/article/download/117/14

Simões, P. A., \& Lins, A. F. (2018). Trajetória e processo: educação matemática inclusiva, o uso do jogo da velha na geometria para alunos deficientes visuais. In 3 Congresso Internacional de Educação Inclusiva. Campina Grande: CINTEDI. Recuperado de: http://www.editorarealize.com.br/revistas/cintedi/trabalhos/TRABALHO EV110 MD1 SA17 ID226 03082018235008.pdf

Spinczyka, D., Maćkowskib, M., Kempac, W. \& Rojewska, K. (2019). Factors influencing the process of learning mathematics among visually impaired and blind people. Computers in Biology and Medicine. 104, 1-9. doi: https://doi.org/10.1016/i.compbiomed.2018.10.025.

Splett, E. S. (2015). Inclusão de alunos cegos nas classes regulares e o processo de ensino e aprendizagem de matemática (Dissertação de mestrado, Universidade Federal de Santa Maria, Santa Maria, Programa de Pós-Graduação em Educação Matemática). Recuperado de: https://repositorio.ufsm.br/handle/1/6755

Stone, B. W., Kay, D. \& Reynolds, A. (2019). Teaching Visually Impaired College Students in Introductory Statistics. Journal of Statistics Education. 00(0), 1-13. Doi: 10.1080/10691898.2019.1677199

Sulistyowati, F., Kuncoro, K. S., Nugraheni, P., Hernowo, H. \& Setyawan, F. (2019). The problems of teaching fractional arithmetic operations for disabled student using Realistic Mathematics Education. Journal of Physics: Conf. Series. 1188, 1-7. doi: 10.1088/17426596/1188/1/012030.

Tavares, E. R. B. (2018). A pessoa com deficiência visual e o processo de aprendizagem em matemática: caminhos e descaminhos. (Dissertação, Universidade Federal de Tocantins, Palmas, Programa de Pós-Graduação em Educação). Recuperado de: https://umbu.uft.edu.br/handle/11612/1454

Toledo, C. C., Paiva, A. P. G., Camilo, G. B., Maior, M. R. S., Leite, I. C. G. \& Guerra, M. R. (2010). Early detection of visual impairment and its relation with school effectiveness. Revista da Associação Médica Brasileira. 56(4), 415-419. doi: http://dx.doi.org/10.1590/S010442302010000400013.

Toste, T. A., Reis, H. M. M. de S.'N., \& Victer, E. F. (2016). Tabuleiro das expressões: um auxiliador no ensino da matemática para alunos com deficiência visual. Revista de Educação, Ciências e Matemática. $\quad 6(1)$ 151-163. $\quad$ Recuperado de: http://publicacoes.unigranrio.edu.br/index.php/recm/article/view/3415

Uliana, M. R., \& Leite, E. A. P. (2019). Educação inclusiva no curso de extensão universitária: estratégias, recursos e materiais didáticos no ensino de matemática para estudantes da 
educação básica com deficiência visual. Pesquisa e Prática em Educação Inclusiva. Manaus. 1(2): 297-311. Recuperado de: http://periodicos.ufam.edu.br/educacaolnclusiva/article/view/4216

Vergara, G. F.P. (2016). Deficiência visual: doze ideias para a aula de matemática em classes inclusivas. (Monografia, Universidade Federal Do Rio Grande Do Sul, Porto Alegre, Licenciatura em Matemática). Recuperado de: https://www.lume.ufrgs.br/handle/10183/134186

Viginheski, L. V. M., Aires, J. P., Silva, S. C. R., Pilatti, L. A., Frasson, A. C., \& Shimazaki, E. M. (2017). Análise de produtos desenvolvidos no mestrado profissional na área de matemática: possibilidades de adaptações para o uso com estudantes cegos. Rev. Diálogo Educ. Curitiba. 17(51): 223-250. doi: http://dx.doi.org/10.7213/1981-416X.17.051.AO05

Wiazowski, J. (2018). Sight, touch, hearing: The current digital options and challenges in access to math content for learners with visual impairments. Forum Pedagogiczne. 2, 227-240. doi: 10.21697/fp.2018.2.16.

World Health Organization - WHO. (2019). World Report on Vision. Geneva: World Health Organization; Recuperado de: https://www.who.int/publications-detail/world-report-onvision

Xavier, T. M. A. M. \& Santiago, Z. M. A. (2019). O soroban como instrumento de aprendizado na formação de professores do ensino básico. In 4 Congresso Nacional de Pesquisa em Ensino de Ciências. Recuperado de: https://editorarealize.com.br/revistas/conapesc/anais.php

\section{COMO CITAR ESTE ARTIGO:}

Barbosa, F. C. S., Medeiros, E. J. R. de, Medeiros, S. R. R. de, Medeiros Júnior, R. N. de (2020). Propostas de ensino de matemática para deficientes visuais: revisão sistemática exploratória da literatura. Holos. 36(8), $1-37$.

\section{SOBRE OS AUTORES}

\section{F. C. S. BARBOSA}

Técnico em Informática pelo IFRN - campus João Câmara (2013), graduado em Matemática (2017) pela Universidade Federal do Rio Grande do Norte - UFRN. Especialista (2019) em Ensino de Ciências Naturais e Matemática pelo IFRN - campus Parnamirim. Mestrando do PROFMAT (mestrado profissional) na Universidade Federal do Rio Grande do Norte - UFRN. Atualmente, Professor do estado da Paraíba e membro do Núcleo Multidisciplinar de Ensino, Engenharia e Ciências (NuMEEC). Tem experiência/interesse nas áreas de Informática e Programação, Matemática, Ensino de Matemática e Tecnologias Educacionais. E-mail: cleiton.sb04@gmail.com

ORCID ID: https://orcid.org/0000-0001-9885-1011

\section{E. J. R. DE MEDEIROS}

Graduado (2006) em Matemática pela Universidade Federal do Rio Grande do Norte - UFRN. Graduando em Ciências e Tecnologia pela Universidade Federal do Rio Grande do Norte - UFRN. Especialista (2011) em Gestão e Organização Escolar pela Universidade Potiguar - UnP. Mestre (2008) e Doutor (2012) em Ciência e Engenharia de Petróleo pela Universidade Federal do Rio Grande do Norte - UFRN. Atualmente, Professor do Instituto Federal do Rio Grande do Norte - IFRN e Coordenador do Núcleo Multidisciplinar de Ensino, Engenharia e Ciências (NUMEEC). Tem experiência/interesse nas áreas de Matemática, Ensino de Ciências, Tecnologias Digitais, Energias e Engenharia de Petróleo.

E-mail: elthon.medeirosl@ifrn.edu.br 


\section{ORCID ID: https://orcid.org/0000-0002-5187-0992}

\section{S. R. R. DE MEDEIROS}

É professora do Instituto Federal de Educação, Ciência e Tecnologia do Rio Grande do Norte (IFRN) - Campus João Câmara e Campus Zona Leste. Tem experiência nas áreas de Saúde Coletiva, Segurança do Trabalho, Metodologia Científica e Ensino de Ciências. Atualmente participa como membro do Núcleo Multidisciplinar de Ensino, Engenharia e Ciências (NuMEEC).

E-mail: stella.medeiros@ifrn.edu.br

ORCID ID: https://orcid.org/0000-0003-0869-9111

\section{R. N. DE MEDEIROS JÚNIOR}

Possui Licenciatura em Física, Especialização em Gestão e Organização Escolar e Mestrado em Engenharia de Petróleo e Gás, hodiernamente é doutorando em Ciência e Engenharia de Petróleo. Tem experiência nas áreas de Formação Docente, Experimentação e Tecnologias Aplicadas ao Ensino de Física, Ciência e Engenharia de Petróleo e Gás. Foi tutor do Programa de Educação Tutorial - PET da Licenciatura em Física do Instituto Federal de Educação, Ciência e Tecnologia do Rio Grande do Norte (IFRN) - Campus João Câmara, onde atualmente é professor, e coordenador do grupo de pesquisa Núcleo Multidisciplinar de Ensino, Engenharia e Ciências (NUMEEC) e membro do Núcleo Multidisciplinar de Ensino, Engenharia e Ciências, e do Núcleo de Pesquisa em Formação Docente e Ensino de Física.

E-mail: nonato.junior@ifrn.edu.br

ORCID ID: https://orcid.org/0000-0003-2580-0795

Editor(a) Responsável: Francinaide Nascimento

Pareceristas Ad Hoc: Maria Sônia Oliveira Veloso e Jeronimo Silva

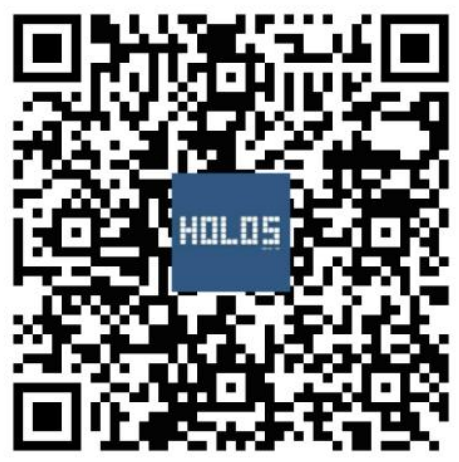

